\title{
BioGreenhouse
}

\section{Impact of water quality and irrigation management on organic greenhouse horticulture}

Martine Dorais, Beatrix W. Alsanius, Wim Voogt, Steeve Pepin, Hakki Tüzel, Yüksel Tüzel and Kurt Möller

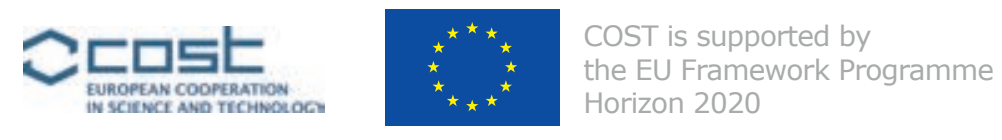

Water Management 


\section{Correct citation of this document}

Dorais, M., Alsanius, B. W., Voogt, W., Pepin, S., Tüzel, İ.H., Tüzel, Y., Möller, K. 2016. Impact of water quality and irrigation management on organic greenhouse horticulture. BioGreenhouse COST Action FA 1105, www. biogreenhouse.org

ISBN: 978-94-6257-538-7

DOI (Digital Object Identifier): http://dx.doi.org/10.18174/373585

\section{Pictures}

Contributors to the pictures are: Wim Voogt, Martine Dorais, Beatrix Alsanius and Steeve Pepin.

\section{Auteurs and Organisations}

Martine Dorais ${ }^{1}$, Beatrix W. Alsanius ${ }^{2}$, Wim Voogt ${ }^{3}$, Steeve Pepin ${ }^{4}$, Hakki Tüzel ${ }^{5}$, Yüksel Tüzel ${ }^{5}$ and Kurt Möller ${ }^{6}$.

1. Agriculture and Agri-Food Canada, Agassiz Research \& Development Centre, Agassiz, Canada.

2. Swedish University of Agricultural Sciences, Department of Biosystems and Technology, Alnarp, Sweden.

3. Wageningen UR Greenhouse Horticulture, Bleiswijk, The Netherlands.

4. Laval University, Dept. of Soil and Agri-Food Engineering, Quebec, Canada.

5. Ege University, Faculty of Agriculture, Izmir, Turkey.

6. Universität Hohenheim, Institute of Crop Science, Stuttgart, Germany.

\section{Acknowledgement}

The information in this booklet is based on the expert opinions of the various authors. Neither they, nor their employers, can accept any responsibility for loss or damage occurring as a result of following the information contained in this booklet.

This booklet is based upon work from COST Action FA1105 BioGreenhouse, supported by COST (European Cooperation in Science and Technology). The authors acknowledge COST Action FA 1105 "Towards a sustainable and productive EU organic greenhouse horticulture" for funding the meetings held in the framework of the activities of WG2 "Soil fertility, suppressiveness and water management" during which the main water management issues in organic protected conditions were discussed. They wish to thank many colleagues for their contribution to this brochure and Ms. José Frederiks (Wageningen UR Greenhouse Horticulture) for processing layout and printing and Roger Hitchings for the proofreading.

Link to the Action: http://www.cost.eu/COST_Actions/fa/FA1105 and: http://www.biogreenhouse.org/ 


\section{Table of contents}

$\begin{array}{lr}\text { Preface } & 7\end{array}$

$\begin{array}{lr}\text { Executive summary } & 9\end{array}$

$\begin{array}{lr}\text { Abbreviations } & 11\end{array}$

$\begin{array}{llr}2.1 & \text { Soil bound cultivation systems } & 15\end{array}$

$\begin{array}{lll}2.1 .1 & \text { Evapotranspiration } & 15\end{array}$

$\begin{array}{ll}2.1 .2 \text { Condensation } & 15\end{array}$

$\begin{array}{lll}2.1 .3 & \text { Irrigation } & 16\end{array}$

$\begin{array}{lll}2.1 .4 & \text { Re-use of drainage water } & 16\end{array}$

$\begin{array}{lll}2.1 .5 & \text { Seepage } & 16\end{array}$

$\begin{array}{lll}2.1 .6 & \text { Precipitation } & 16\end{array}$

$\begin{array}{lll}2.1 .7 & \text { Minor water flows } & 16\end{array}$

$\begin{array}{llr}2.2 & \text { Demarcated beds } & 18\end{array}$

$\begin{array}{llr}2.3 & \text { Pot-based culture systems } & 18\end{array}$

$\begin{array}{ll}3.1 & \text { Inorganic chemical load } \\ & 3.1 .1\end{array}$

$\begin{array}{lll}3.1 .1 \mathrm{pH} & 23\end{array}$

3.1.2 Copper, zinc and manganese $\quad 23$

$\begin{array}{lll}3.1 .3 & \text { Iron } & 24\end{array}$

$\begin{array}{lll}3.1 .4 & \text { Other elements } & 24\end{array}$

$\begin{array}{lll}3.1 .5 & \text { Sodicity } & 24\end{array}$

$\begin{array}{lll}3.1 .6 & \text { Salinity } & 24\end{array}$

$\begin{array}{llr}3.2 & \text { Organic compounds } & 25\end{array}$

3.2.1 Organic matter in water and modes of their assessment 25

3.2.2 Irrigation water quality requirements with respect to organic matter load 26

$\begin{array}{lll}3.3 & \text { Microbial loads } & 27\end{array}$

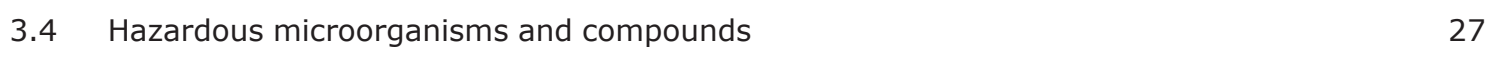

$\begin{array}{llr}4.1 & \text { Rainwater } & 29\end{array}$

$\begin{array}{ll}4.2 & 30\end{array}$

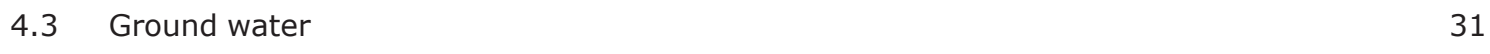

$\begin{array}{lll}4.4 & \text { Surface water } & 31\end{array}$

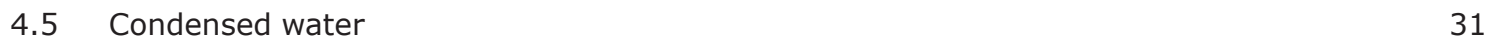

\begin{tabular}{ll}
4.6 & Desalinated water \\
\hline 4.7
\end{tabular}

$\begin{array}{lll}4.7 & \text { Miscellaneous water sources } & 31\end{array}$

4.7.1 Treated and untreated wastewater 31

$\begin{array}{lll}4.7 .2 & \text { Digestate } & 32\end{array}$

4.7.3 Potato starch processing wastewater (Potato protein liquid) 35

$\begin{array}{lll}\text { 4.7.4 Fish waste water } & 35\end{array}$

$\begin{array}{lll}4.8 & \text { Water storage } & 35\end{array}$ 
$\begin{array}{llr}5.1 & \text { Evaporation and transpiration } & 38\end{array}$

$\begin{array}{ll}5.2 & \text { Soil and soil microbiota } \\ \end{array}$

6

Salinity

$\begin{array}{lll}6.1 & \text { Salinity and crop development } & 41\end{array}$

\begin{tabular}{ll}
6.2 & Salinity and soil ecology \\
\hline
\end{tabular}

$\begin{array}{llr}7.1 & \text { Water distribution } & 43\end{array}$

$\begin{array}{lll}7.1 .1 & \text { Drip irrigation } & 43\end{array}$

7.1.2 Strip irrigation by mini sprinklers 44

$\begin{array}{lll}7.1 .3 & \text { Sprinkler systems } & 44\end{array}$

$\begin{array}{lll}7.1 .4 & \text { Sub-irrigation systems } & 44\end{array}$

$\begin{array}{llr}7.2 & \text { Spatial heterogeneity } & 47\end{array}$

$\begin{array}{llr}8.1 & \text { Water treatment } & 49\end{array}$

8.1.1 Physical treatment $\quad 52$

8.1.1.1 Photocatalysis $\quad 52$

8.1.1.2 Thermal treatment $\quad 52$

8.1.1.3 UV treatment 52

8.1.2 Chemical treatment 53

8.1.2.1 Ozone treatment 54

8.1.2.2 Hydrogen peroxide treatment 54

8.1.2.3 Sodium hypochlorite treatment 54

8.1.2.4 Chlorine dioxide 54

8.1.2.5 Benzoic acid treatment 55

8.1.3 Biological treatment $\quad 55$

8.1.3.1 Slow filters $\quad 55$

8.1.3.2 Artificial constructed wetlands 56

$\begin{array}{lr}8.2 \text { Cleaning of the water distribution system } & 59\end{array}$

8.2.3.1 Steam treatment 59

8.2.3.2 Chemical treatments 59

8.2.3.3 Treatment for bicarbonate clogging 59

$\begin{array}{llr}9.1 & \text { Salinity management } & 61\end{array}$

$\begin{array}{lll}9.2 & \text { Irrigation scheduling } & 63\end{array}$

9.2.1 Soil bound cultivation systems $\quad 63$

9.2.2 Demarcated beds 66

$\begin{array}{lll}\text { 9.2.3 Pot-based cultivation system } & 67\end{array}$

$\begin{array}{llr}9.3 & \text { Irrigation management control tools } & 68\end{array}$

$\begin{array}{lll}\text { 9.3.1 Models } & 68\end{array}$

$\begin{array}{lll}\text { 9.3.2 Soil moisture sensors } & 68\end{array}$

$\begin{array}{lll}\text { 9.3.2.1 Tensiometers } & 69\end{array}$

$\begin{array}{lll}\text { 9.3.2.2 Soil moisture sensors } & 70\end{array}$

$\begin{array}{lll}9.3 .3 & \text { Lysimeters } & 70\end{array}$

$\begin{array}{lll}\text { 9.3.4 Decision support systems } & 71\end{array}$

$\begin{array}{lll}\text { 9.3.5 Other irrigation tools } & 71\end{array}$ 
$\begin{array}{lll}10.1 & \text { Effects on plant growth and productivity } & 73\end{array}$

10.1.1 Effects on plant growth

$\begin{array}{lll}10.1 .2 & \text { Effects on yield } & 74\end{array}$

$\begin{array}{ll}10.2 & \text { Effects on nutritive quality attributes } \\ \end{array}$

$\begin{array}{lll}\text { 10.2.1 Irrigation management } & 77\end{array}$

$\begin{array}{lll}\text { 10.2.2 } & \text { Indirect factors and multiple stresses } & 78\end{array}$

$11 \quad$ Sustainability and water conservation 81

$\begin{array}{llr}11.1 & \text { Strategies } & 81\end{array}$

11.1.1 Appropriate crop species and controlled deficit irrigation 81

11.1.2 Appropriate irrigation systems and tools 82

11.1.3 Appropriate crop management $\quad 82$

11.2 Challenges 83

$\begin{array}{ll}11.3 & \text { Water used for greenhouse crops } \\ \end{array}$

12 Conclusions and knowledge gaps

$\begin{array}{llr}12.1 & \text { Summary } & 85\end{array}$

$\begin{array}{llr}12.2 & \text { Knowledge gaps } & 87\end{array}$ 
6 I Impact of water quality and irrigation management on organic greenhouse horticulture 


\section{Preface}

In 2008, at the 16th IFOAM Organic World Congress in Modena (IT), about 25 participants expressed their interest in working together in the field of research and development for organic greenhouse or protected horticulture. A two-day workshop was organised in Cologne in 2009 to discuss the subject and further give further support to the collaboration. Forty-five people from across Europe and from Canada attended this workshop. It was decided to pursue joint efforts in the field of organic protected horticulture, in with particular respect to planting material; soil fertility; composting; water management; disease and pest management; climate management and energy conservation; and sustainability. The group also agreed to submit a COST (European Cooperation in Science and Technology) Action on the same subject. By mid-2011 the proposal "Towards a sustainable and productive EU organic greenhouse horticulture" (or BioGreenhouse for short), was submitted.

At the end of 2011 COST approved this proposal as COST Action FA1105

(see http://www.cost.eu/COST_Actions/fa/FA1105 and www.biogreenhouse.org), which set out to build a network of experts working in the field of organic protected horticulture. The aims of the Action are to develop and to disseminate through coordinated international efforts, knowledge of new and improved production strategies, methods and technologies for the support of sustainable and productive organic greenhouse/ protected horticulture in the EU. This has involved coordinated international efforts and in total, 27 participating COST countries and two COST Neighbouring countries took part in the Action.

This Action offered the framework and funds for experts of the participating countries to meet and to work together in Working Groups focusing on the objectives of the Action. The objectives related to water management were: to develop efficient, sustainable and safe water management strategies using standardised guidelines in a systems approach for different pedo-climatic conditions.

Seven experts from different regions and backgrounds worked together on this topic. They have addressed their task with commitment; by reviewing the state of the art of water management in different organic protected cropping systems in Europe and North America; by examining in detail water requirements, water resources and crop water demand; by describing irrigation technology, irrigation management and their tools; by explaining the interaction between irrigation, crop development and product quality; and by discussing sustainability aspects knowledge gaps.

Together they produced this handbook:

\section{"Impact of water quality and irrigation management on organic greenhouse horticulture"}

I believe this booklet will prove a unique source of information for all people involved in organic protected horticulture: for growers, researchers, students, teachers, consultants and suppliers. This booklet could help to develop and implement more sustainable irrigation strategies in organic greenhouse horticulture.

On behalf of the COST Action BioGreenhouse I want to thank the team of authors for the work they have done, their cooperative spirit and their perseverance. This work will definitely contribute to a more efficient and sustainable irrigation management and will be a basis for developing a new R \& D agenda on organic greenhouse horticulture.

Rob J.M. Meijer

Wageningen UR Greenhouse Horticulture

Chair, COST Action FA1105 BioGreenhouse 
8 Impact of water quality and irrigation management on organic greenhouse horticulture 


\section{Executive summary}

Water quality and water supply are essential for organic greenhouse grown crops to prevent soil contamination by undesirable chemicals and microorganisms, while providing a sufficient amount of water for plant growth. The absence of natural precipitation combined with higher evapotranspiration due to higher temperature and longer cropping period requires an adequate supply of water. Water quality is commonly defined by its chemical, physical, and biological attributes. It is closely linked to the soil/rock native components, surrounding environment and land use. The runoff from urban, industrial, farming, mining, and forestry activities also significantly affects the quality of water available for greenhouse horticulture. High water quality is particularly important in organic greenhouse production in order to prevent soil salinization and ensure optimal soil biological activity. Indeed, unbalanced organic fertilizer inputs may contribute to soil salinity, while soil microbial activities responsible for nutrient mineralization, soil suppressiveness and plant health, are affected by soil pH, ions, and contaminants. Poor water quality can also result in drip and micro irrigation clogging, plant toxicity, and product contamination by human pathogen or illicit compounds.

To achieve sustainable water management, good knowledge of crops' water requirements is essential as is knowledge of the soil water characteristics that determine the irrigation scheduling. Moreover, the adequacy of the irrigation distribution system determines the accuracy of the water supplied. Crop water needs are often determined on the basis of daily evapotranspiration and solar radiation levels. Different irrigation control tools such as soil moisture sensors, plant sensors, lysimeters and models contribute to the optimization of the irrigation management of organic greenhouse crops. In addition to determining crop productivity, water quality and water management also impact on product quality.

In this booklet we first illustrate the water flows through different organic greenhouse growing systems. We state the importance of water quality for organic greenhouse horticulture and give some guidelines regarding the required water quality attributes in terms of inorganic, organic and microbial loads as well as hazardous microorganisms and compounds. We also define advantages and disadvantages of different water resources and describe the important drivers for crop and soil water demand. We then report the effects of salinity on soil mineralisation and crop development in organic greenhouse production systems. The main irrigation technology used for organic greenhouse horticulture is described along with the most important management aspects for irrigation. Because quality attributes of greenhouse products drive consumer demand for organic products, we define the impact of water quality and irrigation management on product quality. Organic farming should use cultural practices that maintain land resources and ecological balance, in addition to promoting biodiversity, biological cycles, and soil biological activity. We therefore state the importance of water resources and their use for organic greenhouse system sustainability. We then conclude by summarizing main aspects of water quality and irrigation management, and by identifying knowledge gaps.

Better prediction of the temporal dynamics of plant and soil microbial water needs in relation to sustainable productivity and high water use efficiency is needed for greenhouse horticultural crops. It is also important in terms of reduced attractiveness to pests and susceptibility to diseases. A reduction in spatial and temporal crop heterogeneity should result from improved growing systems and better water and crop management. Nevertheless, advances in irrigation management for conventional greenhouse crops and development of new control tools can be adapted for use in organic greenhouse horticulture. Similarly, some water treatments of drained or collected waters such as thermal, UV, ozone and biological treatments can be used by growers according to their organic regulation. Consequently, research is needed in different areas of organic greenhouse horticulture: (i) water quality in terms of relevant thresholds for contaminants and potential risks related to plant and human pathogens; (ii) efficient measures to prevent clogging of the irrigation systems; (iii) alternative water treatments and system cleaning products; (iv) better knowledge and guidelines for non-leaching systems; (v) affordable and highly efficient control tools to assist growers; and (vi) knowledge about the environmental impact of different water management and water sources used for organic greenhouse horticulture to help growers fulfilling the organic principles and improve their sustainability. 
10 I Impact of water quality and irrigation management on organic greenhouse horticulture 


\section{Abbreviations}

BOD Biochemical oxygen demand $\left(\mathrm{mg} \mathrm{L}^{-1}\right)$ is the quantity of molecular oxygen consumed by the microorganisms present in a sample at a given time; expressed as either $\mathrm{BOD}_{5}$ or $\mathrm{BOD}_{7}$ measured after either five or seven days of incubation

COD Chemical oxygen demand $\left(\mathrm{mg} \mathrm{L}^{-1}\right)$ is the total quantity of oxygen required to oxidize substances to carbon dioxide and water in a sample

CPOM Coarse particulate organic matter comprises organic matter $>1 \mathrm{~mm}$

DM Dry mass

DOC Dissolved organic carbon represents the soluble fraction (minor than $0.2 \mu \mathrm{m}$ ) of organic matter in a water sample measured as carbon $\left(\mathrm{mg} \mathrm{C} \mathrm{L}^{-1}\right)$

DOM Dissolved organic matter represents the soluble fraction (minor than $0.2 \mu \mathrm{m}$ ) of organic matter in a water sample related to dry weight

FPOM Fine particulate organic matter ranges between particle sizes of $0.2 \mu \mathrm{m}$ and $1 \mathrm{~mm}$

NTU Nephelometric turbidity units

OGH Organic Greenhouse Horticulture

POM Particulate organic matter comprises organic particles $>0.2 \mu \mathrm{m}$ and ranges from finely dispersed material to large particulate matter (litter, plant debris) (see FPOM and CPOM)

TOC Total organic carbon content $\left(\mathrm{mg} \mathrm{L}^{-1}\right)$ is a sum measure of the concentration of all organic carbon atoms bonded in organic molecules and comprises both autochthonous and allochthonous carbon sources

VOC Volatile organic matter 
12 I Impact of water quality and irrigation management on organic greenhouse horticulture 


\section{Introduction}

\section{In short}

- Water quality is important to prevent salinity problems and soil contamination by undesirable compounds and microorganisms.

- Poor water quality can result in drip and micro irrigation clogging, plant toxicity, and product contamination by human pathogens.

- Water supply is essential to insure optimal plant growth and soil biological activity.

- Zero water and nutrient emission is contribute to optimize irrigation scheduling by improved irrigation management.

- Irrigation control tools contribute to the optimization of the irrigation scheduling.

- Efficient water use and/or water recycling are important issues for organic farming.

Water quality and water supply are essential for organic greenhouse grown crops to prevent soil contamination by undesirable chemicals and microorganisms, while providing the correct amount of water required for plant growth. The absence of natural precipitation combined with higher evapotranspiration due to higher temperature and longer cropping period requires an adequate supply of water. Water quality is commonly defined by its chemical, physical, and biological attributes. It is closely linked to the soil/rock native components, surrounding environment and land use. The runoff from urban, industrial, farming, mining, and forestry activities also significantly affects the quality of water available for greenhouse horticulture. High water quality is particularly important to prevent soil salinization and ensure optimal soil biological activity. Indeed, unbalanced organic fertilizer inputs may contribute to soil salinity, while soil microbial activities responsible for nutrient mineralization, soil suppressiveness and plant health, are affected by soil pH, ions, and contaminants. Poor water quality can also result in drip and micro irrigation clogging, plant toxicity, and product contamination by human pathogens (e.g. E. coli, Salmonella spp.) or illicit compounds (e.g. pesticides, hormones, antibiotics, nanoparticles).

The EU directive L250 (European Commission 2008) (European Commission 2008) does not address water sources for irrigation in organic greenhouse horticulture. However, according to the organic regulation (e.g. EC No 834/2007), growers should make responsible use of natural resources such as water. Thus, efficient water use and/or water recycling are important issues for organic farming (EGTOP 2013). According to the European Commission's Expert Group for Technical advice on Organic Production (EGTOP) report on greenhouse production, the use of water to flush surplus nutrients and control soil salinity is not an acceptable practice. As far as desalinization is concerned, it is preferable to avoid salinization through proper fertilization management. Moreover, rainwater collection is strongly encouraged (EGTOP 2013) or requested for operation sites situated in climatic suitable areas with a total structure size $>5000 \mathrm{~m}^{2}$ (IFOAM EU Group 2013). 
Organic production should also contribute to the achievements of European Union environmental policy objectives such as the Water Framework Directive (2000/60/EC) and Nitrates Directive (91/676/EEC). In The Netherlands, following an agreement with grower organisations, water boards, and governmental and other stakeholders, a zero emissions target of 2027 has been set for greenhouse horticulture with soil-grown crops., Reuse of drainage water is often not applicable for soil grown crops due to the wide variation in hydrological conditions. Therefore, zero emission is reached by improving irrigation management. The nutrient balances must also be taken into consideration as described in the booklet on soil fertility management for organic greenhouse horticulture $(\mathrm{OGH})$ in order to avoid salinization or leaching of nutrients. Since the irrigation surplus is the major driving force for nutrient leaching, irrigation should be tuned to crop and soil demands. Consequently, irrigation scheduling, which determines the irrigation events and water supply, plays a crucial role for optimizing organic greenhouse production, while also conserving water resources. To achieve sustainable water management, good knowledge of the crops' water requirements is required as is knowledge of the soil water characteristics that determine the irrigation scheduling. Moreover, the adequacy of the irrigation distribution system determines the accuracy of the water supplied. Crop water needs are often determined on the basis of daily evapotranspiration and solar radiation levels. Different irrigation control tools such as soil moisture sensors, plant sensors, lysimeters and models contribute to the optimization of the irrigation management of organic greenhouse crops. In addition to determining crop productivity, water quality and water management also impact on product quality.

The aims of this booklet are to:

1. Illustrate the water flows through different organic greenhouse growing systems - Chapter 2.

2. State the importance of water quality for organic greenhouse horticulture and give some guidelines regarding the required water quality attributes in terms of inorganic, organic and microbial loads as well as hazardous microorganisms and compounds - Chapter 3.

3. Explain the advantages and disadvantages of different water resources - Chapter 4.

4. Describe the important drivers for crop and soil water demand - Chapter 5.

5. Outline the effects of salinity on soil mineralisation and crop development in organic greenhouse production systems - Chapter 6.

6. Describe the main irrigation technology used for organic greenhouse horticulture - Chapter 7 .

7. Describe the different approaches used to treat water/effluents from organic greenhouses - Chapter 8 .

8. Describe the most important management aspects for irrigation - Chapter 9.

9. Define the impact of water quality and irrigation management on product quality - Chapter 10.

10. State the importance of water resources and use for organic greenhouse system sustainability - Chapter 11.

11. Conclude by setting out knowledge gaps - Chapter 12 . 


\section{Water flows in organic greenhouse horticulture}

\section{In short}

- Evapotranspiration, condensation, irrigation, precipitation and reuse of drained water constitute the main water flows.

- Evapotranspiration and irrigation, the two main water flows, are driven by solar radiation.

- Salinity problems may occur if there is more evapotranspiration than irrigation.

- Water and nutrient leaching may occur if there is more irrigation than evapotranspiration.

- Demarcated beds and potted plant using recycling growing systems limit water and nutrient losses.

- Rainwater is of high value for organic greenhouse crops because of its high quality.

Water flows in organic greenhouse growing systems are similar to water flows in conventional soil-grow or soilless growing systems, with the exception that stricter air humidity and temperature control is generally required to prevent plant diseases. Figure 1 presents water flows in a greenhouse with ground water table within $1.0 \mathrm{~m}$ from the surface and a drainage system with central collection of drainage water discharged or re-used, while Figure 2 presents water flows in a greenhouse with a deep ground water table ( $>2 \mathrm{~m}$ from surface) where soil profile is not in contact with groundwater. In both cases, water flows can be described as water coming from the evapotranspiration, condensation, irrigation, precipitation and reuse of drained water. Figure 3 and Figure 4 present examples of recycled water use in demarcated beds growing systems and of water flows in pot-based culture systems, respectively.

\section{$2.1 \quad$ Soil bound cultivation systems}

The seven components of water flows for soil based cultivation systems are defined as follows:

\subsubsection{Evapotranspiration}

Obviously, the largest and most important water flows in a greenhouse are evapotranspiration and irrigation. Evapotranspiration is the sum of evaporation from the bare soil and the transpiration from the plant. These two water flows are driven mainly by solar radiation and are described in more detail in Chapter 7.

\subsubsection{Condensation}

The evapotranspired water is partly lost to the environment through ventilation and partly condenses against the glass cover and inner construction parts of the greenhouse. The quantity of the condensed water flow depends on interior and outside climatic conditions along with the ventilation rate. For example, under Dutch winter growing conditions, when ventilation is closed, up to $80 \%$ of the total evapotranspiration is condensed inside the greenhouse. Condensed water is very pure and is generally re-used via a collection system. Otherwise, this condensed water will drip from the gutters and return to the soil. Such a local excess of water is not suitable for a healthy and high producing crop. For closed or semi-closed organic greenhouses, most of the evapotranspired water is reused as irrigation water for the crop, which results in a higher water use efficiency (WUE). Lower vapour pressure deficits often observed under closed-greenhouses may also reduce plant transpiration and improve crop water use efficiency (Dannelh et al. 2014). 


\subsubsection{Irrigation}

Greenhouse crops are irrigated to meet the water demand of crops (Chapter 7). Considered over a certain time span, irrigation can be i) lower than, ii) equal to, or iii) higher than the evapotranspiration.

1. In the first situation, depletion of the soil water content will take place. If the soil profile is in contact with groundwater, water will move upward in the soil through capillary action to partly compensate for water loss. Plants will also develop deeper rooting systems to take water from deeper levels. This upward movement of water in the soil will also bring back solutes to the root levels such as leached nitrate. However undesirable ions such as sodium ( $\left.\mathrm{Na}^{+}\right)$will also move upwards, and since water is evapotranspired the salts will eventually accumulate in the soil profile. In the long run this will cause salinity problems (section 7.2).

2. If the irrigation is on average equal to the evapotranspiration crop demand, there will be no leaching, and salinity problems will be limited (section 7.2).

3. In case of an irrigation surplus, the excess water will move deeper in the soil, taking nutrients downwards. If the water passes beyond the active root zone, it becomes out of reach of the plant and causes leaching to ground water. No salinity problem is observed under over irrigation providing the water quality is adequate (Chapter 3).

\subsubsection{Re-use of drainage water}

Under conditions where the groundwater table is high, and if drainage systems are installed and connected to a collection system, drainage water can be re-used (Figure 2). This is already common practice in some Dutch greenhouses, and is required by regulation for soil-grown greenhouse crops. This requires that some important parameters for water quality to then be taken into account (Chapter 3).

\subsubsection{Seepage}

Since water will only enter a drainage system from the saturated zone, i.e. the ground water table, ground water flows will affect the water that actually enters. Depending on the hydraulic situation, this water may originate from outside the greenhouse itself. If the water level in nearby ditches or channels is higher than the drainage depth, for example, hydraulic pressure will trigger seepage into the drainage system from the outside. This will also occur under conditions of elevated groundwater which could be caused by elevation in the surrounding landscape or farther away, heavy rainfall and subterranean conditions. Seepage complicates the re-use of this water due to:

- Salt contamination, if the source is brackish or salt intrusions from seawater, and/or.

- Water intrusion importing all kinds of undesired contaminants if surrounding soils are used for conventional agriculture or other activities.

- It may also cause a quantitative problem, if the volume of seepage in the winter period, or periods of heavy rainfall outside, is higher than the demand.

\subsubsection{Precipitation}

Although precipitation is excluded from the crop by the greenhouse covering, it still is an important water flow. It is a natural resource for plants and the soil, which is excluded by the greenhouse roof covering. Moreover, the quality is superior to almost all other resources. This water is of high value for the crops and should therefore be utilised rather than discharging the rainwater collected by gutters into ditches, sewers or the ground.

\subsubsection{Minor water flows}

To prevent blocking of drip nozzles, irrigation water is filtered through sand filters or fine filters. These filters are backflushed on a regular basis which causes a wastewater flow. Backflush is done automatically on a time basis or the pressure difference between input and output flow. 


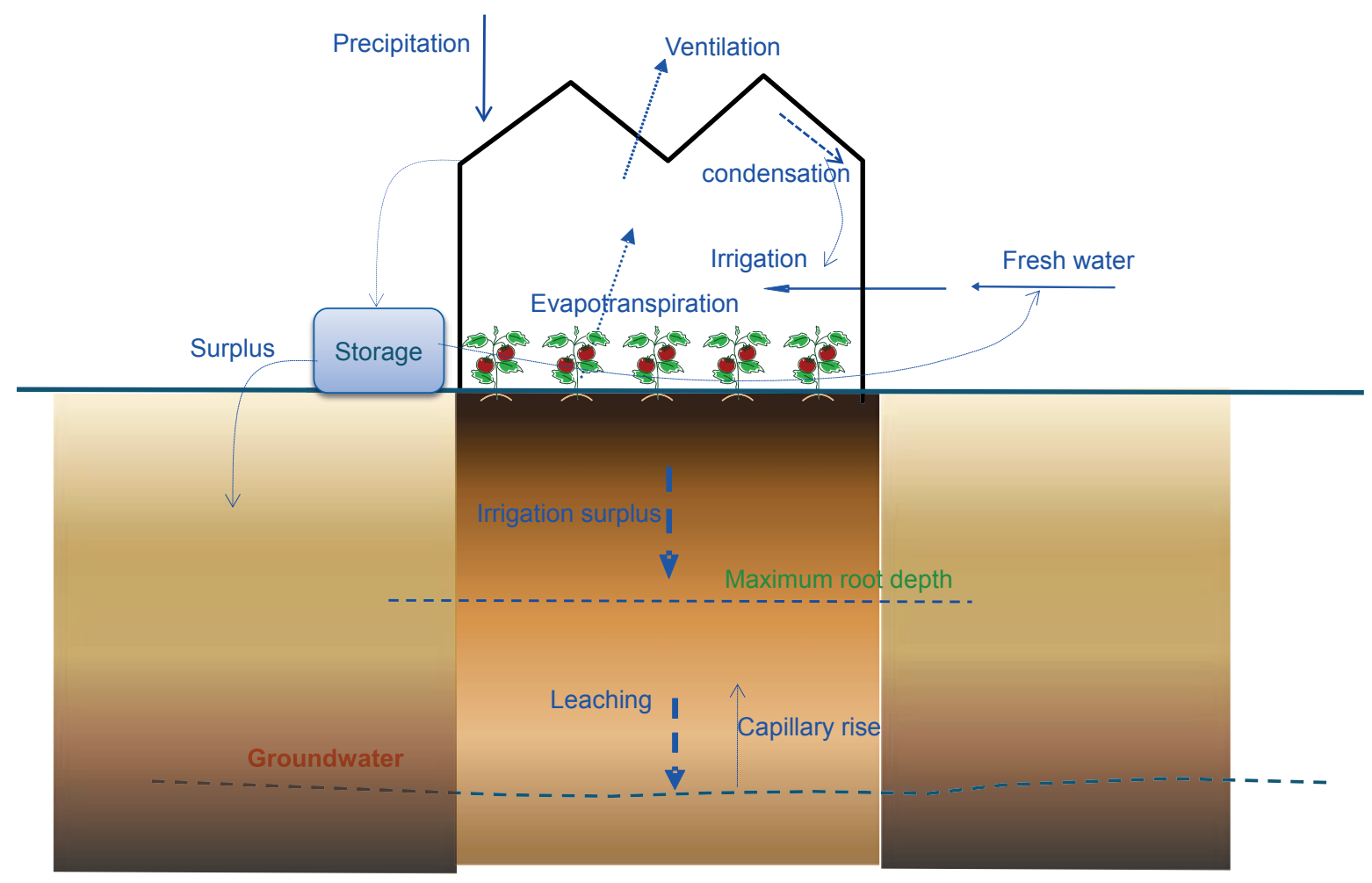

Figure 1 Water flows in a greenhouse with ground water table deeper than $1.0 \mathrm{~m}$, without a drainage system (Illustration: W. Voogt).

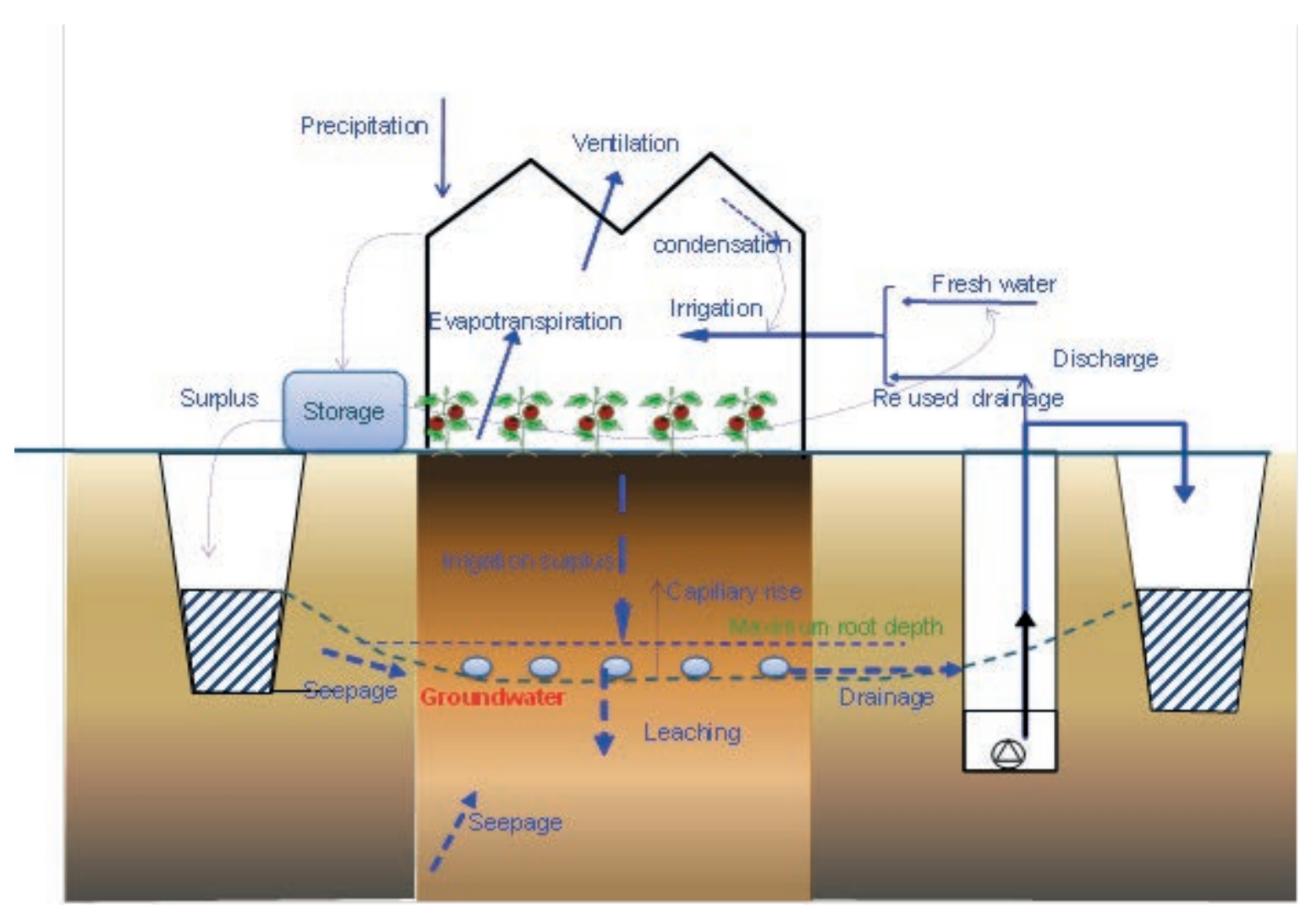

Figure 2 Water flows in a greenhouse with ground water table within $1.0 \mathrm{~m}$ from the surface and a drainage system with central collection of drainage water discharged or re-used (Illustration: W. Voogt). 


\subsection{Demarcated beds}

The water flow characteristics of demarcated beds are similar to open (loss of drained water) or closed (re-use of drained water) conventional growing systems. As previously described for soil based cultivation systems, water flow of demarcated beds comes from the evapotranspiration, condensation, irrigation, and in some cases, from collected rainwater and re-use of drained water. As irrigation management of demarcated beds minimizes water drainage to limit nutrient leaching (section 7.3.2), the volume of re-used drainage water is generally small compared to the total volume of water supplied to the crop. The irrigated soil surface of demarcated beds is smaller than in soil based cultivation systems so the water lost by soil evaporation is therefore lower. In contrast to soil based cultivated systems, no water or ions are moving by capillarity from the ground water to the root zone because the cultivated soil and roots of this growing system are isolated from the native soil. Minor water flows may result from the loss of irrigation water through leakage of the irrigation system and the backwash of the irrigation system filters. When the crop is not over-fertilized with $\mathrm{Na}, \mathrm{Cl}$ and $\mathrm{SO}_{4}$-rich fertilizers or amendments, the built-up of salinity can be limited. However, after the growing season, the cultivated soil can be over irrigated to remove undesirable ions, which can produce a significant water flow at that time. Unfortunately, this over-irrigation also reduces the cultivated soil nitrate content, which is a key nutrient for crop performance.

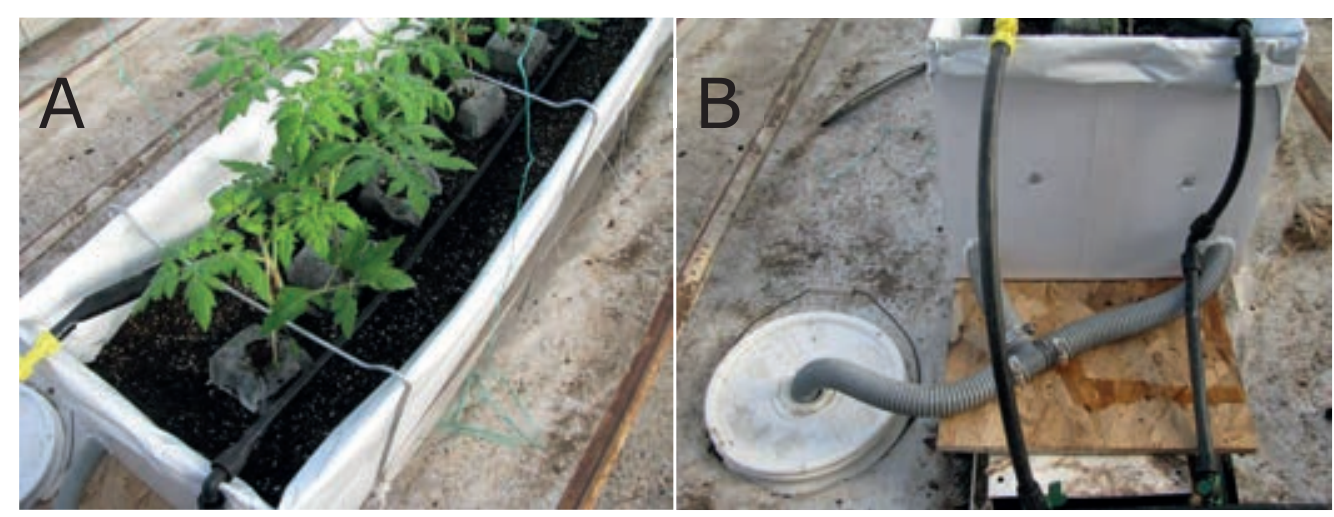

Figure 3 Example of a demarcated bed growing system (A) with drainage water recycling (B) (Les Productions Horticoles Demers, QC, Canada; photo: Martine Dorais).

\subsection{Pot-based culture systems}

These are similar to demarcated bed systems in that the water flow in pot-based culture systems comes from the evapotranspiration, condensation, irrigation, collected rainwater and re-used of drainge water. Depending on the irrigation systems (e.g. drip, boom sprinkler, ebb-and-flow systems; waterproof bench using capillary mat, floodfloor, through-tray, wick system, capillary mat), water evaporation and losses from leakage can be negligible or insignificant. For example, sub-irrigation systems that provide water by capillarity usually have low water losses when the irrigation frequency and volume closely match plant requirements, and unabsorbed water is returned by gravity to a reservoir through a slow drain and constantly re-used. Depending on the types of pots used (e.g. plastic, wood fibre, coir, peat, rice straw, paper) and the use of plastic film to cover capillary mats, loss of water by evaporation from the pot walls and watering surfaces will be more or less important (Ferrarezi et al. 2015a). Moreover, if growers do not have a drainage water treatment system, as described in section 7.2, to reduce risks associated with the spread of root-infesting pathogens (e.g. Pythium, Phytophthora), a significant amount of drainage water can be lost (open system). As the growing period of potted plants is relatively short, salinity build-up is not a major problem if adequate fertilization and irrigation scheduling (section 8.2.3) are provided. For ebb-and-flow systems, however, excess fertilizer salts might accumulate in the top layer of the growing media because water is absorbed by capillarity through holes in the bottom of the pots and lost by evaporation from the pot surface. 


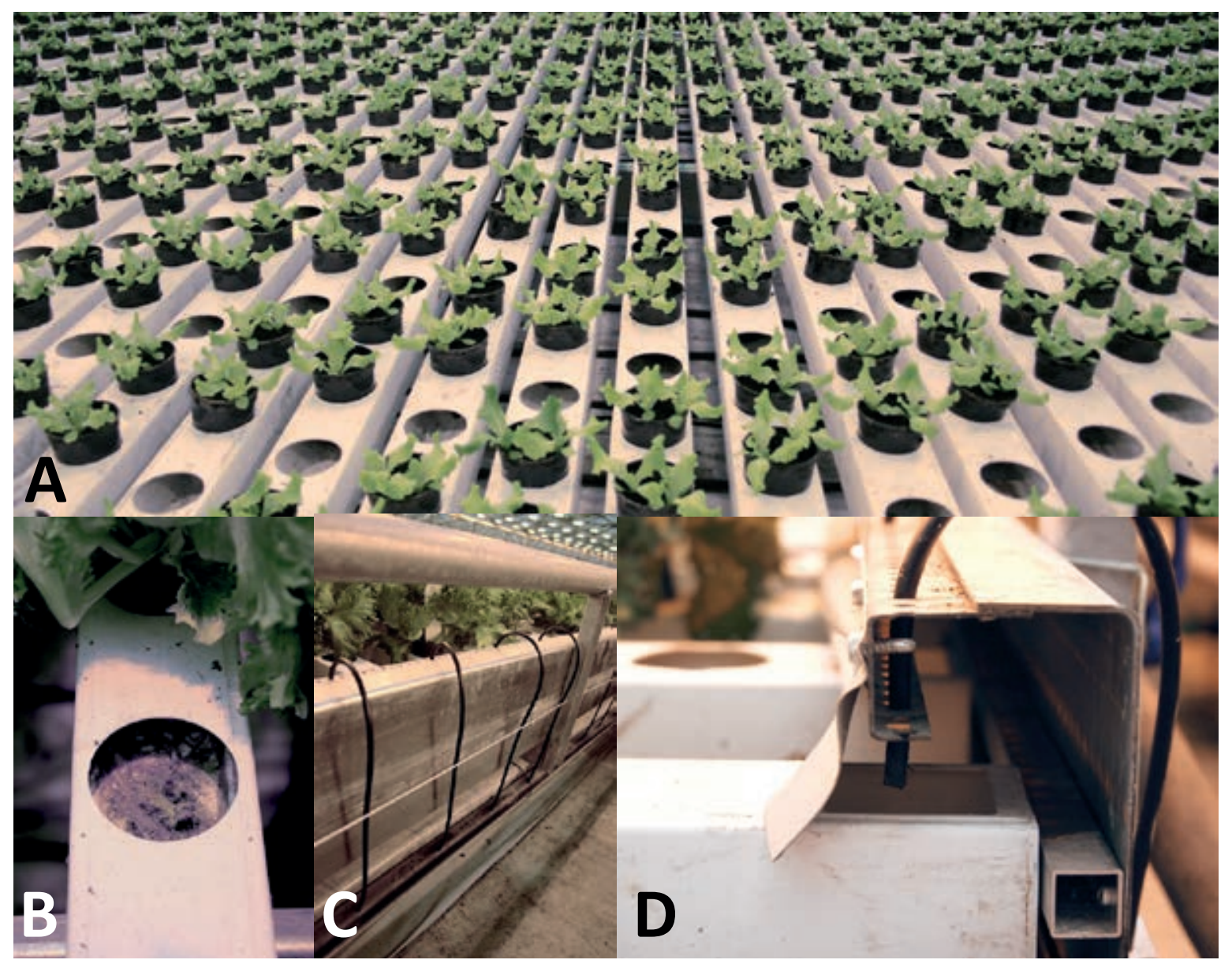

Figure 4 Example of a potted organic growing system with drainage water recycling and treatment. A: subirrigation system with organically grown lettuce; $B$ : top view of the gutter; $C$ and $D$ : fertigation distribution system (Swedponics, Pårp, Sweden; photo: Beatrix Alsanius). 
20 Impact of water quality and irrigation management on organic greenhouse horticulture 


\section{Water quality requirements}

\section{In short}

- Water electrical conductivity values, due to the concentrations of $\mathrm{Na}, \mathrm{Cl}, \mathrm{Ca}, \mathrm{Mg}$ and $\mathrm{SO}_{4}$, should be lower than $0.5 \mathrm{mS} \mathrm{cm}^{-1}$.

- To minimize leaching, $\mathrm{Na}$ and $\mathrm{Cl}$ concentrations should be lower than $1 \mathrm{mmol} \mathrm{L}^{-1}$, while $\mathrm{Mg}$ and $\mathrm{SO}_{4}$ should be lower than $0.7 \mathrm{mmol} \mathrm{L}^{-1}$ and $\mathrm{Ca}$ lower than $1.5 \mathrm{mmol} \mathrm{L}^{-1}$.

- $\mathrm{HCO}_{3}$ should be lower than $5 \mathrm{mmol} \mathrm{L}^{-1}$ to avoid any problem related to high $\mathrm{pH}$.

- Micronutrients (e.g. Zn, Cu, Mn, B) should be below the toxicity range.

- Fe should be lower than $10 \mu \mathrm{mol} \mathrm{L} \mathrm{L}^{-1}$ to avoid clogging of the irrigation system, and lower than 100 $\mu \mathrm{mol} \mathrm{L} \mathrm{L}^{-1}$ to prevent leaf burning.

- Organic compounds in irrigation water favour clogging and plant pathogens.

- The microbial load originating from the source of water and/or irrigation system may cause clogging and might be detrimental to plant and human health.

- Irrigation water of organic crops should be free of plant protection chemicals as well as pharmaceutical and personal care products.

Horticultural water may be used for irrigation, suspension and distribution of fertilizers as well as for harvesting, plant conditioning and processing. This chapter focuses on water quality requirements for irrigation and fertigation purposes with respect to the load of inorganic and organic compounds as well as microorganisms.

\subsection{Inorganic chemical load}

The mineral composition of the irrigation water affects the soil chemical properties in terms of ions and salt accumulation. Indeed, minerals present in excess of the plant uptake are accumulated in the root environment. Subject to the regulations in force, for a specific area and growing system used, extra water supply is provided to control soil and substrate salinity by leaching undesirable ions such as $\mathrm{SO}_{4}, \mathrm{Na}$ and $\mathrm{Cl}$. Usually $\mathrm{Na}$ and $\mathrm{Cl}$ are the most abundant ions present in water although they are sparingly absorbed by most greenhouse crops. However, other ions like $\mathrm{Ca}, \mathrm{Mg}$ or $\mathrm{SO}_{4}$ may also be present in excess concentration. The precise ion concentrations acceptable in the irrigation water for specific crops or cultivars vary because of the great differences in their uptake concentrations. The ion root uptake by greenhouse crops is also affected by the concentration of other ions. However, for greenhouse production, $\mathrm{Na}$ is more critical than $\mathrm{Cl}$, because of the lower uptake of this element by most crops. Consequently, the acceptable water electrical conductivity (EC) values mainly relate to the concentrations of $\mathrm{Na}, \mathrm{Cl}, \mathrm{Ca}, \mathrm{Mg}$ and $\mathrm{SO}_{4}$ in the context of the available organic and inorganic fertilizers.

Table 1, Table 2 and Table 3 provide general guideline values of the desirable water qualities for irrigation of greenhouse crops according to three leaching scenarios, as well as limits for ion concentrations in the irrigation water which prevent their accumulation in the root environment (Voogt 2009). The quality standards listed under group 1 are applicable for water sources suitable for all crops and those systems and conditions that do not need leaching, as recommended by the organic regulation. Water sources complying with group 2 (5-20\% required leaching) is acceptable for all crops, systems and conditions in protected cultivation. Water quality of group 3 can only be used under the condition of a high drainage fraction (20-30\%). Leaching of salts can be achieved by adding water during the cropping period if possible. Alternatively, this can be realized after crop termination. Water of group 3 is not recommended for crops, since this requires huge volumes of leaching during the cultivation and will contribute significantly to environmental pollution. It is important to point out that due to the requirement for leaching, these two last groups do not comply with the EU Water Frame Directive and Nitrates Directive and organic farming principles. 


\section{Table 1}

Maxima for $\mathrm{EC}$ and $\mathrm{Na}$ and $\mathrm{Cl}$ concentrations in irrigation water to be used in various growing systems. The water characteristics of group 1 are required under no or $<5 \%$ of leaching. The water characteristics of group 2 are required under $5-20 \%$ leaching, while the water characteristics of group 3 are required under $>20 \%$ leaching (Voogt 2009).

\begin{tabular}{|c|c|c|c|}
\hline Water quality class & $\mathrm{EC}\left(\mathrm{mS} \mathrm{cm}^{-1}\right)$ & $\mathrm{Na}\left(\mathrm{mmol} \mathrm{L}^{-1}\right)$ & $\mathrm{Cl}\left(\mathrm{mmol} \mathrm{L}^{-1}\right)$ \\
\hline 1.1 & $<0.5$ & $<0.2$ & $<0.2$ \\
\hline 1.2 & $<0.5$ & $0.2-0.5$ & $0.2-0.5$ \\
\hline 1.3 & $<0.5$ & $0.5-1.0$ & $0.5-1.0$ \\
\hline 2.1 & $<0.5$ & $<1.0$ & $<1.0$ \\
\hline 2.2 & $<0.5$ & $1.0-2.0$ & $1.0-2.0$ \\
\hline 2.3 & $<0.5$ & $2.1-3.5$ & $2.1-3.5$ \\
\hline 3.1 & $0.5-1.0$ & $<1.5$ & $<1.5$ \\
\hline 3.2 & $0.5-1.0$ & $1.5-3.0$ & $1.5-3.0$ \\
\hline 3.3 & $0.5-1.0$ & $3.0-4.5$ & $3.0-4.5$ \\
\hline 4.1 & $1.0-1.5$ & $<1.5$ & $<1.5$ \\
\hline 4.2 & $1.0-1.5$ & $1.5-3.0$ & $1.5-3.0$ \\
\hline 4.3 & $1.0-1.5$ & $3.0-4.5$ & $3.0-4.5$ \\
\hline
\end{tabular}

Table 2

Validation of water quality classes with respect to the combination of cropping system and irrigation and the EC and $\mathrm{Na}$ and $\mathrm{Cl}$ concentrations from Table 1.

\begin{tabular}{|c|c|c|c|c|}
\hline & Main classes & & & \\
\hline Group & 1 & 2 & 3 & 4 \\
\hline Sub class & Soilless, Soil grown & $\begin{array}{l}\text { Soilless with free } \\
\text { drainage }(<20 \% \\
\text { drain), Soil grown }\end{array}$ & $\begin{array}{l}\text { Soilless with free } \\
\text { drainage (>20 \% } \\
\text { drain), Soil grown }\end{array}$ & Soil grown \\
\hline 1 & Suitable for all crops & Suitable for all crops & Suitable for all crops & Suitable for all crops \\
\hline 2 & Suitable for all crops & Suitable for all crops & Suitable for all crops & $\begin{array}{l}\text { Suitable for all } \\
\text { crops without drip } \\
\text { irrigation)* }\end{array}$ \\
\hline 3 & $\begin{array}{l}\text { Suitable for salt } \\
\text { sensitive crops with } \\
\text { high Na uptake }\end{array}$ & $\begin{array}{l}\text { Suitable for salt } \\
\text { tolerant crops }\end{array}$ & $\begin{array}{l}\text { Suitable for soil grown } \\
\text { salt tolerant crops }\end{array}$ & $\begin{array}{l}\text { Suitable for soil } \\
\text { grown salt tolerant } \\
\text { crops without drip } \\
\text { irrigation)* }\end{array}$ \\
\hline
\end{tabular}

*Periodical leaching necessary 


\section{Table 3}

Limitations for ion concentrations other than $\mathrm{Na}$ and $\mathrm{Cl}$ in the irrigation water to prevent their accumulation in the root environment (Voogt 2009).

\begin{tabular}{|c|c|c|c|c|c|}
\hline \multirow[t]{3}{*}{ Characteristic } & \multirow[t]{3}{*}{ Unit } & \multicolumn{4}{|l|}{ Groups } \\
\hline & & 1 & 2 & 3 & Limits \\
\hline & & $(0-5 \%)$ & $(5-20 \%)$ & $(>20 \%)$ & \\
\hline $\mathrm{pH}$ & & $*$ & $*$ & $*$ & \\
\hline $\mathrm{Ca}$ & $\mathrm{mmol} \mathrm{L}^{-1}$ & $<1.5$ & $<2.5$ & $<3.5$ & $0.7-2.0$ \\
\hline $\mathrm{Mg}$ & $\mathrm{mmol} \mathrm{L}^{-1}$ & $<0.7$ & $<1.25$ & $<2.0$ & $0.3-0.7$ \\
\hline $\mathrm{SO}_{4}$ & $\mathrm{mmol} \mathrm{L}^{-1}$ & $<0.7$ & $<1.25$ & $<2.0$ & $0.5-1.5$ \\
\hline $\mathrm{HCO}_{3}$ & $\mathrm{mmol} \mathrm{L}^{-1}$ & $<5.0$ & $<7.5$ & $<10.0$ & \\
\hline
\end{tabular}

$* \mathrm{pH}$ depends on other parameters, like $\mathrm{HCO}_{3}$

\section{$3.1 .1 \quad \mathrm{pH}$}

The $\mathrm{pH}$ of irrigation water is of low importance in itself, it is the $\mathrm{HCO}_{3}{ }^{-}$concentration, which causes high $\mathrm{pH}$ buffering in the root environment that is more important. Adding acids to the irrigation water can neutralize $\mathrm{HCO}_{3}{ }^{-}$. For substrate systems, it is necessary to neutralize the $\mathrm{HCO}_{3}{ }^{-}$, if the concentration is higher than $1 \mathrm{mmol}$ $\mathrm{L}^{-1}(60 \mathrm{ppm})$. In $\mathrm{OGH}$, this can only be achieved by the use of organic acids, such as citric or acetic acids. These acids can be supplied from a concentrated acid solution and then diluted in a mixing tank before irrigation. It must be realised that the addition of these organic acid anions (citrate and acetate) will increase the EC but will not contribute to the nutrition of the plants. Moreover, these acid residuals will form an energy source for microorganisms which will boost the development of biofilms in the irrigation system and may cause clogging of drip irrigation systems. It is, therefore, recommended to use water that is low in $\mathrm{HCO}_{3}{ }^{-}$, to avoid necessary acidification.

For soil grown crops, neutralisation of the $\mathrm{HCO}_{3}{ }^{-}$is usually not necessary, since the quantity of $\mathrm{HCO}_{3}{ }^{-}$added by the irrigation is only a fraction of the total carbonate buffer $\left(\mathrm{CaCO}_{3}\right)$ in the soil. However, high $\mathrm{HCO}_{3}{ }^{-}$may increase the risk of clogging of irrigation systems and therefore, if drip irrigation is used, it could be advisable to neutralize. However, as formulated above, the acid residuals may also cause clogging in the longer term.

\subsubsection{Copper, zinc and manganese}

The concentration of these micro elements does not affect the water salinity, but may induce plant toxicity. Zinc $(\mathrm{Zn})$ can occur in irrigation water if the water is transported by galvanised gutters or tubes. For soil grown crops toxicity is unlikely because $\mathrm{Zn}$ is adsorbed on clay and humus particles. In the long run, however, it may cause soil pollution. A similar trend is observed for copper $(\mathrm{Cu})$, which may be adsorbed by organic (humus) particles specifically (Verloo 1980). These adsorption processes also occur with organic substrates, which contain peat and coir. $\mathrm{Cu}$ and $\mathrm{Zn}$ are common constituents of animal feed supplements so manure applications also provide additional $\mathrm{Cu}$ and $\mathrm{Zn}$ (in addition to their fertiliser role) resulting in higher soil content and plant uptake. The use of copper containing fungicides to help control fungal and bacterial diseases also provides additional $\mathrm{Cu}$. Manganese $(\mathrm{Mn})$ toxicity depends on the $\mathrm{pH}$ in the root environment. Mn precipitates in form of manganese oxides with increasing $\mathrm{pH}$. Conversely, $\mathrm{pH}$ values below 6.0 are beneficial for the availability of Mn, although it may constitute a risk of phytotoxicity. 


\subsubsection{Iron}

High concentrations of iron (Fe) in the irrigation water are not toxic for crops. Iron however will precipitate easily and this will initiate clogging of drip-irrigation systems. Therefore water sources should be more or less free of Fe with a maximum concentration of $<10 \mu \mathrm{mol} \mathrm{L}^{-1}$. When using sprinklers, clogging of nozzles is not usually a problem, but high concentrations $\left(>100 \mu \mathrm{mol} \mathrm{L} \mathrm{L}^{-1}\right.$ ) of Fe will precipitate on the crop canopy which can be a problem. For ornamental crops or herbs in pots this should be avoided and lower concentrations are required, because of a lower "pollution acceptance" for these plants. At low $\mathrm{pH}$, Fe concentrations $>100 \mu \mathrm{mol} \mathrm{L} \mathrm{L}^{-1} \mathrm{may}$ cause leaf burning.

Bivalent Fe ions in the irrigation water can be harmful to plants. This bivalent Fe form, coming from anaerobic wells, oxidizes easily forming $\mathrm{Fe}^{3+}$ ions if $\mathrm{O}_{2}$ is dissolved in the water. The trivalent Fe precipitate as $\mathrm{Fe}(\mathrm{OH})_{3}$ : $4 \mathrm{Fe}^{2+}+\mathrm{O}_{2}+18 \mathrm{H}_{2} \mathrm{O} \rightarrow 4 \mathrm{Fe}(\mathrm{OH})_{3} \downarrow+8 \mathrm{H}_{3} \mathrm{O}^{+}$. Water aeration or water treatment by ozone before its use is an easy way to solve this problem. This oxidation reaction produces $\mathrm{H}^{+}$ions thus decreasing the $\mathrm{pH}$, which may cause hindrance of the oxidation process. The $\mathrm{pH}$ of water should be sufficiently buffered, to neutralize the released $\mathrm{H}^{+}$ions. The $\mathrm{pH}$ buffer water mainly contains $\mathrm{HCO}_{3}$. After the Fe is oxidized, a filtration stage is necessary to separate the precipitated Fe from the water. Although Fe is not highly toxic to plants, leaf burning and pollution of the greenhouse structure can be observed when high soluble Fe loaded water is applied by overhead spraying (van den Ende 1970).

\subsubsection{Other elements}

Other elements that can be traced in irrigation water as a problem for greenhouse crops are boron (B) and fluorine $(F)$. Boron can accumulate in the root zone when the concentration is higher than the uptake. High concentrations are phytotoxic. Fluorine is particularly phytotoxic to bulb and tuber crops. The recommended

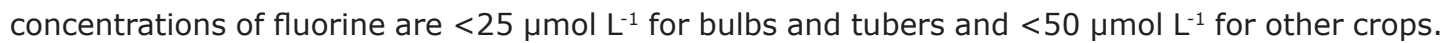

\subsubsection{Sodicity}

A specific problem related to water quality is the so-called sodicity. If the water contains equivalently more (bi) carbonate $\left(\mathrm{HCO}_{3}{ }^{-}\right)$than $\mathrm{Ca}$ and $\mathrm{Mg}$ and is instead balanced with $\mathrm{Na}$, it will negatively affect the soil structure. If this water is used for irrigation, carbonate will precipitate with $\mathrm{Ca}$ or $\mathrm{Mg}$ ions present in the soil. The levels of bivalent cations in the irrigation water are unable to balance this, and this causes $\mathrm{Ca}$ or $\mathrm{Mg}$ to be removed from the soil/substrate solution and the adsorption complex. The remaining Na from the irrigation water becomes dominant in the soil and substrate solution, and on the adsorption complex. By definition, in sodic soils $15 \%$ or more of the cation exchange sites of the soil are occupied by $\mathrm{Na}^{+}$. Soils and substrates affected by this phenomenon are chemically characterized by high $\mathrm{Na}$, and low $\mathrm{Ca}$ and $\mathrm{Mg}$ concentrations. Sodicity follows a different pathway than salinity. Non-saline sodic soils are characterized by poor physical conditions, as exchangeable sodium deflocculates such soils, and dispersed soils have low permeability to water and air. They tend to be sticky when wet, and very hard when dry. When sodic soils are saline, the high salt concentrations promote flocculation so that permeability is nearly normal. In sodic soils, plant growth is adversely affected by the poor physical conditions. Even crops that tolerate high levels of exchangeable sodium nutritionally often fail because of the adverse physical conditions.

\subsubsection{Salinity}

Ions in the irrigation water accumulate in the root zone when the concentration is higher than the uptake rate. Ions such as $\mathrm{Na}^{+}$and $\mathrm{Cl}^{-}$, which are taken up in a relatively low concentration, but are often abundantly present in irrigation water, greatly contribute to salinity build-up. $\mathrm{Ca}, \mathrm{Mg}$, and $\mathrm{SO}_{4}$ are plant nutrients as well but their concentrations in irrigation water can easily exceed the crop uptake and thus contribute also to salinity (Sonneveld 2000). Ions such as $\mathrm{NO}_{3}{ }^{-}, \mathrm{NH}_{4}{ }^{+}, \mathrm{K}^{+}$, and $\mathrm{H}_{2} \mathrm{PO}_{4}^{-}$are usually present in low concentrations in irrigation water, and the demand is usually much higher. Therefore these ions do not contribute to salinity. If they do, it comes from excessive fertilization (Sonneveld and van der Burg 1991). 


\subsection{Organic compounds}

Irrespective of the production system (organic, biodynamic, integrated, conventional), the load of organic compounds in irrigation water is a function of the raw water source. Other sources of organic compounds found in the irrigation water in organic greenhouse cropping systems include: uncleaned equipment, growing medium, organic plant nutrients, macro- and microphytes. The level of organic compounds in the irrigation water and fertigation solution is an important factor. The combination of organic compounds and the nutrients dissolved in the fertigation solution is a driving force for microbial growth in the dispersed water and on surfaces (biofilms) associated with the greenhouse cropping systems. This can subsequently affect oxygen consumption and competition. They also provide a potential energy source for saprophytic life style of plant pathogens. Biofilms attached to the pipelines, especially small gauge pipelines and fittings, may lead to clogging. Particulate forms of organic matter associated with fertigation in organic greenhouse horticulture provide surfaces for microbial attachment and a means of survival and passive transport of plant pathogens.

\subsubsection{Organic matter in water and modes of their assessment}

Organic carbon fluxes in irrigation water have been comprehensively presented by Alsanius et al. (2014). Organic matter in waters may be separated into autochthonous (indigenous) and allochthonous (externally provided) sources. Autochthonous organic matter derives from the water body itself, for example organic matter produced by algae. Allochthonous organic matter derives from the surrounding terrestrial environment. The major part of carbon input to surface waters occurs through direct input associated with the advective transport of surface water. The total organic carbon content (TOC) comprises both autochthonous and allochthonous carbon sources. These may be grouped based on their size into particulate organic carbon (POM) and dissolved organic matter (DOM). The latter group may also include colloidal and small particles (Münster 1993). With respect to size, three groups of organic matter are separated:

1. Coarse particulate organic matter (CPOM) with particle sizes $>1 \mathrm{~mm}$.

2. Fine particulate organic matter (FPOM) with particle sizes between $0.2 \mu \mathrm{m}$ and $1 \mathrm{~mm}$.

3. Dissolved organic matter (DOM; assessed as dissolved organic carbon (DOC)) $<0.2 \mu \mathrm{m}$.

They may consist of either living or dead material with different potential for degradation. An additional carbon source is volatile organic carbon (VOC). Modes for discrimination of DOC are presented in Table 4.

\section{Table 4}

Modes for discrimination of dissolved organic carbon (DOC) upon bioavailability and molecular weight.

\section{Parameters for discrimination \\ Bioavailability}

Biodegradable DOC

Semi-labile DOC (resistant to microbial attack)

Recalcitrant DOC
Molecular weight

Low molecular weight fraction (<1000 Da)

High molecular weight fraction (>1000 Da)

As organic matter content leads to oxygen consumption and eventually to competition for oxygen, organic carbon content in water is also measured indirectly as oxygen content and oxygen saturation as well as chemical ( $\mathrm{COD} ; \mathrm{mg} \mathrm{O}_{2} \mathrm{~L}^{-1}$ ) and biochemical oxygen demand $\left(\mathrm{BOD}_{5} ; \mathrm{BOD}_{7} ; \mathrm{mg} \mathrm{O}_{2} \mathrm{~L}^{-1}\right.$ ). Oxygen content expressed as $\mathrm{mg}$ $\mathrm{O}_{2} \mathrm{~L}^{-1}$ denotes the amount of dissolved oxygen (DO), whereas oxygen saturation (\%) is a relative measure and stands for the upper limit of oxygen that can be dissolved under given conditions (e.g. temperature, organic matter content, load of macro- and microorganisms). The biochemical oxygen demand (BOD; $\mathrm{mg} \mathrm{O}_{2} \mathrm{~L}^{-1}$ ) is defined as "the amount of oxygen required by bacteria while stabilizing decomposable organic matter under aerobic conditions" (Lester and Birckett 1999). It is determined after either five $\left(B O D_{5}\right)$ or seven $\left(B O D_{7}\right)$ days of incubation. In contrast, the chemical oxygen demand ( $\mathrm{COD} ; \mathrm{mg} \mathrm{O}_{2} \mathrm{~L}^{-1}$ ) describes the "total quantity of oxygen required to oxidize substances to carbon dioxide and water" (Lester and Birckett 1999). 


\subsubsection{Irrigation water quality requirements with respect to organic matter load}

Irrigation water standards often avoid information on suitable levels of organic carbon content. An exception is the German DIN 19650 (DIN 19650 1999), recommending more detailed analysis if the chemical oxygen demand (COD) exceeds $60 \mathrm{mg} \mathrm{L}^{-1}$. In the case of biochemical oxygen demand, risk assessment is recommended for greenhouse horticulture in integrated production when $\mathrm{BOD}_{5}$ exceeds $10 \mathrm{mg} \mathrm{O}_{2} \mathrm{~L}^{-1}$ (Göhler and Molitor 2002). This compares to standards from water industry where $4 \mathrm{mg} \mathrm{O}_{2} \mathrm{~L}^{-1}$ stands for good water quality, $<3 \mathrm{mg} \mathrm{O}_{2} \mathrm{~L}^{-1}$ for good river water quality, and $<20 \mathrm{mg} \mathrm{O}_{2} \mathrm{~L}^{-1}$ for good sewage effluent quality. In contrast to these sources, the BOD levels of raw sewage and high strength processing water from vegetable industry are much higher at $300 \mathrm{mg} \mathrm{O}_{2} \mathrm{~L}^{-1}$ and $10000 \mathrm{mg} \mathrm{O}_{2} \mathrm{~L}^{-1}$ respectively (Lester and Birckett 1999). Empirical data indicate that DOCand COD-values in raw water and nutrient solution in integrated greenhouse horticulture with recirculating nutrient solution are strongly correlated, and measurement of DOC is routinely recommended (Alsanius 2011, Alsanius et al. 2011). It remains to be seen if this translates to organic greenhouse horticulture.

Trophic levels in water sources used for irrigation may be ultra-oligotrophic, oligotrophic, mesotrophic, eutrophic or hypertrophic. As a result, water clarity (turbidity, transmittance), dissolved organic carbon content, and total biomass increase from a low to a high trophic level. There is a concomitant occurrence of macrophytes and algae as well as primary phytoplankton, and microbial productivity also rises. As a result, oxygen saturation decreases with increasing trophic level in the water source (Sigee 2005).

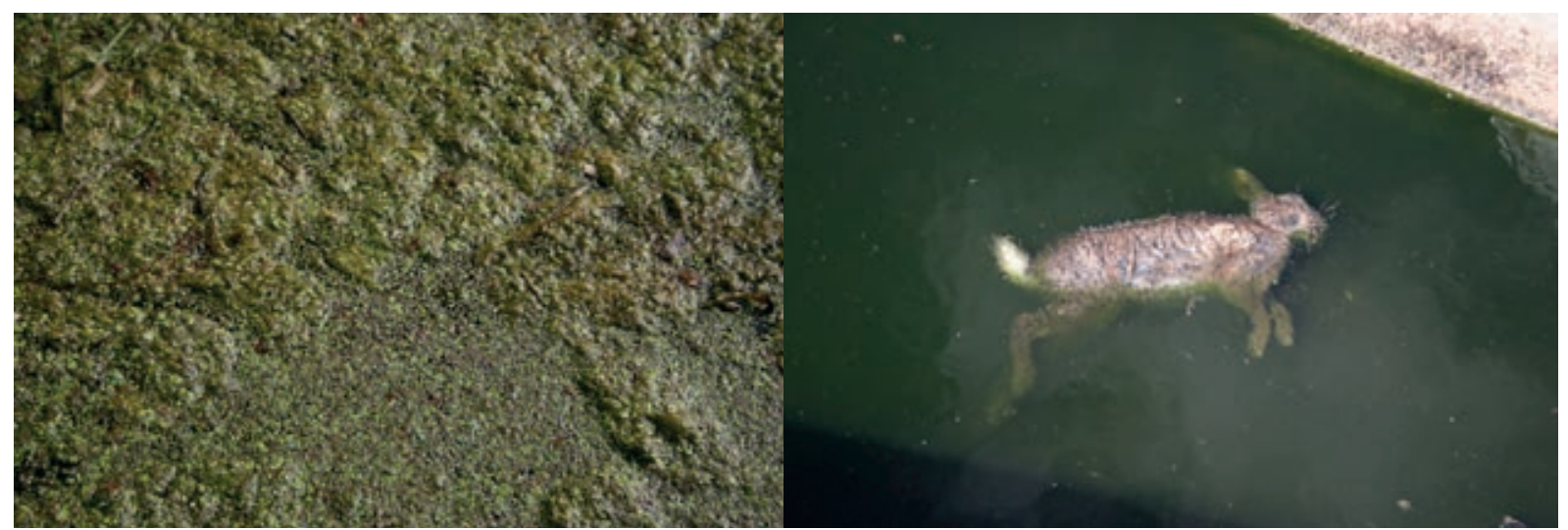

Figure 5 Organic load in irrigation water (photo: Beatrix Alsanius).

In general, the organic carbon content in municipal water (potable water quality) and ground water is low. However, the lining of drilled wells may release organic compounds to the piped water. Furthermore, the content of organic matter in well water may be affected by sewage water ingress. Rainwater is often considered to be low in organic carbon, but the amount of DOC is variable (Koprivnjak and Moore 1992). The organic carbon content in collected rainwater is affected by the collection surfaces' cleanliness and the mode of storage. The organic carbon content in standing waters (lakes, ponds, impoundments) is a function of carbon of microbial origin and photosynthetic activity of algae along with factors such as light penetration (incl. UV-irradiation), shape, size (depth, surface), and hydrology (flow rate, retention time). From a trophic point of view, shallow and deep lakes need to be distinguished. Shore areas account for higher organic matter inputs due to the surrounding vegetation and of shore vegetation in particular in the case of shallow lakes. The central part of deep lakes is thermally stratified, thus OC dynamics are not only a function of the layer's position within the water body, but also of the oxygen and UV-radiation gradients. In this context also, the occurrence and activity of photosynthetic organisms and concomitantly the accumulation of autochthonous carbon in upper layers exposed to sunlight needs to be taken into account as does the accumulation of OC as a consequence of sedimentation in lower levels. The conditions in irrigation ponds and impoundments in general compare to those prevailing in shallow lakes (Alsanius et al. 2014).

Running waters differ from standing waters by virtue of a continuous and higher flow rate and are characterized by good and static aeration, and unidirectional, often turbulent flow. In running waters, allochthonous carbon is the most dominant source for $\mathrm{OC}$, supplied from the surrounding vegetation. 


\subsection{Microbial loads}

Waterborne microorganisms may be stimulatory, neutral or detrimental to plant growth. Irrigation water may also be a vehicle for the transmission of zoonotic microorganisms or other human pathogens and in case of production of edible crops, threaten the biosafety of the produce and human health. As in other contexts, microbial loads in water sources used for irrigation in organic greenhouse horticulture are a function of the organic carbon bioavailability, oxygen content, temperature and pH (Alsanius, 2014). Apart from these factors, microbial proliferation is fuelled by the availability of readily available nutrients, such as nitrogen and phosphorus. Heterotrophic microorganisms are therefore found in higher numbers in eutrophic waters. The occurrence and proliferation of microbes follow the same pattern as the bioavailability of organic carbon i.e. potable (municipal), ground water, rainwater < surface waters, treated and untreated sewage water. However, shallow wells or contamination through side water ingress may affect well water's high standard. Other factors encouraging microbial proliferation in water sources with high hygienic standards are the mode of collection and storage of rainwater. Furthermore, the microbial load of surface waters changes with regard to seasonal weather events.

In Europe, few standards for the hygienic quality of irrigation water have been established. DIN 19650 (1999) is one exception and it groups irrigation water quality into four classes with respect to its mode of application and target crop as well as locale. In general, high numbers of heterotrophic microorganisms do not necessarily translate into human health risks or to a high load of faecal organisms, but they do indicate a potential for microbial proliferation. Indicator organisms are used to characterize irrigation water hygiene and faecal contamination. The numbers of total coliforms, faecal coliforms, E. coli and enterococci as well as the presence of Salmonella spp. are commonly used as indicator organisms in irrigation water contexts (Canadian Council of Ministers of Environment, 1999, Blumenthal et al. 2000, Blumenthal et al. 2001, British Columbia Ministry of Environment, 2001).

Irrigation water quality is not only affected by the hygienic status at the point source but also by the pipelines and point of delivery. Microbes may occur in the free water phase or be attached to biofilms within the irrigation water delivery system. In contrast to potable water, the irrigation water supply distribution systems are not exposed to pressure when not operating. Stagnant water allows microorganisms to grow and biofilms may grow to considerable thickness inside water pipelines. Both retention and release processes occur (Pachepsky et al. 2011, Shelton et al. 2012, Alsanius et al. 2016).

Clogging of the emitters is a common problem in drip irrigation systems and leads to uneven distribution of irrigation water and nutrients, and also to decreased flow rates. It is a multifactorial problem caused by chemical precipitation, microbial proliferation and consequent biofilm formation, biofouling and suspended matter (Gilbert et al. 1982, Adin 1986, Nakayama and Bucks 1991, Dazhuang et al. 2009) and is therefore related to water quality (Adin 1986, Capra and Scicolone, 2007, Li et al. 2009). De Krej et al. (2003) found that methane in the raw water along with organic acids (formic acid, acetic acid) contribute to clogging. In the literature this phenomenon has been specifically highlighted for drip irrigation using wastewater. Different authors emphasize the interaction between clogging and emitter type and position of the emitter along the lateral. Improvements in emitter design can improve resistance to clogging e.g. pressure compensation (Duran-Ros et al. 2009), high discharge rate emitters (Ravina et al. 1997), and labyrinth emitters (Capra and Scicolone 2004).

\subsection{Hazardous microorganisms and compounds}

Raw water, particularly surface water, rainwater collected from contaminated surfaces or inappropriately stored and treated sewage water may be carriers of plant and human pathogens. Cucumber mosaic virus (Rydén 1965), Erwinia chrysanthemi and Erwinia carotovora spp. carotovora (Persson 1991) have been found in Swedish surface waters (running water). Hong et al. (2014) recently presented a comprehensive list of plant pathogens associated with different water bodies used for irrigation. Bacterial and fungal pathogens as well as nematodes were often linked to pond water and only a few could be linked to all kinds of irrigation water sources (well water, standing and running surface water, wastewater, and ocean). Interestingly, oomycetes (i.e. Pythium spp., Phytophthora spp.) and viruses could be linked to both standing and running surface waters. 
Irrigation water is also a potential route for transmission of human pathogens, including viruses (hepatitis $A$, norovirus), bacteria (Salmonella spp., shigatoxin producing E. coli, Shigella spp., Campylobacter spp., Yersinia spp., Listeria monocytogenes, Aeromonas spp., Vibrio spp.), protozoa (i.e. Giardia spp., Crytosporidium), and helminthes (Alsanius 2014). Transmission can take place either through direct transfer to edible plants parts (e.g. leaves, roots) and subsequent potential internalization, or through transfer to soil and transmission to the crop by water splash.

The use of chemical plant protection production (PPP) does not comply with organic horticulture standards. PPP and pharmaceutical and personal care products (PPCP) may however enter organic cropping systems when contaminated surface and groundwater sources are used. PPP may enter surface and ground water through leakage and drainage from conventionally/integrated cropped field or greenhouse surfaces and have repeatedly been found in surface waters in the adjacent areas to production areas (Kreuger et al. 2010, Vermeulen et al. 2010, Beulke et al. 2011). They can remain persistent over a long time in aquatic systems and aqueous solutions with low organic matter content (Sarkar et al. 1999, Abbate et al. 2007, Abbate et al. 2009, Alsanius et al. 2013, Alsanius and Bergstrand 2014). PPCP residues in water sources are an emerging issue and have been recovered from sewage water (both influent and effluent) as well as surface waters and in groundwater in the adjacent areas to landfills. These residues include antibiotic compounds, analgesics and pain killers, synthetic steroids, beta-blockers, antiepileptic as well as cytostatic drugs (Halling-Sörensen et al. 1998, Hirsch et al. 1999, Heberer 2002, Kemper 2008, Fatta-Kassinos et al. 2011). They may derive from different point or diffuse sources, such as animal husbandry, run-off from agricultural land treated with animal manure or slurry sludge, waste disposals or effluents from hospitals and households. Plant assays have shown that some PPCP are taken up by plants (Migliore et al. 2000, Herklotz et al. 2010, Winker et al. 2010, Eggen et al. 2011, Karnjanapiboonwong et al. 2011, Shenker et al. 2011). Uptake and transport within the plant differed for the different model plants and compounds. Apart from its adverse impact on human health, phytotoxicity was shown in some of the studies. 


\section{$4 \quad$ Water resources}

\section{In short}

- The main sources of water use for crop irrigation are ground water, surface water, rainwater, process waters and municipal water.

- Condensed water and rainwater are the most sustainable sources of water, although their availability does not fulfil plant water requirements.

- Municipal water often has high concentrations in $\mathrm{Na}, \mathrm{Cl}$ and $\mathrm{SO}_{4}$, which are not suitable for organic greenhouse crops.

- The quality of ground water is highly variable and it should not be the main source of irrigation for renewability and availability reasons.

- Surface water may contain undesirable components, some of which are not allowed in organic farming.

- Treated or untreated wastewater may be a sustainable source of water according to their specific quality characteristics (e.g. desalinated water, greywater, digestate, fish effluent).

In greenhouse systems, irrigation water must be drawn from an external supply. The choice of the water source has both quantitative (discussed in Chapter 7) and qualitative aspects. Yet, there is no regulation that prescribes the water resources to be used for organic greenhouse horticulture. However, consideration of organic farming principles leads to the obvious choice of sustainable and renewable sources. Likewise, rainwater is the obvious source, as a greenhouse is preventing natural precipitation, it should be given back to the soil. Other water sources, depending on availability, can be groundwater, surface water, process waters or municipal water. These sources may then be used in addition to the (collected) rainwater, but their use should always be considered in view of such sustainable issues as the renewability of the source, the threats of salinity which may necessitate leaching in the long run, or the requirement of additional treatments. Alternatively, surface water recycled from production areas, treated and untreated wastewater may serve as water sources for irrigation.

\subsection{Rainwater}

Rainwater is likely to be the first choice for organic greenhouse horticulture as it is a natural and renewable, hence the most sustainable, source. However, for Europe and North America, the seasonal distribution of precipitation commonly deviates from crop demand. Rainwater collection and storage (Figure 6 ) is then necessary and should be one of the basic provisions for organic greenhouses. The dynamics of precipitation and demand and the consequences for size of the storage is discussed in section 4.9. The quality of rainwater is almost undisputed. Contamination can occur as there can be deposits on the greenhouse roof which are washed off with the rain. This can be the case if greenhouses are located close to fields with intensive agricultural activities. Where pesticides are sprayed, drift during spraying may deposit on the roof. The quantities are low and unlikely to be harmful to the crop as they are diluted by the rainfall, but irrigation water for organic crops should be free of synthetic pesticides. Moreover, traces of pesticides can be found in the grown products, which is undesirable. If there is a risk of contamination it is recommended into install a so-called "first flush" provision. This will collect the first rainwater separately and this can be discharged to the sewer. This provision is also recommended where greenhouses are located in the vicinity of sea, as salt spray or salt depositions will increase the salt $\mathrm{EC}$ and $\mathrm{NaCl}$ concentration. This is only a problem for soilless culture systems and the re-use of drainage water. 


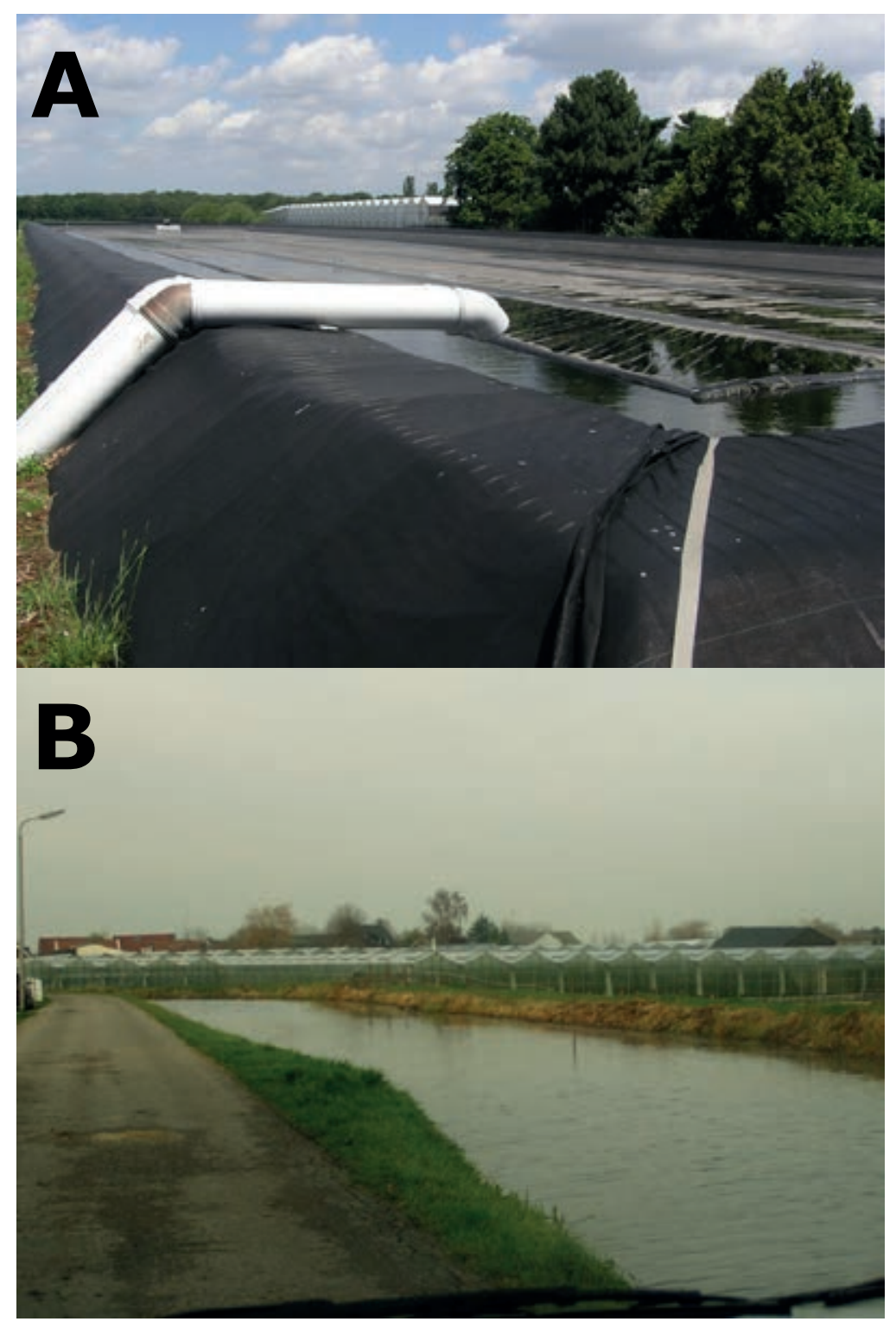

Figure 6 Rainwater management for irrigation. A: Rainwater storage as a high quality source of irrigation water; B: Potential seepage can complicate the re-use of drained water (photos: Wim Voogt).

\subsection{Municipal water}

Municipal water can be derived from various sources. As it is intended for human consumption and applications, the biological quality is high; however there is no guarantee that the chemical quality is satisfactory. In particular the concentrations of $\mathrm{Na}, \mathrm{Cl}$ and $\mathrm{SO}_{4}$ can be of serious concern. For soil grown crops this is not usually a problem, but this type of water is not always suitable for soilless systems, especially when drainage water is re-used. As a back-up provision, this water has the advantage that it is usually always available. However the quantity available can be a problem as the capacity of the connection is usually limited to a few $\mathrm{m}^{3} \mathrm{~h}^{-1}$. 


\subsection{Ground water}

Ground water may be extracted from aquifers by drilled wells or from natural springs. The chemical quality can be very different depending on the source and the local geological conditions. Usually ground water is high in $\mathrm{pH}$ and contains bicarbonate; however in some situations, ground water can be void of carbonates and $\mathrm{pH}$ levels below 5 can occur. Next to carbonates, Ca and $\mathrm{Mg}$ are commonly present, although $\mathrm{Na}$ may be present as the primary cation. The water is then less usable, as $\mathrm{Na}$ will exchange with Ca ions from clay minerals and negatively affect soil structure. $\mathrm{Cl}$ and $\mathrm{SO}_{4}$ may also be present. Well water may contain micronutrients. Micronutrient concentrations are not usually a problem for soil grown crops as at least they contribute to the plant nutrition. For soilless crops, however, the concentrations of some micronutrients such as $\mathrm{B}, \mathrm{Mn}$ and $\mathrm{Cu}$ are known to be problematic in some cases. Fe in particular is important for technical reasons as described in section 2.1. From a sustainability perspective, the use of ground water must be considered in view based on it availability and renewability. Groundwater is being depleted at a global level causing drought stress and many other problems. Therefore, it is not recommended as the main water source. In all cases, shallow groundwater tables $(<20 \mathrm{~m})$ must not be used, as they may be contaminated with plant pathogens or pesticides.

\subsection{Surface water}

Surface waters comprise running waters (i.e. rivers, creeks, ditches), natural waters (i.e. lakes, ponds) and artificial (i.e. impoundments collecting surface run-off water, recollection ponds from production areas, recreational water), and standing waters (Alsanius et al. 2014, Ross 2014) (Figure 7). There can be wide variations in the concentrations of beneficial components (e.g. K, Ca, Mg, micronutrients) and undesired components (e.g. salts, heavy metals and chemical components) as well as the organic loads. The use of these sources should be evaluated by a thorough investigation of probable contaminations and the potential presence of pesticides.

\subsection{Condensed water}

As described in section 2.1, condensed water is produced inside the greenhouse during periods with low ventilation (winter, spring, autumn). The water quality is perfect, however in old greenhouses, with galvanized gutters, the concentration of heavy metals (e.g. Zn) can be very high and this water will eventually contaminate the soil. Gutters should be made of aluminium or if steel is used, they should be coated. A collection system is required; otherwise the condensed water will drop off and be returned to the soil.

\subsection{Desalinated water}

Water sources with too high concentrations of undesirable components can be made suitable for irrigation water by desalinization. This can also make crop growing possible in water scarce areas in the world. Commonly reverse osmosis installations are used (Figure 7E). There are no limitations on the use of this technology in organic farming so far as is known. The product water is very pure and can be used for any crop - growing system combination. However, the production costs of this water are considerable. Sometimes the water is diluted with non-desalinated water to reduce the cost.

\subsection{Miscellaneous water sources}

\subsubsection{Treated and untreated wastewater}

The origins of wastewater are very diverse and they include wastewater from human wastes (blackwater), septic tank discharges, washing water (greywater), industrial drainage and process water (including cooling water and toxic wastes), drainage water from infrastructure (urban run-off water and highway drainage water), as well as storm drainage water. Wastewater may be regenerated through wastewater treatment, a four step approach 
that includes (i) removal of coarse material (preliminary treatment), (ii) screening and sedimentation (primary treatment), (iii) biological and chemical treatment through activated sludge, filtration over trickling filter and oxidation ponds assisted with disinfection (secondary treatment) and (iv) removal of biological oxygen demand, nutrients, pathogens and parasites (tertiary treatment) (Bitton 2011). These sources vary with respect to quality parameters; however, differences may also be substantial within the raw water source as it can be affected by the locale and season. Table 5 shows some quality characteristics of different sources of water used for greenhouse crop irrigation. Wastewater may constitute an alternative source of irrigation water subject to local agricultural and organic regulations, and their quality in terms of constituents.

\subsubsection{Digestate}

According to the Annex 1 of the EU regulation (EC 889/2008), the use of digestates from household wastes, when produced in a closed and monitored collection system, is accepted. The use of digestates from agricultural wastes (e.g. animal manures, crop residues, energy crops) and/or wastes from the food processing industry are also allowed, but should not be applied directly to the edible parts of the crop. Depending on the feedstock materials digested, this wastewater may contain well-balanced and easily available nutrients for greenhouse crops with a balanced N/P ratio, although the N/K ratio can be affected by $\mathrm{K}$ shortage. For example, the anaerobic digestion (AD) of $4500 \mathrm{~kg} \mathrm{FW}$ of greenhouse tomato leaves ( 3 pruned leaves per plant per week per ha) can provide $13.4 \mathrm{~kg} \mathrm{~N}, 1.9 \mathrm{~kg} \mathrm{P}, 18.5 \mathrm{~kg} \mathrm{~K}, 25 \mathrm{~kg}$ Ca and $3.7 \mathrm{~kg} \mathrm{Mg}$ under perfect recovery system conditions, based on an average leaf nutrient content of $2.9 \% \mathrm{~N}, 0.4 \% \mathrm{P}, 4.0 \% \mathrm{~K}, 0.8 \% \mathrm{Mg}$ and $5.4 \% \mathrm{Ca}$ (Dorais and Dubé, 2011). It has been reported that applications of digestates to sandy and loamy soils increased the availability of macronutrients such as $\mathrm{P}$ and $\mathrm{K}$, and, to a lower extent, N. Digestates may also provide carbon for microbiological processes (Makádi et al. 2016). The effects of digestates, however, depend on soil characteristics.

The available database on digestate characteristics regarding macronutrient composition provides a good insight on specific digestate characteristics as determined by the feedstock (Table 5). Roughly, $1000 \mathrm{~L}$ of digestate provide approximately $0.5 \mathrm{~kg}$ total $\mathrm{N}$, with 50 to $70 \%$ as $\mathrm{NH}_{4}{ }^{+}-\mathrm{N}$. Liquid digestate can supply only 5 to $10 \%$ of the water required by the crops when plant $\mathrm{N}$ demand is taken into account, depending on crop yields and water requirements. The database on the $\mathrm{NaCl}$ contents in digestates is weak. It can be assumed that digestates derived from food, catering and household wastes as well as animal manures are relatively high in $\mathrm{NaCl}$, whereas digestates from crop biomass including clover grass or silage maize biomass can be expected to be low in these elements. 

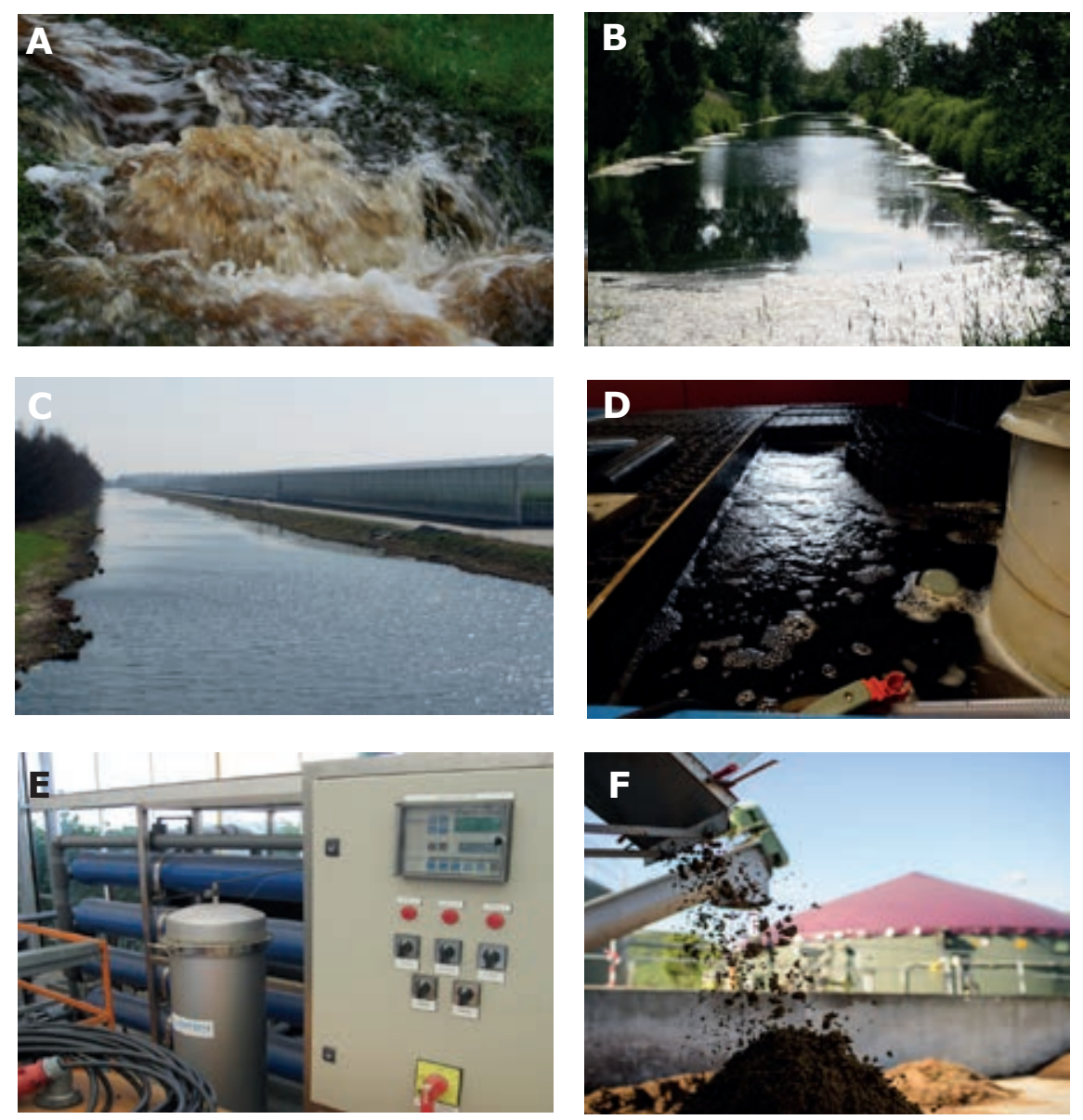

Figure 7 Water sources. A: running surface water; B and C: standing surface water; D: recollected wastewater from fish tanks; E: reverse osmosis water; F: digestate. (photos: Beatrix Alsanius and Wim Voogt and University of Hohenheim). 


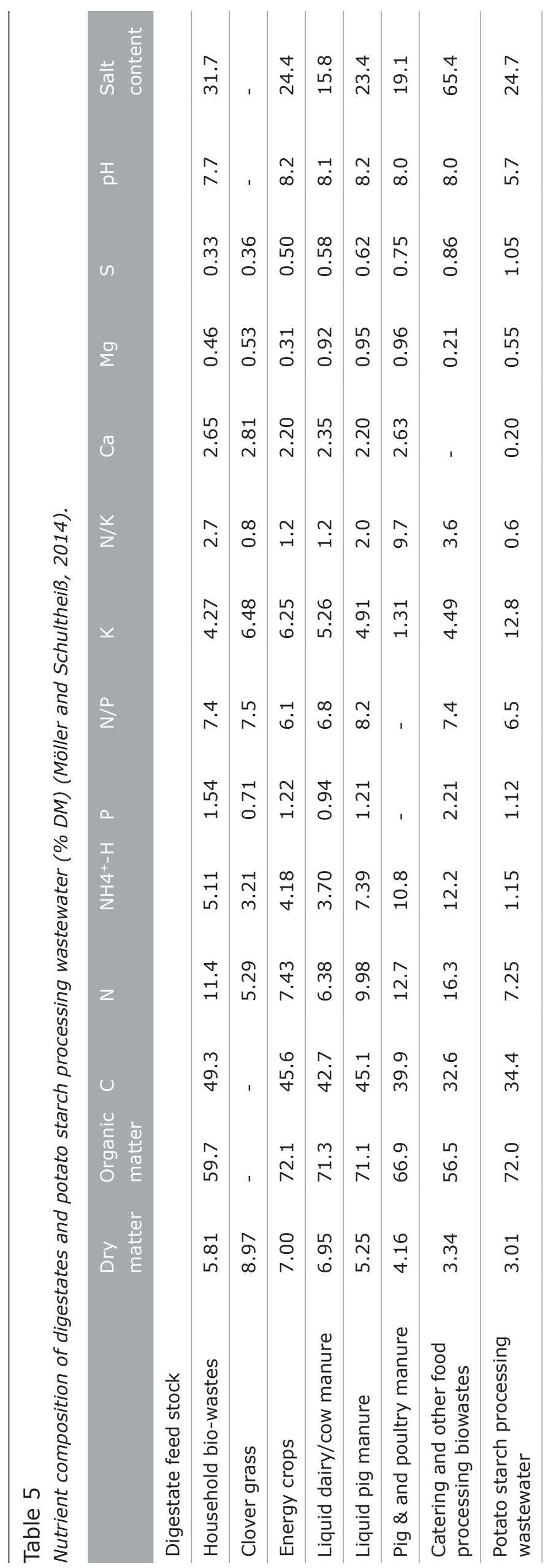




\subsubsection{Potato starch processing wastewater (Potato protein liquid)}

Wastewater from potato starch production is rich in nutrients like $\mathrm{N}, \mathrm{K}$ and $\mathrm{S}$, while simultaneously showing a relatively balanced N/P ratio. $1000 \mathrm{~L}$ of potato starch processing wastewater provide approximately $0.2-0.3 \mathrm{~kg}$ total $\mathrm{N}, 10$ to $20 \%$ as $\mathrm{NH}_{4}{ }^{+}-\mathrm{N}$. Most of the $\mathrm{N}$ is rapidly mineralized after field application (Möller and Schultheiß, 2014). Therefore potato starch processing wastewater can supply only 10 to $20 \%$ of the water required by the crops once plant $\mathrm{N}$ demand is taken into account, depending on crop yields and water requirements.

\subsubsection{Fish waste water}

Wastewater from fish production systems (Figure 7D) is rich in nutrients such as nitrogen (N), phosphorus (P) calcium (Ca), and specific organic compounds (Cripps and Bergheim 2000, Piedrahita 2003). For example, nutrient content analysis of wastewater collected from rainbow trout fed with two commercial fish feeds showed that it was rich in $\mathrm{NH}_{4}\left(123-186 \mathrm{mg} \mathrm{L}^{-1}\right)$ and $\mathrm{Ca}\left(169-217 \mathrm{mg} \mathrm{L}^{-1}\right)$ with a moderate content of $\mathrm{P}\left(59-64 \mathrm{mg} \mathrm{L}^{-1}\right)$ and low contents of $\mathrm{NO}_{3}\left(11-19 \mathrm{mg} \mathrm{L}^{-1}\right)$ and $\mathrm{K}\left(11-23 \mathrm{mg} \mathrm{L}^{-1}\right.$ ) (Gravel et al. 2014). In multiple enterprise farms, the recycling of fish wastewater as irrigation water for greenhouse crops represents an opportunity to reduce the risk of water pollution and increase soil fertility, although special attention should be given to wastewater rich in $\mathrm{Na}$. In addition to being a source of nutrients, fish wastewater could also be viewed as a preventive method for the control of soil borne plant pathogens. Fish effluent sludges are rich in microorganisms and their activity could suppress the development of plant pathogens such as Pythium spp. and Fusarium spp., causal agents of root rot and stem rot in greenhouse vegetable production. In fact, recent studies showed that fish effluents reduced the mycelial growth of both pathogens in vitro (Gravel et al. 2014). Depending on the fish feeding, a higher general microbial activity was related to a higher pathogen inhibition. Pathogen suppressiveness also occurred when fish effluents were sterilized by filtration or autoclaving, although at a lower rate, indicating that metabolites contained in the fish effluent also played a role in the suppressiveness rather than just a direct effect of the microorganisms. Mixed fish effluents also reduced organic tomato plant root colonization by $P$. ultimum and F. oxysporum (Gravel et al. 2014).

\subsection{Water storage}

Where rainwater is the main source of water, proper storage is essential to buffer the water surplus from precipitation events with periods of high water demand. Greenhouse construction must therefore be suitable for rainwater collection with effective gutter systems. Storage should preferably take place in large tanks or basins. In some cases large ponds are suitable but this will depend on local soil conditions. Underground storage in stable aquifers is a solution but in the case of aquifers containing brackish or saline groundwater, a considerable surplus of water must be injected first to create a reliable buffer of sweet water. Moreover, groundwater movement must be limited. Rainwater storage capacity depends on crop demand and local climate conditions like the average expected rainfall and dry spells. The variability in these patterns determines the size of the buffer, which also depends on the availability of alternative water sources. Models have been developed to estimate the capacity of the required water storage (Voogt et al. 2012) and a simulation of various scenarios resulted in a wide variation in the required buffer size between regions (Bezemer and Voogt 2008). 
36 Impact of water quality and irrigation management on organic greenhouse horticulture 


\section{$5 \quad$ Water demand}

\section{In short}

- Water demand is mainly determined by crop evapotranspiration, which is the sum of soil surface evaporation and plant transpiration.

- Evapotranspiration depends on climate conditions, type of crop, water quality, soil characteristics, growing systems and cultural practices.

- Many approaches can be used to estimate crop ET based on climate and plant growth parameters using empirical and mechanistic models, artificial neural networks, fuzzy logic and genetic algorithms.

- Water demand should also optimize soil bacterial and fungal activities as small reductions in soil moisture content decrease mineralization rates.

- Excessively wet soil conditions or events of wetting pulses affect soil microbial activity and soil structure.

Organic greenhouse crops are intensive production systems that require large amounts of water to cool the plant and facilitate nutrient transport. Water also constitutes around $93 \%$ of the total plant fresh biomass. Depending on the type of crop, the growing systems and the producing area, water consumption can be as high as $0.9 \mathrm{~m}^{3} \mathrm{~m}^{-2}$ per year. For example, an amount of 0.4 to $5.6 \mathrm{~L}$ can be supplied to a tomato plant depending on its developmental stage, season, growing systems (soil or soilless cultivation), and water and/or soil salinity. This amount of water also takes into account the water needed to maintain adequate soil salinity as well as meeting plant water demand. In addition to replacing the water lost through plant transpiration and soil surface evaporation, water demand for organic crops should also consider the needs of soil microbiota, which constitutes one of the keystones of organic farming.
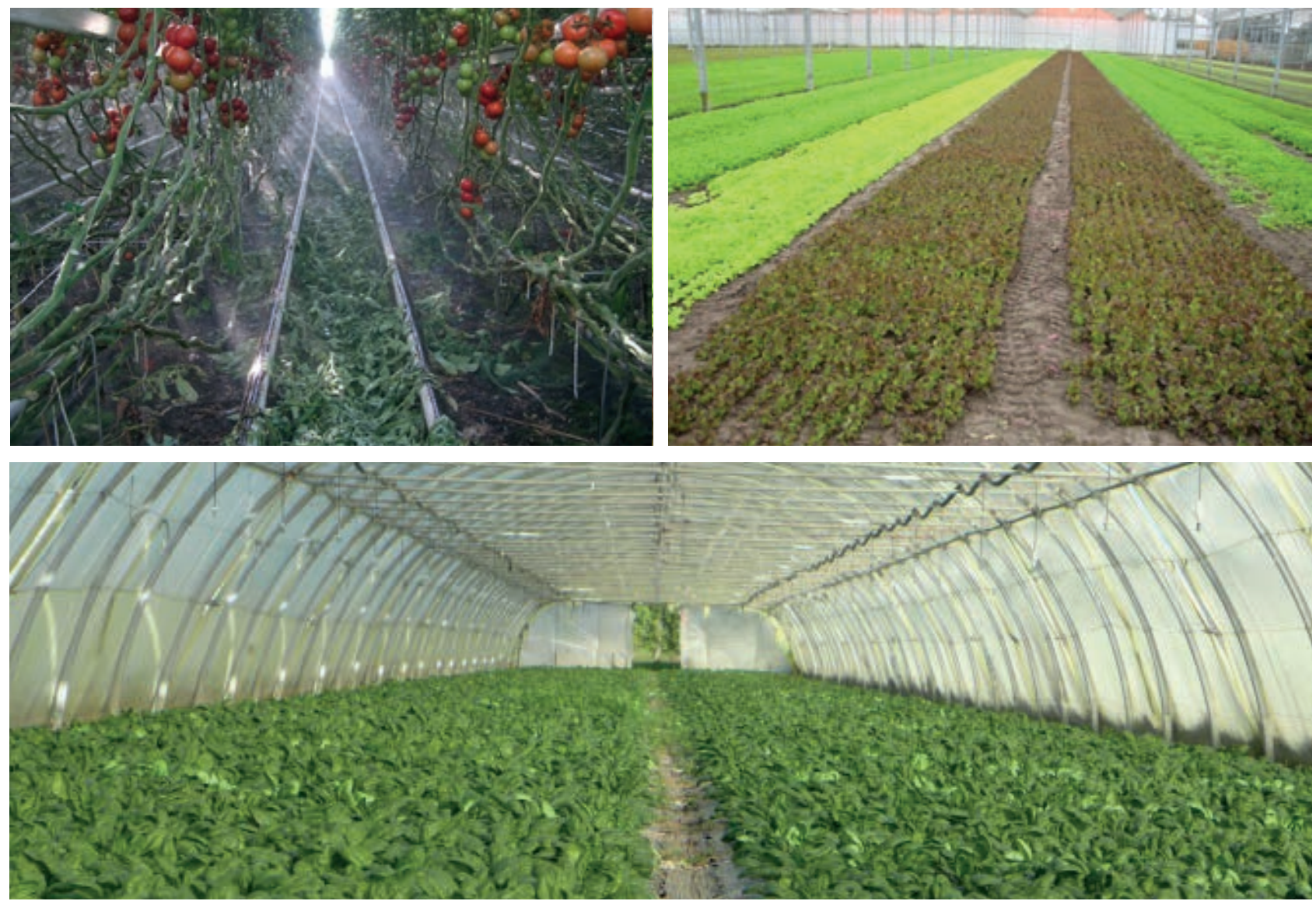

Figure 8. Water evaporation from the crop and the soil, called crop evapotranspiration, is mainly driven by solar radiation and vapour pressure deficit. (photos: Wim Voogt and Martine Dorais). 


\subsection{Evaporation and transpiration}

Evaporation (E) occurs when liquid water at the soil surface is converted into water vapour which then disperses into the atmosphere. Solar radiation, air temperature, air humidity and wind speed are the main factors affecting soil water evaporation. Transpiration $(T)$, on the other hand, is the vaporisation of liquid water contained within the plant tissues and removal to the atmosphere in the gas phase. Transpiration depends on the energy supply, vapour pressure gradient and wind speed. However, solar radiation, air temperature and humidity should also be taken into consideration. The transpiration rate is affected by the crop development stage, the crop species itself, environmental conditions and cultural practices. Both processes occur concurrently. Evapotranspiration (ET) is the sum of evaporation and plant transpiration. Evaporation is higher at the earlier crop stage due to the lower transpiration, while transpiration increases with the increase in plant growth. For instance almost $100 \%$ of ET is formed through evaporation at the sowing stage (when the crop is small) whereas $90 \%$ of ET comes from transpiration at full crop (Allen et al. 1998).

Evaporation and transpiration are affected by climate conditions (e.g. solar radiation, temperature, humidity, and wind speed), crop (e.g. type, variety, developmental stage, density), soil (e.g. water content, salinity), growing systems (e.g. soil based cultivation, soilless growing system), and cultural practices (e.g. mulching, irrigation method) (Voogt and van Winkel, 2008). Measuring evaporation and transpiration separately is difficult, so the processes are usually measured and/or computed as a combined flux (ET) (Figure 8).

Crop water requirement is defined as the total water volume needed by a crop to sustain a maximum rate of crop evapotranspiration $\left(\mathrm{ET}_{\mathrm{c}}\right)$. Crop evapotranspiration $\left(\mathrm{ET}_{\mathrm{c}}\right)$ is the evapotranspiration from well-grown crops. The water loss through ET is the amount of water required for irrigating the crop. For greenhouse horticulture, there are various methods available for the determination of the rate of evapotranspiration (ET). These methods are based on the calculation of the total amount of water lost through transpiration and evaporation. ET can be measured or estimated by direct or indirect methods. The most precise direct method of measuring ET is with the use of weighing lysimeters (Baille et al. 1994). The use of weighing lysimeters is limited in practice due to their cost and operating difficulty. It is therefore often considered to be the reference method, and is used in particular for well-watered crops to test other ET measurement methods (Lazzara and Rana, 2010). Drainage type lysimeters can also be used to determine crop evapotranspiration, and the quantity and quality of drainage water (Tuzel et al. 2009). Estimation methods include the measurement of net radiation, temperature and water vapour deficit. To determine $\mathrm{ET}_{c^{\prime}}$ many climate based estimation methods have been adapted. They require calculation of reference evapotranspiration $\left(\mathrm{ET}_{\mathrm{o}}\right)$ and crop coefficients $\left(\mathrm{K}_{\mathrm{c}}\right)$.

$\mathrm{ET}_{\mathrm{c}}=\mathrm{K}_{\mathrm{c}} \times \mathrm{ET}_{\mathrm{o}}$

where $\mathrm{ET}_{c}$ is crop evapotranspiration ( $\left.\mathrm{mm} \mathrm{d}^{-1}\right), \mathrm{K}_{c}$ is crop coefficient (dimensionless), and $\mathrm{ET}_{0}$ is reference crop evapotranspiration $\left(\mathrm{mm} \mathrm{d}^{-1}\right)$, i.e. the total of evaporation and transpiration from a reference crop surface (grass or alfalfa). There are many approaches used to calculate $\mathrm{ET}_{0}$ and among them the FAO Penman-Monteith (PM) equation is accepted as the global standard (Allen et al. 1998). The current use of the Penman-Monteith equation is based on the calculation of ET for outdoor climates.

The Penman-Monteith equation requires several climate variables (temperature, relative humidity, solar radiation and wind speed). If those variables are not available, $\mathrm{ET}_{0}$ can be calculated with different equations. When solar radiation, wind speed or relative humidity variables are missing, the Hargreaves equation is recommended for $\mathrm{ET}_{\text {o }}$ calculations (Allen et al. 1998). The Penman-Monteith and the Hargreaves models for calculating $\mathrm{ET}_{\mathrm{o}}$ are given below.

$\mathrm{ET}_{\mathrm{o}}=\frac{0.408 \Delta\left(\mathrm{R}_{\mathrm{n}}-\mathrm{G}\right)+\gamma \frac{900}{\mathrm{~T}+273} \mathrm{u}_{2}\left(\mathrm{e}_{\mathrm{s}}-\mathrm{e}_{\mathrm{a}}\right)}{\Delta+\gamma\left(1+0.34 \mathrm{u}_{2}\right)}$ (FAO Penman-Monteith)

$\mathrm{ET}_{\mathrm{o}}=0.0023\left(\mathrm{~T}_{\text {mean }}+17.8\right)\left(\mathrm{T}_{\text {max }}+\mathrm{T}_{\text {min }}\right)^{0.5} \mathrm{R}_{\mathrm{a}}$ (Hargreaves-Samani)

where $\mathrm{ET}_{0}$ is reference evapotranspiration ( $\left.\mathrm{mm} \mathrm{d}^{-1}\right), \mathrm{R}_{\mathrm{n}}$ is net radiation $\left(\mathrm{MJ} \mathrm{m}^{-2} \mathrm{~d}^{-1}\right), G$ is soil heat flux $\left(\mathrm{MJ} \mathrm{m}^{-2} \mathrm{~d}^{-1}\right), T$ is daily air temperature at $2 \mathrm{~m}$ height $\left({ }^{\circ} \mathrm{C}\right), \mathrm{u}_{2}$ is wind speed at $2 \mathrm{~m}$ height $\left(\mathrm{m} \mathrm{s}^{-1}\right), \mathrm{e}_{\mathrm{s}}$ is saturation vapour pressure $(\mathrm{kPa}), \mathrm{e}_{\mathrm{a}}$ is actual vapour pressure $(\mathrm{kPa}), \mathrm{e}_{\mathrm{s}}-\mathrm{e}_{\mathrm{a}}$ is the vapour pressure deficit (VPD, $\left.\mathrm{kPa}\right), \Delta$ is theslope vapour pressure curve $\left(\mathrm{kPa}^{\circ} \mathrm{C}^{-1}\right), \mathrm{Y}$ is the psychrometric constant $\left(\mathrm{KPa}^{\circ} \mathrm{C}^{-1}\right)$, and $\mathrm{R}_{\mathrm{a}}$ is extra-terrestrial radiation $\left(\mathrm{MJ} \mathrm{m}^{-2} \mathrm{~d}^{-1}\right)$. 
Pan evaporation is another common method to estimate $\mathrm{ET}_{\mathrm{o}}$ (Doorenbos and Pruitt 1977). It requires a locally calibrated $\mathrm{K}_{\mathrm{p}}$ (pan coefficient) constant in order to obtain good estimates of ET for plastic greenhouses (Castilla 1999). The crop coefficient $\left(K_{c}\right)$ integrates the effects of four primary characteristics that distinguish the cropped surface from the reference surface namely crop height, albedo, canopy resistance, and evaporation from the soil surface (Allen et al. 1998). $\mathrm{K}_{c}$ is affected by many variables such as crop type, climate, soil evaporation, crop growth stage, cultural practices and even irrigation method. Crop management (plant spacing, crop height, etc.) is different in greenhouse production. The crop coefficient theory was developed for open field conditions and $\mathrm{K}_{c}$ values obtained from outdoor experiments should not therefore be used in greenhouse production. Considering the differences in growing techniques and greenhouse conditions, transferring $\mathrm{K}_{\mathrm{c}}$ values from field studies can still be discussed even though $\mathrm{K}_{\mathrm{c}}$ values are provided from greenhouse experiments.

Since the crop coefficients are crop specific and depend on the growth stage, climatic conditions, and management practices they must be determined experimentally. The crop coefficient is related to the degree of soil cover by crop canopy and thus to leaf area index (LAI). Several authors have attempted to model the evaluation of $\mathrm{K}_{\mathrm{C}}$ and LAI during the growing season. For instance, simple $\mathrm{K}_{\mathrm{C}}$ models based on thermal time (i.e., cumulated growing degree day (GDD)) were designed and validated for some greenhouse crops by Orgaz et al. (2005). A single $\mathrm{K}_{c}$ is generally used in irrigation planning, design of irrigation management, basic irrigation schedules, and real-time irrigation scheduling for non-frequent water applications whereas a dual $\mathrm{K}_{\mathrm{c}}$ approach, which is based on crop transpiration and soil evaporation separately, is basically used in research, real-time irrigation scheduling for frequent water application, and soil and hydrologic water balance studies (Allen et al. 1998).

In recent years, researchers have developed several models to estimate crop evapotranspiration using greenhouse climate variables (mostly radiation and vapour pressure deficit) and several crop measurements such as leaf area index (LAI) and stomatal resistance $\left(r_{s}\right)$ (Stanghellini 1987, Carmassi et al. 2007, Colla et al. 2009, Boulard et al. 1997, Boulard and Wang 2000). Some of these models are given below.

$\mathrm{ET}_{\mathrm{c}}=0.946[1-\exp (-0.69 \mathrm{LAI})] \frac{\mathrm{R}}{\lambda}+0.188$

$\mathrm{ET}_{\mathrm{c}}=0.34[1-\exp (-0.6-\mathrm{LAI})] \mathrm{R}+30.27-\mathrm{LAI}-\mathrm{VPD}$

$\mathrm{ET}_{\mathrm{c}}=2 \mathrm{LAI} \frac{1}{\lambda} \frac{\Delta\left(\mathrm{R}_{\mathrm{n}}-\mathrm{G}\right)+\mathrm{K}_{\mathrm{t}} \frac{\mathrm{VPD} \cdot \rho \cdot \mathrm{C}_{\mathrm{p}}}{\mathrm{r}_{\mathrm{a}}}}{\Delta+\gamma\left(1+\frac{\mathrm{r}_{\mathrm{c}}}{\mathrm{r}_{\mathrm{a}}}\right)}$

where $\mathrm{ET}_{\mathrm{c}}$ is the crop evapotranspiration, $\mathrm{R}$ is the solar radiation $\left(\mathrm{W} \mathrm{m}^{-2}\right), \mathrm{I}$ is the latent heat of vaporization $\left(\mathrm{MJ} \mathrm{kg} \mathrm{kg}^{-1}\right), \mathrm{VPD}$ is the vapour pressure deficit of the air $(\mathrm{kPa}), \rho$ is the mean atmospheric density $\left(\mathrm{kg} \mathrm{m}^{-3}\right)$, $\mathrm{C}_{\mathrm{p}}$ is the specific heat air (equal to $0.001013 \mathrm{MJ} \mathrm{kg}^{-1}{ }^{\circ} \mathrm{C}^{-1}$ ), $r_{c}$ is the canopy resistance, $r_{a}$ is the aerodynamic resistance, LAI is the crop leaf area index $\left(\mathrm{m}^{2} \mathrm{~m}^{-2}\right), \mathrm{K}_{\mathrm{t}}$ is a unit conversion ( $3600 \mathrm{~s} \mathrm{~h}^{-1}$ for $\mathrm{ET}_{0}$ in $\left.\mathrm{mm} \mathrm{h}^{-1}\right), \Delta$ is the slope vapour pressure curve $\left(\mathrm{kPa}{ }^{\circ} \mathrm{C}^{-1}\right)$, and $\mathrm{Y}$ is the psychrometric constant $\left(\mathrm{kPa}{ }^{\circ} \mathrm{C}^{-1}\right)$.

The evapotranspiration rate is determined by separate and joint effects of various climatological and morphological variables. Developing empirical and physical models that account for all effects is not feasible. As the number of variables used in a model increases, the ease of use and transferability of the model decreases and requires site-specific calibration with many measurements. When the effects of different techniques used in greenhouse production are taken into account, estimation methods such as artificial neural networks (ANN), fuzzy logic and genetic algorithms show promising results with site-specific training and limited variables. Future irrigation scheduling devices and decision support systems should include such models (ANN) and with on-line training, perfect model for site-specific conditions will develop over the years.

\subsection{Soil and soil microbiota}

One of the pillars of organic farming is a thriving and effective soil bionetwork (Alrøe and Kristensen 2004). The development and activity of soil microorganisms is of high importance and is indispensable for the decomposition and mineralisation of the added organic amendments and soil organic matter as well as disease suppressiveness. A certain level of soil humidity is crucial for the optimal functioning of these mechanisms (Figure 9).

Impact of water quality and irrigation management on organic greenhouse horticulture | 39 
Manzoni et al. (2012) showed that both bacterial and fungal activity rapidly decreases in drying soils. Similarly, Bloem et al. (1992) stated that even a small reduction in soil moisture decreased the mineralisation rate significantly, although the number of bacteria was not affected. In contrast, an over-wet soil will boost anaerobic microbial activity, which has a detrimental environmental effects such as gaseous losses of $\mathrm{N}$ by denitrification, or even reduction processes of $\mathrm{SO}_{4}$ in extreme conditions, and also on plant growth through the accumulation of organic acids. Consequently, there will be an optimum soil water content at which aerobic microbial processes are at maximum and anaerobic microbial activities the lowest. This is likely to be at a soil water content where the limitations of $\mathrm{O}_{2}$ diffusion and supply are equal (Skopp et al. 1990). This optimum will depend mainly on soil specific physical properties such as texture and air-filled porosity. Since these properties will vary greatly among all different soil types, guidelines for the optimum soil moisture content cannot be given. A general recommendation is to avoid saturation, and keep the soil at field capacity. Under natural conditions the soil water content is a dynamic parameter, changing constantly due to evapotranspiration and irrigation. Orchard and Cook (1983) showed that rewetting after drying caused a large and rapid increase in microbial activity to levels even higher than before the constant moist control treatments. This may be explained by additional quantities of readily available $\mathrm{C}$ from the lysis of microbial cells and the release of compatible solutes. However, Borken and Matzner (2009) demonstrated that this so called 'wetting pulse' in mineralisation following wetting of a dry soil is relatively short-lived and that frequent drying and wetting diminishes this wetting pulse. Hence, for optimal conditions complete drying should be prevented, as this not only negatively affects the soil microbiota, but also the soil structure, such as soil hydrophobicity and shrinkage, resulting in preferential flow in the soil at irrigation.

The pre-planting base dressings of organic amendments and fertilisers are usually applied to and incorporated across the broad soil surface, or at least to the broad plant rows. Consequently, the broad soil must be wetted equally to support microbial processes and to stimulate rooting over a large zone. It should be noted that in case of drip irrigation, only a limited section of the soil is moistened and therefore is not recommended as the sole irrigation system in an organic crop.

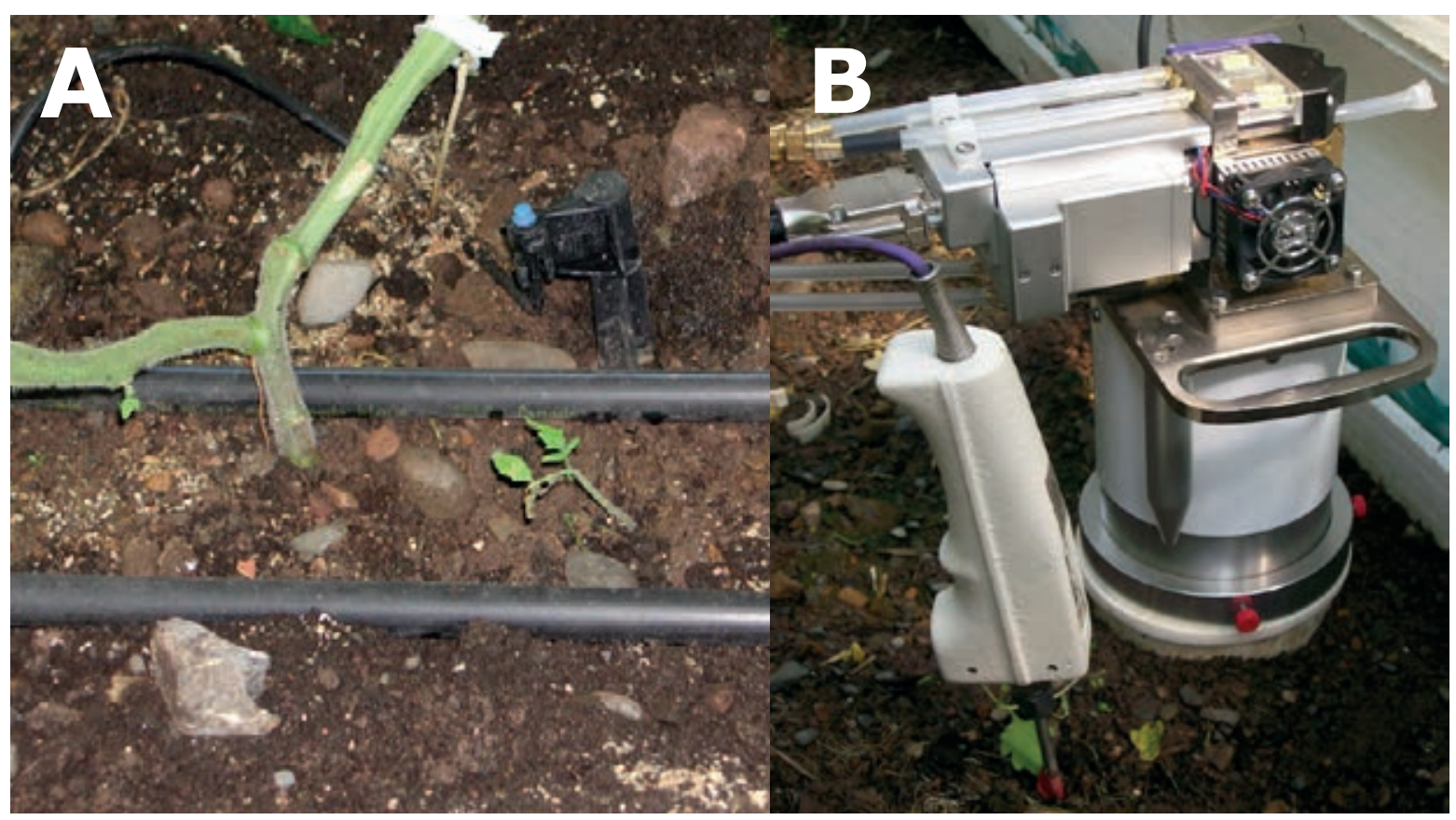

Figure 9 A) Water supply should consider soil bacterial and fungal activities to ensure optimal mineralization rates and plant resilience to abiotic and biotic stresses; $B$ ) Soil $\mathrm{CO}_{2}$ flux measured with a portable gas exchange system (LI-6400 from Li-Cor, equipped with a soil respiration chamber) is a good indicator of soil biological activity (photos: Steeve Pepin and Martine Dorais). 


\section{Salinity}

\section{In short}

- Poor water quality is a major cause of soil salinity for greenhouse crops, although organic fertilizers may also contribute significantly to soil salinization due to unbalanced nutrients.

- Crops can be affected by salinity via an osmotic effect (high salt content) and/or an ionic effect (ion toxicity, unbalanced ion content at the cell level).

- Salinity effects on crops vary depending on species, cultivars, rootstock, type of soil, type of growing system, environmental conditions (radiation, temperature, humidity, $\mathrm{CO}_{2}$ concentration), irrigation and fertilization management.

- Salt accumulation negatively affects soil structure by sodicity as the well as mineralization rate.

- Salinity can increase product quality attributes, although lower yield is often observed.

Soil salinity for organic greenhouse crops is strongly connected with water quality as well as irrigation and fertilization management. Salinity in greenhouse crops is a fairly high risk, since a surplus of natural precipitation as found in open fields in wintertime is absent. Improper water quality is the major cause of salinity in conventional greenhouses (Sonneveld 2000), while for organic crops, the type of fertilizers used also play an important role.

\subsection{Salinity and crop development}

The problems of soil salinity can partly be prevented by using water sources of good quality (section 3.1). These standards, developed for conventional horticulture, are also relevant for organic greenhouse horticulture. In addition to water quality, approved organic fertilizers are additional factors. In fact, an unbalanced nutrient supply from manures, composts, and other soil amendments including mineral fertilizers $\left(\mathrm{K}_{2} \mathrm{SO}_{4}\right)$, can be a significant source of undesired salts (Voogt et al. 2012). In cases where the water is of moderate quality, the additional input of salts by fertilizers may cause an overly high salt load in total, which necessitates leaching at the end of the growing period. Although salinity can have a positive impact on organic fruit and vegetable gustatory attributes and their nutritive value (Dorais and Alsanius 2015, Orsini et al. 2015), the negative effects of salinity on yield and product quality for greenhouse crops was reviewed by Sonneveld (2000) and Dorais et al. (2001).

In contrast to field crops, the greater impact of salinity on greenhouse crops is due to their higher nutrient concentration in the growing medium. High levels of nutrients are intentionally kept in the soil or substrate solution to control the growth of plants under low light conditions and/or to improve the quality of the product (Sonneveld and Voogt 2009). This is particularly important for organic fruit crops during their early stage, when fruit load is relatively low. Consequently, when the water quality is high (low EC), nutrients contribute almost exclusively to the osmotic potential of the solution in the root environment to create a balance with the crop. On the other hand, moderate water quality can also be used to increase soil salinity, although salinity problems will occur later on depending on the climatic conditions, soil characteristics, and water and fertilization management.

To evaluate the of salinity effects on crops one has to distinguish between osmotic and specific effects. Osmotic effects are determined by the osmotic potential of the solution. When the osmotic potential of the nutrient solution is increased in the root environment, plants react by generating higher osmotic potentials inside their cells, to keep the osmotic difference the same (Sonneveld and Voogt 2009). These adaptations of the plant are likely to be responsible for growth reduction. It is important to realize that osmotic stress and growth reduction can have a positive effect by controlling crop development as well as enhancing product quality. On the other hand, specific effects are related to toxicity. For example, increasing concentrations of $\mathrm{Na}$ or $\mathrm{Cl}$ can result in the higher uptake of these ions which may cause toxicity effects due to unbalanced concentrations at the cell level. It may also result in specific antagonistic effects such as the reduction in Ca transport and translocation into young developing plant tissue. 
In general, the impact of salinity depends on many factors, among them the crop, the cultivar, the rootstock and crop-cultivation conditions. These include temperature, humidity, $\mathrm{CO}_{2}$ concentration, and irrigation and fertilization strategies. Basically, the osmotic potential is built up by nutrients and ions such as $\mathrm{Na}$ and $\mathrm{Cl}$. Thus, the osmotic potential in the soil and substrate solution is determined by nutrients as well as residual salts. A certain level of nutrients is required for plant nutrition. Higher levels can be considered as osmotic and can influence, along with the rest of the salts, the physiological processes in plants through osmotic adjustments, by which both growth and product quality are affected either negatively or positively.
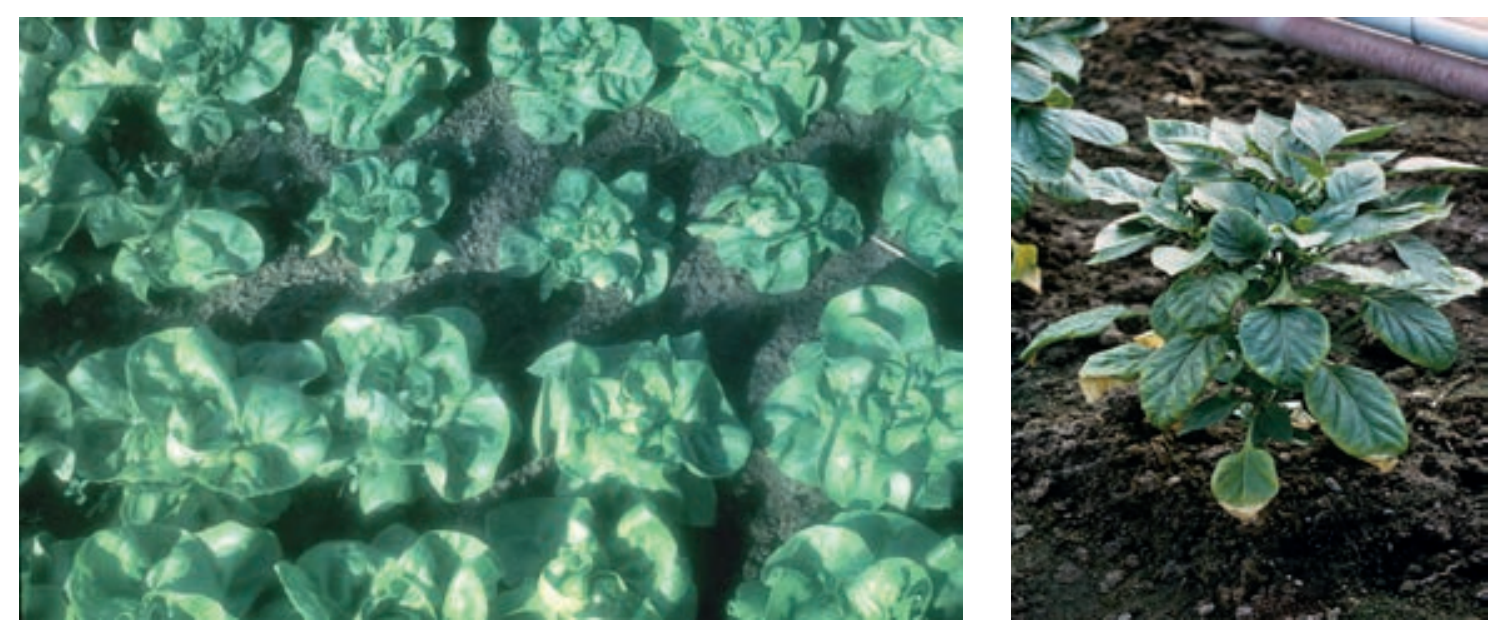

Figure 10 Heterogeneity due to salinity build-up in organic greenhouse lettuce $(A)$ and reduced growth and leaf damage due to salinity build-up in sweet pepper (B) (photos: Wim Voogt).

\subsection{Salinity and soil ecology}

Next to negative effects on plant growth and development, salt accumulation negatively affects soil structure by sodicity, which is the preferential replacement of $\mathrm{Ca}$ by $\mathrm{Na}$ at the adsorption complex (Bernstein 1975). The negative effects on soil ecology are particularly important for $\mathrm{OGH}$. While the effects of salinity and sodicity on soil chemical and physical properties and plant growth are well known and often reviewed, there have been relatively few studies done on the effects on soil ecology processes. A decrease in the mineralisation rate with increased $\mathrm{NaCl}$ levels was reported by Laura (1974) as well as other authors who reported losses of both enzymatic activity and $\mathrm{CO}_{2}$ respiration at increased salinity rates. Increasing salinity thus has detrimental effects on biologically processes in the soil, such as $\mathrm{C}$ and $\mathrm{N}$-mineralisation (Pathak and Rao 1998). The effects are likely to be due to osmotic stress of microorganisms, as well as with plant roots. Despite this, soil microorganisms have the ability to adapt to or tolerate osmotic stress caused by drought or salinity, especially when regularly confronted with such conditions (Wichern et al. 2006). However in organic greenhouses the complex system of soil fertility and root activity relies on a constant and highly active soil food web, so salinity should be avoided. 


\section{$7 \quad$ Irrigation technology}

\section{In short}

- Drip irrigation provides high plant water use efficiency and minimizes nutrient leaching, but can limit soil biological activity and the mineralization of top dressing amendments, and clogging may occur.

- Strip irrigation provides adequate water to the plant and stimulates soil microbiological activities within the plant row, but heterogeneity occurs with build-up of salinity in the paths, and clogging may occur.

- Sprinklers provide uniform soil moisture and microbiological activity ensuring high mineralization rates, but plants become wet which causes high humidity in the greenhouse.

- Sub-irrigation, which relies on capillary action, has high water use efficiency but salinity build-up and plant pathogen dispersion may occur, while the soil surface moisture level may limit the biological activity and the mineralization rate.

- Spatial heterogeneity of soil moisture constitutes an important challenge for organic greenhouse crops and is dependent on the design of the irrigation distribution system, clogging and plant growth.

The irrigation technology for greenhouse crops greatly influences their water use efficiency as well as crop productivity, plant uniformity and product quality. During the last few decades, several irrigation distribution methods for greenhouse crops have been developed such as drip irrigation, strip irrigation, sprinkler irrigation and sub-irrigation systems. The design of the irrigation system, however, should limit spatial heterogeneity of the water distribution and soil moisture content, which constitute an important challenge for organic growers.

\subsection{Water distribution}

In organic greenhouse horticulture systems, various irrigation systems are use to supply crops. The systems can be classified in the following groups.

\subsubsection{Drip irrigation}

These drip systems are characterized by local wet spots, while the surrounding surface is kept dry. It allows water to drip slowly to the roots of plants through emitters. The irrigation intensity is low, only $1-3 L h^{-1}$ per drip nozzle. There are various types and different technologies. The simplest systems are tubes with in-line drippers.

\section{Advantages}

- It prevents runoff and evaporation, causing less humidity to develop in the greenhouse climate.

- Fertilizer and nutrient losses can be minimized due to localized application and reduced leaching, providing this is managed correctly.

- Moisture within the root zone can be maintained at field capacity.

- Weed growth is reduced.

- Water distribution is highly uniform, providing maintenance and construction are done properly.

- Fertigation can easily be included with minimal waste of fertilizers.

- The plant and fruits remain dry, reducing the risk of disease. 


\section{Disadvantages}

- Clogging is a serious risk if the water is not properly filtered and the equipment is not properly maintained.

- Drip tubes cause extra labour after harvest and before planting.

- Local wet zones in the soil prevent the development of soil microbiota, and the mineralization of soil organic matter and soil amendments.

- Broadcast top dressings of fertilizers will dry out and will not mineralize.

- While drip irrigation systems typically result in lower water consumption because of a reduced leaching fraction, the soil or substrate may become inadequate for crop production if the irrigation water is highly saline or alkaline, due to salinity or infiltration problems. Without sufficient leaching, salts applied with the irrigation water may build up in the root zone, usually at the edge of the wetting pattern.

\subsubsection{Strip irrigation by mini sprinklers}

This type of system is characterized by the irrigation of narrow strips, water being usually supplied only along plant rows. The system is placed just at the soil surface keeping the crop dry during irrigation.

\section{Advantages}

- It prevents evaporation and causes lower humidity in the greenhouse.

- Moisture within the root zone can be maintained at field capacity.

- A larger portion of soil surface and root zone is wetted, stimulating the soil micro-organisms and promoting the mineralization of organic matter over the whole soil profile.

- Fertigation can be included.

- The plant and fruits remain dry, reducing the risk of disease.

\section{Disadvantages}

- Only the plant row is wetted causing drying out and salinity build-up in the paths. For crop rotation with full surface crops like leafy vegetables, extra leaching is required.

- The Heterogeneity is primarily due to the location of mini sprinklers close to the soil surface (i.e. a few $\mathrm{cm}$ above the ground); small differences in alignment affect supply.

- The nozzles are susceptible to clogging, causing heterogeneity in supply.

\subsubsection{Sprinkler systems}

These types have broad spraying patterns, hence the whole surface is irrigated. The spray lines are placed high in the greenhouse, above the crop canopy. The plants are wetted with each irrigation event.

\section{Advantages}

- The whole surface and root zone is wetted, stimulating the soil micro-organisms and promoting the mineralization of organic matter over the whole soil profile.

- Fertigation can be included, but proper programming during the irrigation event is necessary to avoid nutrient precipitation on the leaf canopy.

\section{Disadvantages}

- The plants become wet each time.

- The irrigation intensity is relatively high; short irrigation rounds are technically impossible and lead to high heterogeneities, hence leaching is a risk.

\subsubsection{Sub-irrigation systems}

These systems deliver water and nutrients at the base of containers and the dampening of substrates arises through capillarity (i.e. wicking phenomenon). They are closed systems that recirculate water from a central reservoir to benches (e.g. ebb-and-flow, trough) and flooded floor systems. The solution is drained back to the reservoir after irrigation. Collection trays and capillary mats are also efficient sub-irrigation systems. 


\section{Advantages}

- Uniform distribution of water through substrate within the containers.

- The plant canopy remains dry, which improves plant health.

- Fertigation can be included.

- Reduced risk for dispersal of root-borne pathogens.

- No leaching is anticipated as excessive water is collected which can be reused after decontamination.

\section{Disadvantages}

- The bottom of the gutter needs to be flat and have an even slope to distribute the irrigation water evenly and to avoid puddles.

- Specific attention needs to be given to the water-holding capacity and capillarity of the growing medium.

- There is a risk for accumulation of salts in the upper part of the root zone.

- Algae grow on the bottom of the gutter unless it is well covered.

- Gutters may be difficult to clean after the harvest/removal of the crop.

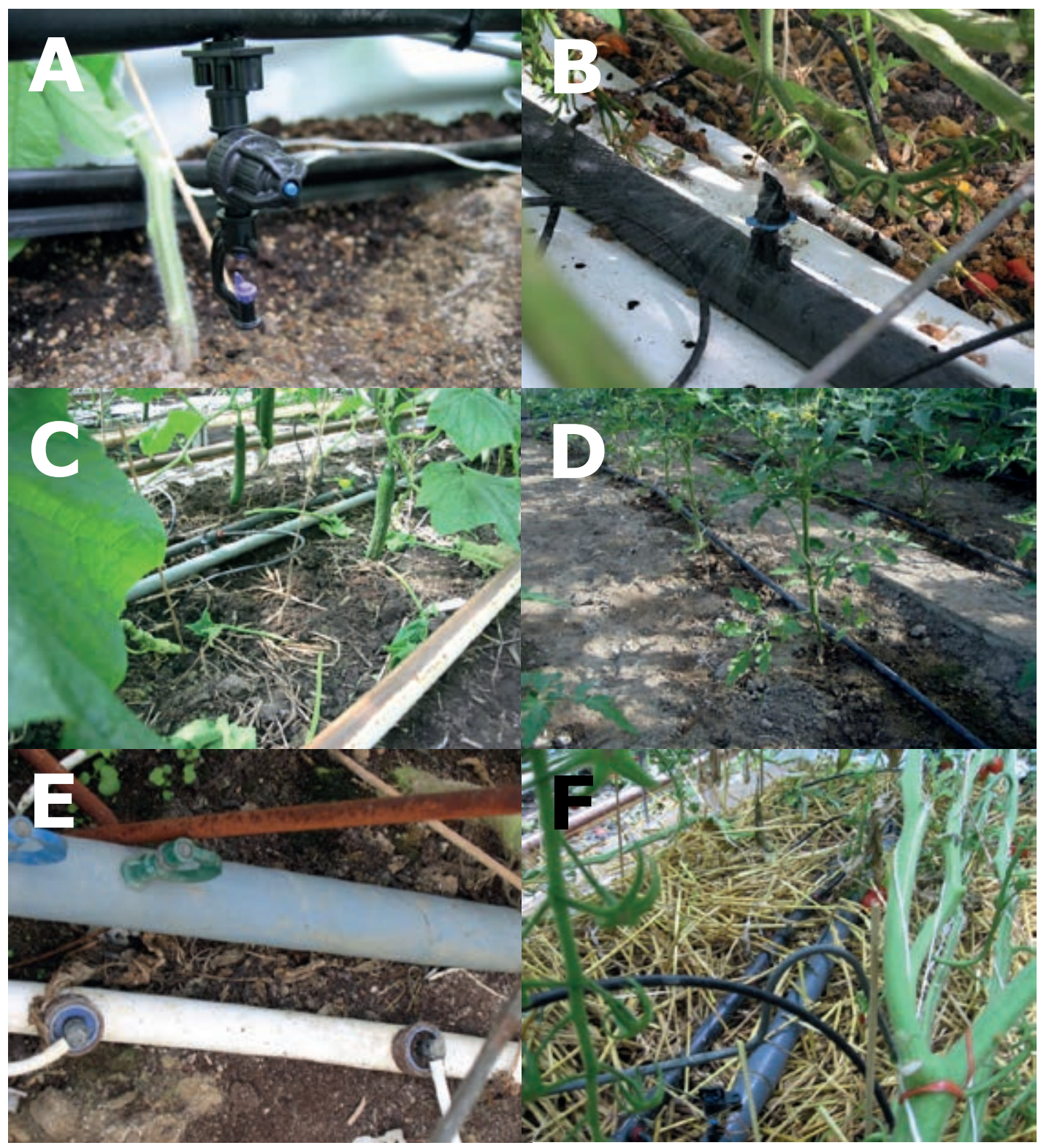

Figure 11 Distribution systems for irrigation water used in organic greenhouse horticulture. $A$ and B: Mini-sprinkler irrigation system for organic tomato crops; $C$ and D: Drip irrigation system for organic cucumber and tomato; $E$ and F: Combined mini-sprinkler and drip irrigation system for organic tomato crops. (photos: Wim Voogt and Martine Dorais). 


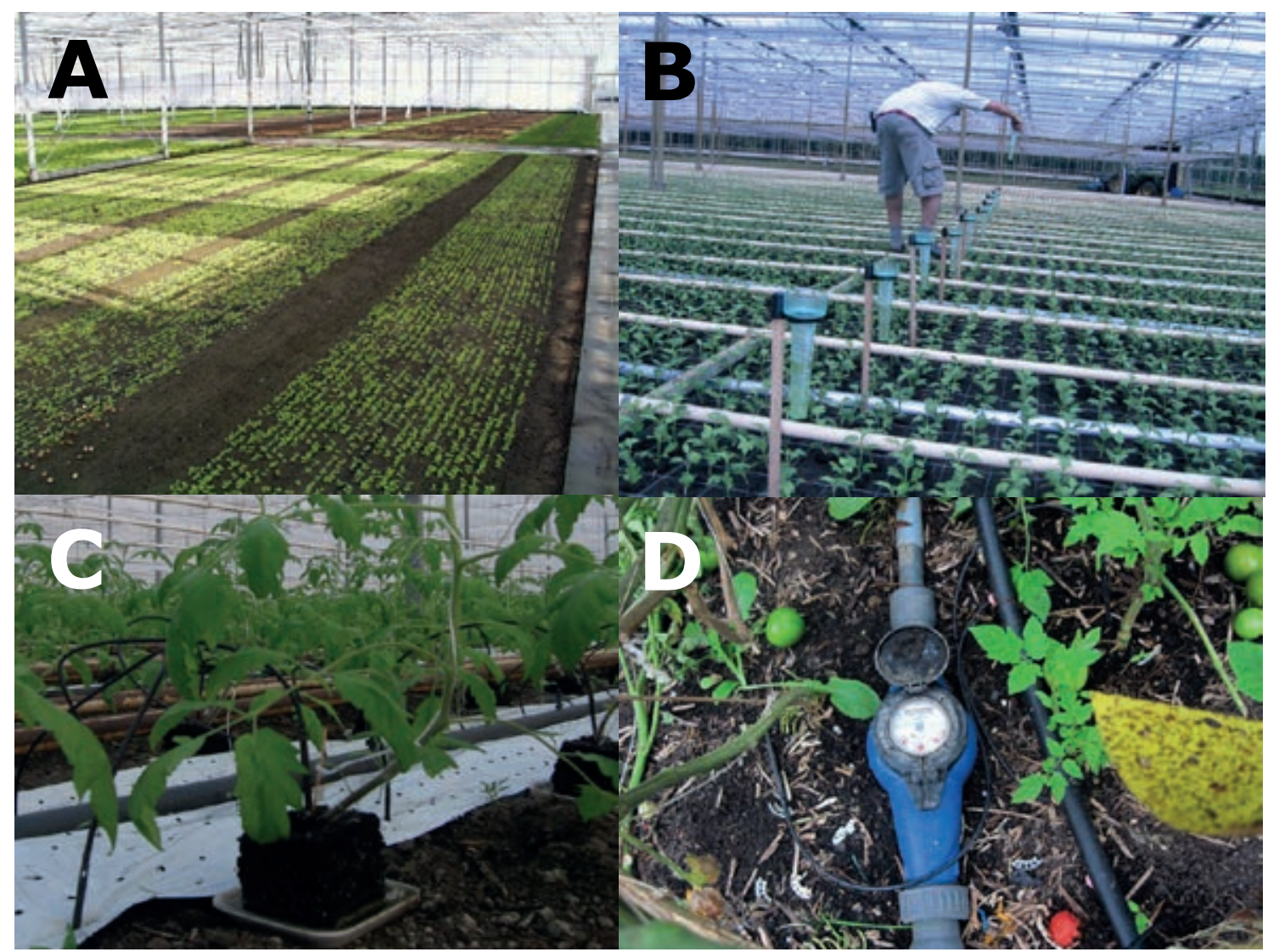

Figure 12 Delivery for irrigation water and water control systems. A: Broad sprinkler irrigation system; B: Control of water supplied; C: Drip irrigation of organic tomato seedlings; D: Water meter (photos: Wim Voogt).

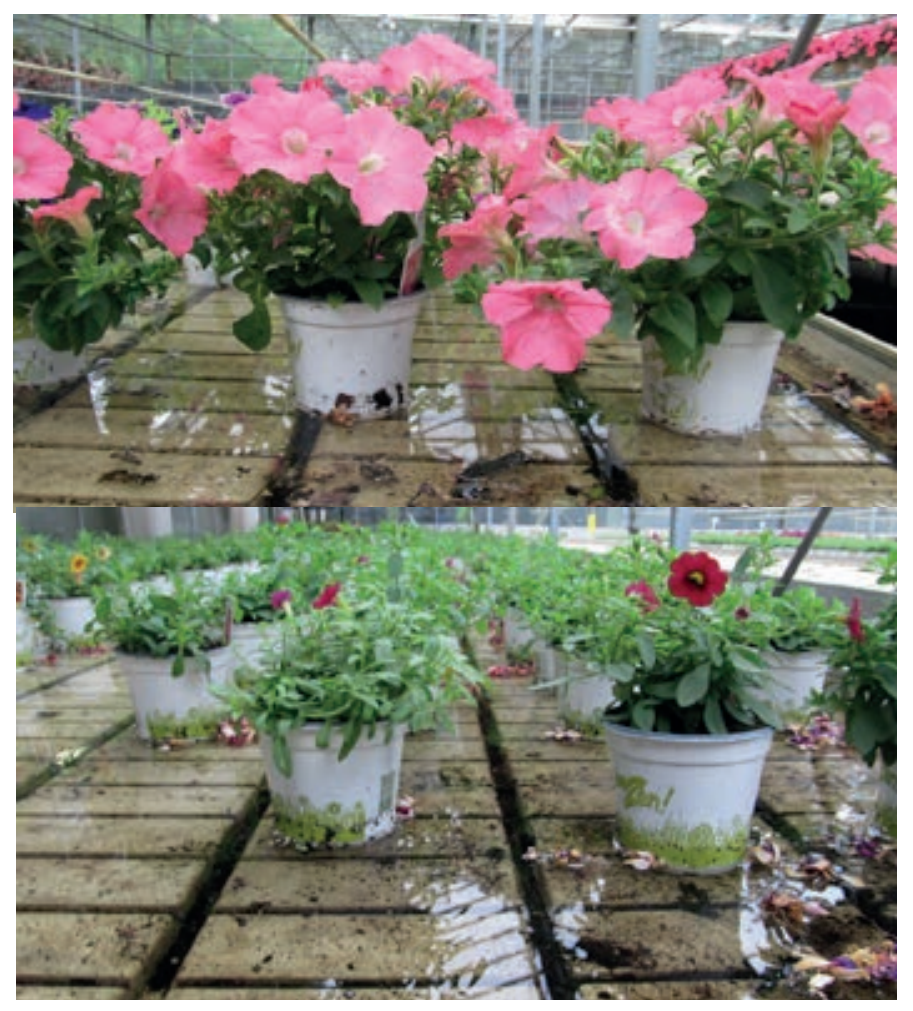

Figure 13 Subirrigation of potted plants by ebb-and-flow irrigation system (photos: Martine Dorais). 


\subsection{Spatial heterogeneity}

Spatial heterogeneity of water distribution and soil moisture content is a big challenge in irrigation management in greenhouses. The water uptake of individual plants varies strongly as does the water supply of irrigation systems (van Schie et al. 1092, van der Burg and Hamaker 1987). These last authors reported that the average variation coefficient of the water supply increased from 4.8 to $13.2 \%$, during the growing season of a tomato crop, while the variation coefficient of the water uptake was on average $10.2 \%$. This agrees with data from commercial greenhouses where the variation coefficient of drippers easily increases to values of $20 \%$ (van Schie et al. 1982). With sprinkler systems, the variation coefficient is often higher, Sonneveld (1995) having reported values greater than $20 \%$. Irrigation systems therefore require an ample water supply to equalize the effects of the plants on one hand and the irrigation system at the other. Model calculations with unequal water distribution by sprinkler irrigation system for chrysanthemum showed that with a variation coefficient of $27 \%$, one must apply $22 \%$ more water to supply all plant sufficiently (Assinck and Heinen 2001).

While part of this variation is inherent to the design and technical installation of the irrigation system, the unequal distribution of water is aggravated by clogging. This is often caused by precipitation of constituents from the primary water used, from fertilizers added, or from the growth of algae or microorganisms. The composition of precipitated materials was analysed from drippers of different greenhouse holdings in The Netherlands (de Bes 1986). In the precipitated material substantial quantities of ortho-P, $\mathrm{Ca}, \mathrm{Fe}, \mathrm{Al}, \mathrm{Si}, \mathrm{S}$ and organic material were found. These elements easily precipitate at higher $\mathrm{pH}(>6.5)$ values. The fertigation of suspended organic matter, as is common practice in organic farming, is a huge risk for clogging and is not recommended. Soluble organic matter will precipitate as a result of changes to the $\mathrm{pH}$ or by addition of cations from fertigation practices. Organic matter easily can easily occur in well water due to the development of bacteria. Some specific species are strongly stimulated by methane, which is sometimes found in well water (de Kreij et al. 2003). This has shown to be a high risk for bacterial slime causing severe blocking of drip irrigation emitters. 
48 I Impact of water quality and irrigation management on organic greenhouse horticulture 


\section{$8 \quad$ Water treatment}

\section{In short}

- Selection of the most suitable water treatments should consider the water source (raw water, prior use/ reuse, prior discharge) as well as its chemical and microbial properties.

- Physical, chemical and biological treatments can be used to reduce or eliminate plant pathogens and/or undesirable compounds such as ions, pesticides and other contaminants.

- Ion exchange and reversed osmosis are common water treatment methods to reduce the load of ions such as $\mathrm{Na}^{+}, \mathrm{Ca}^{2+}, \mathrm{Cl}^{-}$, and $\mathrm{SO}_{4}{ }^{3-}$.

- Photocatalytic treatment has shown high efficacy against human pathogens but improvement is needed to treat root-borne pathogens.

- Thermal and UV treatments are largely used to treat raw or drainage water before reuse, although UV equipment should be combined with a membrane filter system when drainage water is highly loaded with organic particles.

- Ozone and hydrogen peroxide are the most common chemical water treatments allowed in organic greenhouse horticulture when alternatives are not available or feasible.

- Biological treatments such as slow filters, bioreactors, and artificial wetlands constitute sustainable and highly efficient alternatives to eliminate plant pathogens and reduce, in some cases, undesirable compounds (ions, pesticides).

- Hydrogen peroxide, ethanol and isopropanol as well as sodium and calcium hypochlorite could be used for cleaning the distribution system or adjunct equipment, all having their own challenges and limitations to use.

In order to comply with the organic farming principles and the EU Water Framework Directive as well as other local water regulations, drainage water should be recycled within the growing system or used on farm for alternative crops (e.g. field production). Consequently, different approaches to treat the greenhouse effluent have been proposed such as physical, chemical and biological treatments. To preserve high water quality and avoid clogging or build-up of plant or human pathogens, the water distribution system also has to be appropriately cleaned.

\subsection{Water treatment}

Despite the substantial impact of water use in sustainable production systems, IFOAM (2013) gives no consideration to water treatment in organic greenhouse horticulture at all in its "position paper on organic greenhouse production". A little more guidance is given in the EGTOP report on organic greenhouse production (EGTOP 2013). However, water treatment is not explicitly mentioned. Measures can be read between the lines in their reflections on cleaning and disinfection; but the need for reconditioning from a chemical point of view is not included.

Water treatment in organic greenhouse horticulture fulfils different basic purposes with respect to the water source, the site within the greenhouse system and expected use. Furthermore, the chemical or microbial/ hygienic water properties may also be in focus. Thus the following purposes and properties need to be defined when speaking about water treatment and the choice of adequate actions:

- Water source and site within the organic greenhouse.

- Raw water treatment.

- Treatment prior to reuse.

- Treatment prior to discharge.

- Properties.

- Chemical properties (reconditioning).

- Microbial properties (removal of plant or human pathogens). 
Table 6 presents physical, chemical and biological methods that address the different purposes for treatment.

Greenhouse wastewater from organic crops may contain a heavy and unbalanced load of nutrients and residual salts resulting from the organic amendment, and can constitute a potential environmental risk. For example, effluent coming from an organic tomato crop grown in demarcated beds varied according to the fertilization management and time of sampling but could reach $400 \mu \mathrm{g} \mathrm{mL}^{-1} \mathrm{~N}, 111 \mu \mathrm{g} \mathrm{mL}^{-1} \mathrm{~K}, 26 \mu \mathrm{mL}^{-1} \mathrm{P}, 90 \mu \mathrm{g} \mathrm{m} \mathrm{L}^{-1} \mathrm{Ca}, 31$ $\mu \mathrm{g} \mathrm{mL}^{-1} \mathrm{Mg}, 743 \mu \mathrm{g} \mathrm{mL}^{-1} \mathrm{SO}_{4}, 4 \mu \mathrm{g} \mathrm{mL}^{-1} \mathrm{Cl}$ and $375 \mu \mathrm{g} \mathrm{m}^{-1} \mathrm{Na}$ (Bolduc et al. 2013). Crop effluent recycling can be challenging or unfeasible for soil-grown organic production systems, as is explained in section 2.1. Nevertheless tail-water ponds designed to capture runoff and tail-water return systems installed to recycle runoff back to the field seem to be successful management practices for nutrient cycling in an organic farm (Smukler et al. 2012) and although confined by the constraints mentioned in section 2.1, drainage water is commonly recycled in Dutch organic greenhouses (Voogt 2005).

Despite the importance of high water quality in organic greenhouse horticulture for the prevention of soil salinity and accumulation of elements in undesired concentrations in the soil/growing medium and root zone as well as in discharge water, reconditioning of water is unfortunately poorly treated in organic greenhouse legislation, guidelines and technical advice. Furtermore, information from the scientific literature is also limited.

Physical, chemical and biological actions can be taken to limit the dispersal of plant pathogens by the irrigation water. In this context, measures within the cropping system need to be distinguished. There are broadspectrum measures that also affect other organisms than the target pathogen and these include plant beneficial and neutral microbiota. Examples of broad-spectrum measures are thermal treatment and UV-irradiation. Selective measures address the target pathogen or group of target pathogens (e.g. slow filtration). Active disinfestation methods kill the target organism (e.g. thermal treatment, UV-irradiation, oxidation) whereas passive disinfestation methods remove it (e.g. filtration). Moreover, disinfestation methods may be performed as spot disinfestation or in situ. Spot disinfestation measures are executed at one specific site within the cropping system. The treated water is then recolonized by the microbiota of the environment it is released to. For most spot disinfestation methods, a water reservoir for the treated water is needed. In situ measures act within the cropping system and may limit the spread of plant disease between plants.

Raw water treatment to mitigate the spread of root pathogens needs to be considered if there is a high risk of significant pathogen prevalence, for example in rainwater collected from greenhouse roofs in greenhouse dense areas. It also needs to be considered if surface water supplemented with runoff water from field crops sharing the same pathogens as the greenhouse crop (e.g. potato, tomato) is used. Wise use of water in organic greenhouse horticulture includes the reuse of drainage water. Water treatment for limiting the dispersal of root pathogens is recommended under such management conditions. 


\section{Table 6}

Water treatment measures in organic greenhouse horticulture.

\begin{tabular}{|c|c|c|c|c|c|}
\hline Measure & $\begin{array}{l}\text { Raw water } \\
\text { treatment }\end{array}$ & $\begin{array}{l}\text { Treatment } \\
\text { prior to reuse }\end{array}$ & $\begin{array}{l}\text { Treatment } \\
\text { prior to } \\
\text { discharge }\end{array}$ & Reconditioning & $\begin{array}{c}\text { Pathogen } \\
\text { removal }\end{array}$ \\
\hline
\end{tabular}

Physical

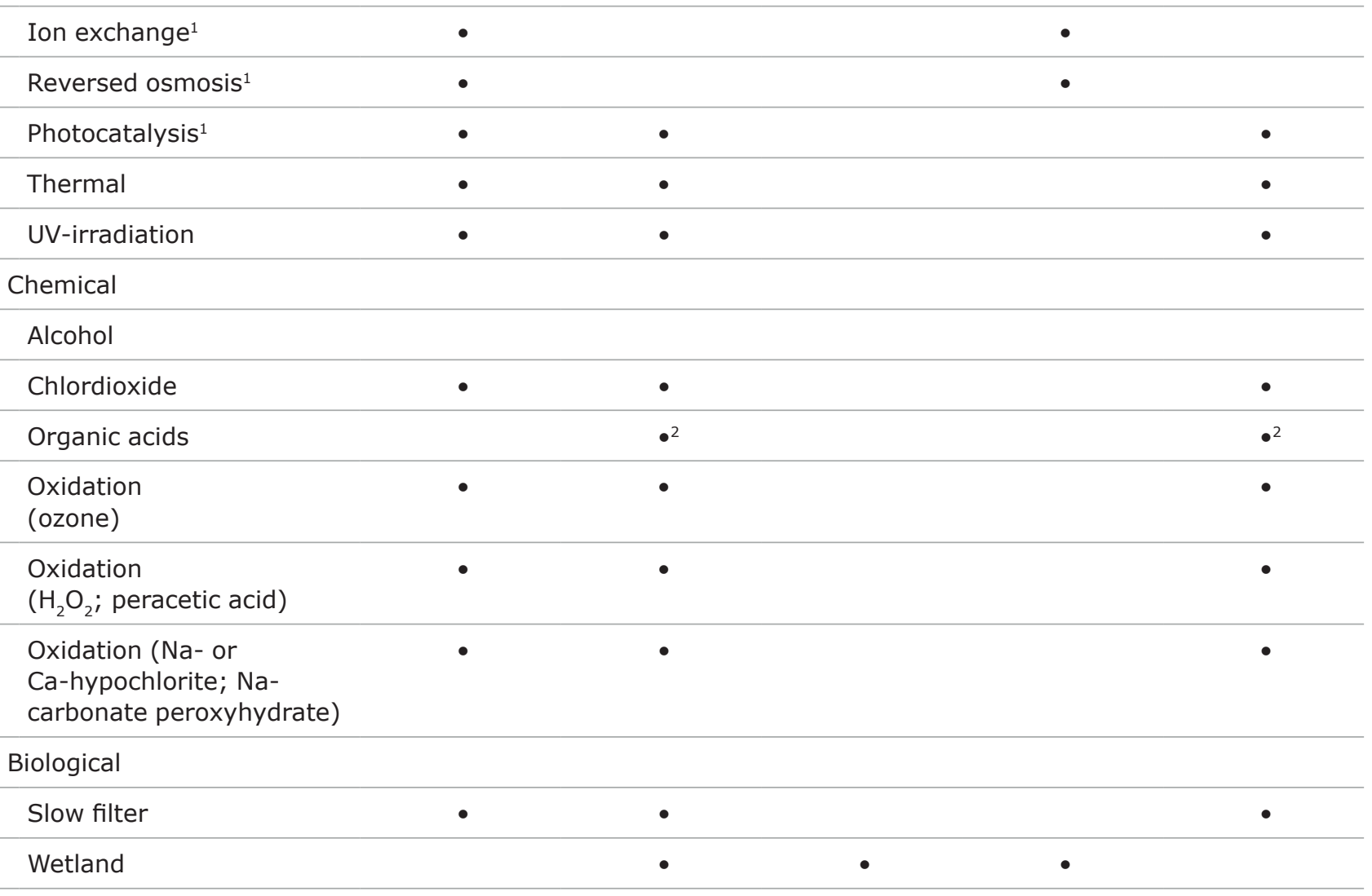

1These measures are not listed in legislation, guidelines or technical advice for organic greenhouse horticulture

2Benzoic acid

To exclude conflicts in terminology, some terms, often utilized in this chapter, are defined:

Active compound Biologically active substance

Antimicrobial Harmful to microbes through killing or growth inhibition

Bactericidal Killing bacteria

Bacteriostatic Preventing bacterial from propagation

Disinfection Killing or irreversible inactivation of a pathogen

Decontamination "Process, which removes or destroys contamination and thereby prevents microorganisms or other contaminants reaching a susceptible site in sufficient quantities to initiate infection or any other harmful response" (NHS 2015)

Efficacy Capacity of an intervention to produce the expected result under ideal circumstances (Gartlehner et al. 2006)

Effectiveness Determination of the degree of the beneficial effect in empirical conditions (Gartlehner et al. 2006)

Lethal dose (LD)

Dose at which a given percentage of the target population is killed

Microbicidal Destructive to microbes

Sanitizer Agent reducing "microbial numbers to a safe level" (Madigan et al. 2015)

Sterilization Process of killing, irreversible inactivation or removal of all living microbial organisms (both vegetative and survival structures) 


\subsubsection{Physical treatment}

Reconditioning of raw water and drainage water prior to reuse has not received any attention in the organic horticulture guidelines yet. However, there is a need to consider such measures at least for areas where access to enough rainwater is limited and high quality groundwater is scarce or affected by side infiltration of sea water (coastal areas). Ion exchange and reversed osmosis are common water treatment measures to reduce the load of ions such as $\mathrm{Na}^{+}, \mathrm{Ca}^{2+}, \mathrm{Cl}^{-}$, and $\mathrm{SO}_{4}{ }^{3-}$.

\subsubsection{Photocatalysis}

Photocatalysis (Figure 14) is a relatively recent introduction for pathogen removal in irrigation water in commercial horticulture. This technology is environmentally sound, as the end products of the process are $\mathrm{CO}_{2}$ and $\mathrm{H}_{2} \mathrm{O}$. The basic principal is based on a source of UV-irradiation that emits the rays towards a titanium dioxide membrane. During this process, radicals are formed, oxidizing all kinds of organic material in the water including microorganisms. For high efficacy, photocatalytic water treatment requires high water quality, which can be achieved by rapid filtration (pore size: $70 \mu \mathrm{m}$ ). The photocatalytic equipment does not require much space and is operated with a high flow rate, which offers the possibility for in-line solutions. This means that no water reservoir for treated water is needed. Photocatalytic treatment has shown high efficacy with respect to enteric bacteria pathogenic to humans under field conditions (Alsanius et al. 2011). However, exposure times during in-line treatment in greenhouses are too short to be effective against root pathogens in horticultural greenhouse crops according to an empirical study in closed hydroponics (Alsanius and Bergstrand 2007). To the best of our knowledge, photocatalytic water treatment has not been studied in organic settings.

\subsubsection{Thermal treatment}

Thermal treatment, as used in conventional closed growing systems, can be used to reduce the pathogen levels in raw water or drainage water before reuse. Commercial systems are available. According to the European Council Regulation (EC) No 834/2007 (art 12.1 (g)) (European Union 2007) thermal treatment would be the first choice for water treatment to prevent damage from pathogens spreading with irrigation water. It may be performed either by direct (flame heating) or indirect (heat exchanger) heating. The efficacy of the treatment is a function of temperature and exposure time (Alsanius and Brand 2000). High temperatures kill viruses as well as the vegetative cells of fungi and bacteria. To kill survival structures of fungi and bacteria, higher temperatures and exposure times are needed. Bacterial spores need to be subjected to $121^{\circ} \mathrm{C}$ and pressure ( 1 bar) in order to be killed (Alsanius and Brand 2000). Thermal treatment is commonly viewed as a broad-spectrum treatment as other organisms than the target organism/s may also be killed. However, by adapting the temperature to the lethal temperature of the target organism, a certain degree of selectivity may be achieved. As equipment for thermal water treatment is placed at a certain point within the production system's water circuit, thermal treatment is considered spot disinfestation. Readily available organic compounds after treatment allow a rapid recolonization of the heat-treated water once it leaves the heat treatment unit.

\subsubsection{UV treatment}

UV-radiation, largely used in conventional closed growing systems, is included in the EGTOP technical advice on organic greenhouse production (EGTOP 2013), but is not specifically named in EC regulation 834/2007. UVradiation comprises a wavelength spectrum of $100 \mathrm{~nm}$ to $400 \mathrm{~nm}$; three fractions are of biological importance, namely UVA (315-400 nm), UVB (280-315 nm) and UVC (100-280 nm). The highest lethal microbicidal effect occurs at a wavelength of $253.7 \mathrm{~nm}$ (Kramer and Assadian 2008) and is a consequence of DNA disruption and a heating effect. The microbicidal effect of UV treatment is a function of strength, exposure time, the microorganism's properties as well as water quality (transmission). As a rule of thumb, $100 \mathrm{~mJ} \mathrm{~cm}^{-2} \mathrm{are}$ sufficient for removal of fungi and bacteria, whereas $250 \mathrm{~mJ} \mathrm{~cm}^{-2}$ are needed to kill viruses. However, lethal dose requirements vary between different organisms (Alsanius and Brand 2000). Compared to non-pigmented structures, pigmented structures are less sensitive to UV-radiation. This means that exposure times and intensities need to be higher for pigmented structures to obtain the intended effect. One also needs to keep in mind that some organisms may be photoreactivated. Good transmission and thus high water quality are necessary as in the case of photocatalysis. To reduce relatively high levels of organic particles within the raw water or crop effluent the UV equipment (Figure 14) needs to be combined with a membrane filter system (70 $\mu \mathrm{m})$. UV lamps are subject to ageing and the required efficacy must be maintained. Furthermore, biofilm build-up on UV lamps must be routinely removed. 


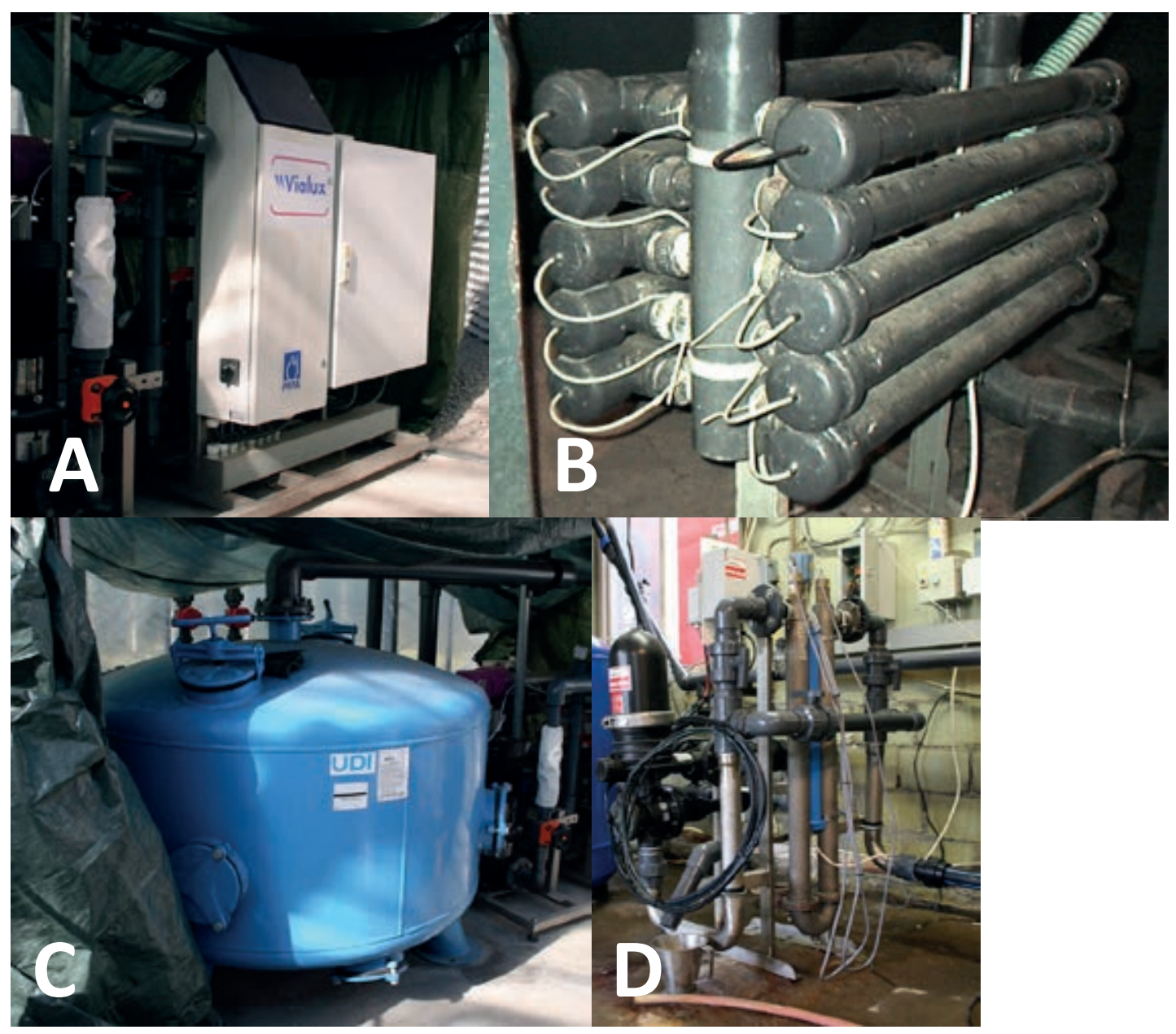

Figure 14 Examples for equipment to decontaminate irrigation water by physical means. A: UV-unit (Alfred Pedersen \& Søn, Dalköpinge, Sweden); B: UV-unit (Erik Hansen, Påarp, Sweden); C: Filtration unit preceeding UV treatment (Alfred Pedersen \& Søn, Dalköpinge, Sweden); D: Photocatalysis (Lillhems Handelsträdgård, Vallakra, Sweden) (photo: Beatrix Alsanius)

\subsubsection{Chemical treatment}

Chemical water treatment in organic greenhouse horticulture to mitigate transmission of pathogens is restricted to situations where no "biological, physical, or breeding alternatives or cultivation practices or other effective management practices are available" (EC No 834/2007, Art. 16; European Union 2007). They must be authorized for use in organic production by the European Commission. The list of candidate compounds given by EGTOP contains:

- Basic candidate compounds named as alcohol (ethanol), organic acids (acetic acid, citric acid), peroxides $\left(\mathrm{H}_{2} \mathrm{O}_{2}\right.$, peracetic acid), and ozone.

- Candidate compounds for restricted authorization such as alcohol (isopropanol), organic acids (benzoic acid), peroxides (sodium carbonate peroxyhydrate, $\mathrm{Na}$ - and $\mathrm{Ca}$-hypochlorite), and chlordioxide.

Of these, the alcohols as well as acetic and citric acids are intended for cleansing and disinfection of tools and equipment rather than for water decontamination.

Oxidation treatments are non-selective towards organic matter and the microbiota inhabiting water sources. If the oxidation process is incomplete, readily available nutrients will support the recolonization of rapidly proliferating microorganisms and thereby affect the microbiological balance, comparable to processes described for physical treatment. 


\subsubsection{Ozone treatment}

Water treatment with ozone is an expensive measure, but has a broad microbicidal effect. Ozone is a highly toxic gas. The lethal dose for vegetative bacterial cells and spores was reported to be between 1 and 5 ppm $\mathrm{O}_{3}$. Multiple factors influence its microbicidal effect, i.e. concentration, exposure time, temperature and $\mathrm{pH}$. $\mathrm{High}$ levels of organic material in the water reduce the efficacy of the treatment.

\subsubsection{Hydrogen peroxide treatment}

Hydrogen peroxide $\left(\mathrm{H}_{2} \mathrm{O}_{2}\right)$ is a useful active compound in conventional greenhouse cropping systems, and is also listed for organic greenhouse horticulture. Its microbicidal effect depends on causing damage to important microbial enzyme systems. In contrast to strict anaerobic bacteria, aerobic bacteria may be able to detoxify $\mathrm{H}_{2} \mathrm{O}_{2}$ by the formation of catalase. Its efficacy depends on concentration and exposure time as for other chemical water treatment technologies. Temperature and $\mathrm{pH}$ are also decisive parameters. Relatively high concentrations of $\mathrm{H}_{2} \mathrm{O}_{2}$ are needed for disinfestation of drainage water prior to reuse.

\subsubsection{Sodium hypochlorite treatment}

Sodium hypochlorite has not been tested to a great extent in connection with irrigation water and greenhouse horticulture. Positive effects have been found in controlling bacterial blight in sweet pepper. However,

phytotoxicity symptoms may be observed on the grown crop in response to excessive concentrations of sodium hypochlorite.

\subsubsection{Chlorine dioxide}

The gas chlorine dioxide is used for oxidative water treatment and was recently introduced into applications in greenhouse horticulture. It is effective over a broad $\mathrm{pH}$-range ( $\mathrm{pH} \mathrm{4-10)} \mathrm{but} \mathrm{its} \mathrm{efficacy} \mathrm{decreases} \mathrm{substantially}$ in the presence of organic material. The compound is highly explosive (Kramer and Assidian 2015). It is unstable in high concentrations in aqueous solution, especially in the presence of light. Its shelf life is also limited at lower concentrations and specific storage conditions need to be provided. Therefore it needs to be generated on site (Figure 15), by mixing dry or liquid ingredients (Na-chlorite + strong acid or Na-chlorite, strong acid + hypochlorite) (Copes et al. 2014). Chlorine dioxide has proven to be efficient in the reduction of various fungal and bacterial plant pathogens. Careful specification of dosage, delivery system and nozzles is needed to ensure successful treatment. Substantial volatile losses through outgassing were found in the presence of deflector nozzles as compared to flat spray nozzles (Krauthausen, et al. 2011).

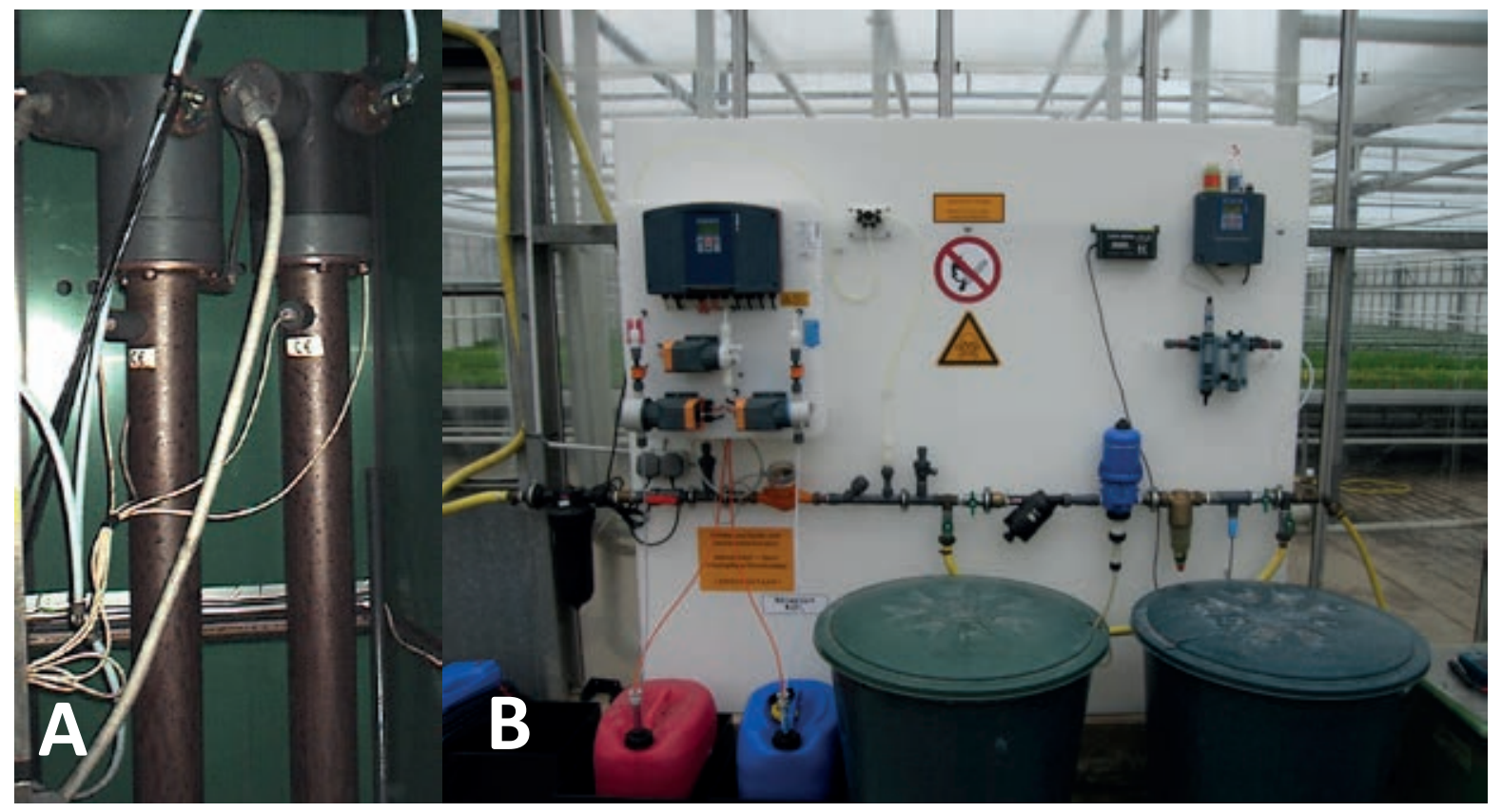

Figure 15 Example for equipment to decontaminate irrigation water by A: ozone (Erik Hansen, Påarp, Sweden) and chlorine dioxide (Hassinger, Germany) (photos: A: Thomas Brand, B: Walter Wohanka) ${ }^{1}$

1 Reprinted with permission of the copyright holders. 


\subsubsection{Benzoic acid treatment}

Benzoic acid is known for its antimicrobial effect in food production and has been tested in irrigation water in conventional greenhouse cropping systems using a commercial formulation containing $9 \%$ of benzoic acid. Apart from a potent antimicrobial effect, the commercial benzoic acid formulation had a stimulatory impact on fluorescent pseudomonads both under both laboratory and greenhouse conditions. This is a group of bacteria known for their disease antagonistic effects (Wohanka and Lindemann 2004).

\subsubsection{Biological treatment}

In contrast to most physical and chemical water disinfestation treatments, biological methods, such as slow filters, do not affect the total microbiota. The filter effluent is still microbially colonized, but certain microbial groups are affected. Two prominent methods are slow filtration and wetlands. Both have been used for a long time for the disinfection of potable water and were introduced to horticulture in the 1980s.

\subsubsection{Slow filters}

Slow filters, bioreactors and artificialy constructed wetlands achieve a similar levels of efficacy $(>99 \%)$ in terms of plant pathogen reduction (Fusarium spp., Pythium spp.) in greenhouse wastewater compared to active disinfection methods (Alsanius et al. 2011; Brand and Alsanius 2004; Déniel et al. 2004; Wohanka 1995). Slow filter efficacy is a function of filter material, its particle size, flow rate and filter surface area. A flow rate of 100$300 \mathrm{~L} \mathrm{~m}^{-2} \mathrm{~h}^{-1}$ has shown the highest efficacies for removal of plant pathogens. Organic material accumulates on top of the filter unit, creating a filter skin ("Schmutzdecke") as a function of production system and water quality of the filtered water. The filter skin plays a decisive role in the biological filter function and may not be disrupted by physical means. Water supply to the filter unit should therefore be sprinkled (Figure 16). Accumulating organic matter may increase resistance of the filter and cause clogging. A majority of the filter skin needs then to be removed mechanically. Backflushing or vacuum removal of the filter skin is not compatible with slow filtration if high levels of biological activity are to be maintained. Likewise, constructed wetlands removed $99.99 \%$ of plant pathogens such as Pythium spp. and Fusarium spp. (Gruyer et al. 2013) and keep beneficial microorganisms alive. However, these filtering techniques are not generally removing all kinds of pathogens. Despite the encouraging efficacy with respect to Oomycetes (Pythium spp., Phytophthora spp.) and some real fungi (e.g. Fusarium oxysporum) as well as the virus vector, Olpidium spp., efficacy with respect to viruses is inferior.

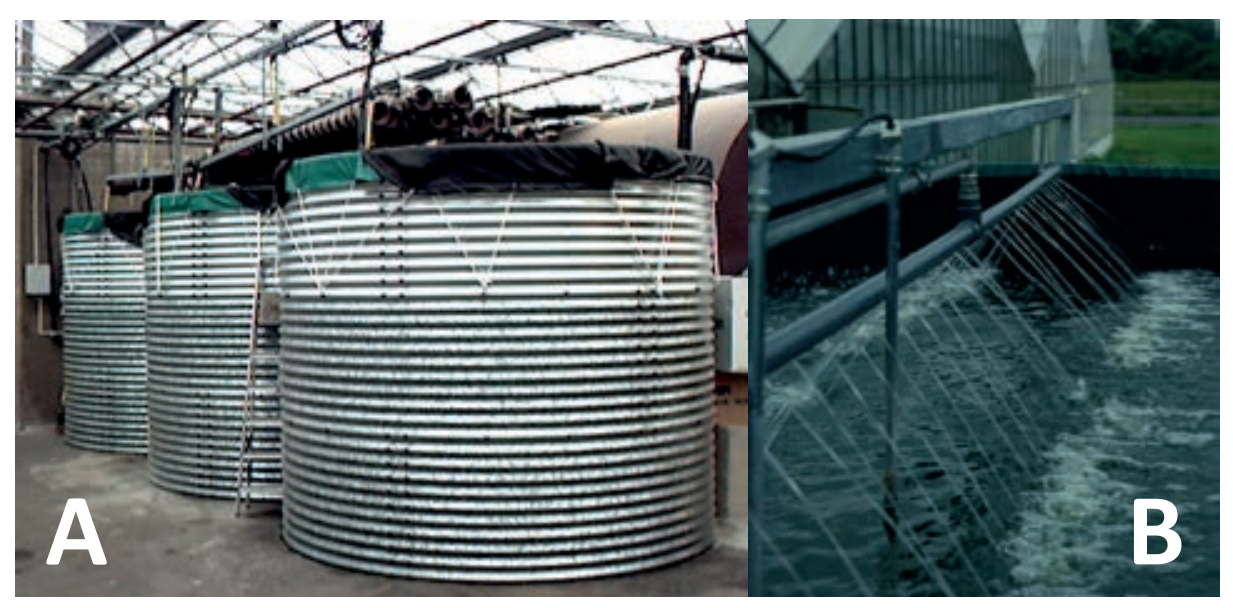

Figure 16 Examples for decontamination of irrigation water by filtering. A: Slow filter consisting of three units, (i) collection tank for drainage water, (ii) slow filter unit and (iii) tank for treated water (Österlen tomater, Glimmingehus, Sweden); B: sprinkler unit to the slow filter (Kienzler, Gensingen, Germany). (photos A: Beatrix Alsanius; B: Walter Wohanka)2.

2 Reprinted with permission of the copyright holders. 


\subsubsection{Artificial constructed wetlands}

Artificial constructed wetlands, also referred to reed beds, have also proved useful as interesting alternatives for the removal of undesirable elements prior to drainage water reuse and discharge. Specific ions such as $\mathrm{SO}_{4}{ }^{2-}$ can accumulate to high levels because of plant uptake preferences, resulting in an unbalanced nutrient solution. In contrast to physical methods, such as ion exchange and reversed osmosis, artificial constructed wetlands are efficient and relatively inexpensive to build and operate (Grasselly et al. 2005). They offer a sustainable and practical way to remove problematic nutrients and pathogens when land use is not a barrier. Artificial wetlands contributed to the reduction of $\mathrm{N}$ and $\mathrm{P}$ pollutants by up to $100 \%$, and reduced $\mathrm{SO}_{4}$ by up to $98 \%$ when the dissolved organic carbon to $\mathrm{SO}_{4}$ ratio was 0.28-0.36 (Grasselly et al. 2005, Gruyer et al. 2011, Lévesque et al. 2011, Bolduc et al. 2013, Gruyer et al. 2013a,b,). However, the efficiency of nutrient removal from greenhouse effluent varies according to wetland types. Horizontal surface (HS) flow and horizontal subsurface (HSS) flow (Figure 17) were more efficient than vertical subsurface (VSS) flow (Figure 18, Figure 19) in reducing nitrate pollutants from greenhouse wastewater (Lévesque et al. 2014). Nevertheless, removal of $\mathrm{NH}_{4}-\mathrm{N}$ and $\mathrm{PO}_{4}-\mathrm{P}$ loadings was comparable in all wetlands tested. The $\mathrm{N}_{2} \mathrm{O}-\mathrm{N}$ emitted was 7 and 60 times higher in HS than in HSS and VSS constructed wetlands, respectively. HS also emitted 6 times more $\mathrm{CO}_{2}-\mathrm{C}$ than $\mathrm{HSS}$ and twice the amount released by VSS.

Because denitrification is accomplished by anaerobic heterotrophic bacteria (Pseudomonas spp. or Clostridium spp.), the process is strongly dependent on $\mathrm{C}$ availability. However, organic $\mathrm{C}$ present in greenhouse wastewaters is derived from damaged roots, microorganisms, and other organic debris (Prystay and Lo 2001, Park et al. 2008) but is generally insufficient to provide a significant source of C for optimal wetland activity. As denitrification is the most energetically favourable form of anaerobic respiration, sulphate reduction by the sulphate-reducing bacteria tends to occur when $\mathrm{NO}_{3}$ is not available (Whitmire and Hamilton 2005). Consequently, wetlands are limited in their capacity to denitrify and reduce $\mathrm{SO}_{4}$ simultaneously unless an adequate C source is provided (Gersberg et al. 1984, Stengel et al. 1987, Whitmire and Hamilton 2005, Kadlec and Wallace 2009). As greenhouse effluents are poor in soluble dissolved carbon, carbon enrichment by adding sucrose resulted in the removal of up to $99 \%$ of $\mathrm{NO}_{3}$ and $98 \%$ of $\mathrm{SO}_{4}$ by an $\mathrm{HSS}$ wetland filled with pozzolana as compared to $\sim 1 \%$ when no external carbon was added (Gruyer et al. 2013). Nevertheless, some macrophytes such as Phragmites australis and Eichhornia crassipes are sensitive to high $\mathrm{SO}_{4}$ and $\mathrm{NO}_{2}$ effluent content, respectively, while Typha latifolia is well adapted to highly $\mathrm{N}$ and $\mathrm{SO}_{4}$ charged wastewater (Lévesque et al. 2014). Adding biochar to the filter media of constructed wetlands reduced the $\mathrm{N}_{2} \mathrm{O}$ and $\mathrm{CO}_{2}$ greenhouse gas emissions (Bolduc et al. 2013). 


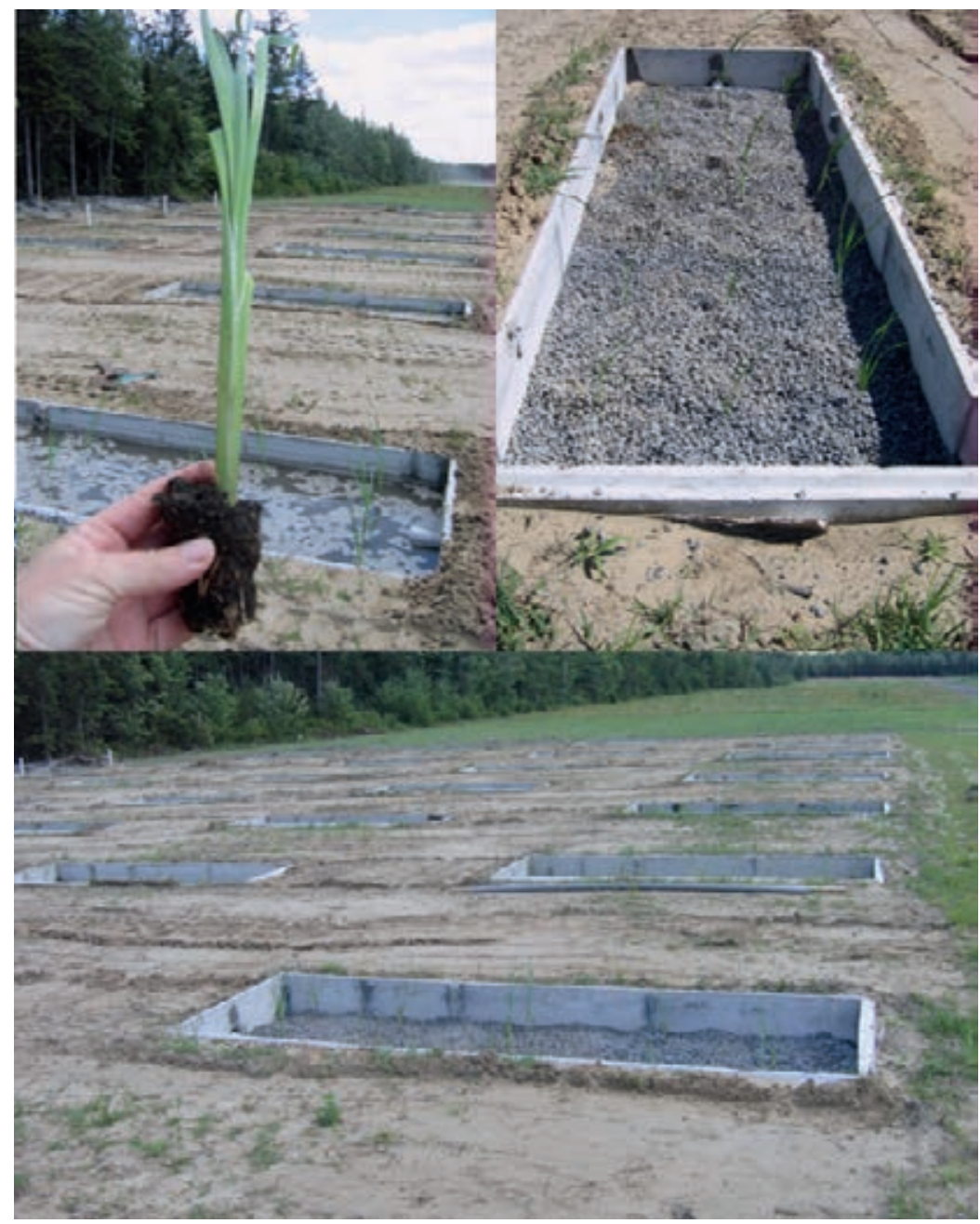

Figure 17 Horizontal subsurface flow artificial wetland units colonized with Typha latifolia to treat greenhouse effluent coming from tomato crops (photos: Martine Dorais). 


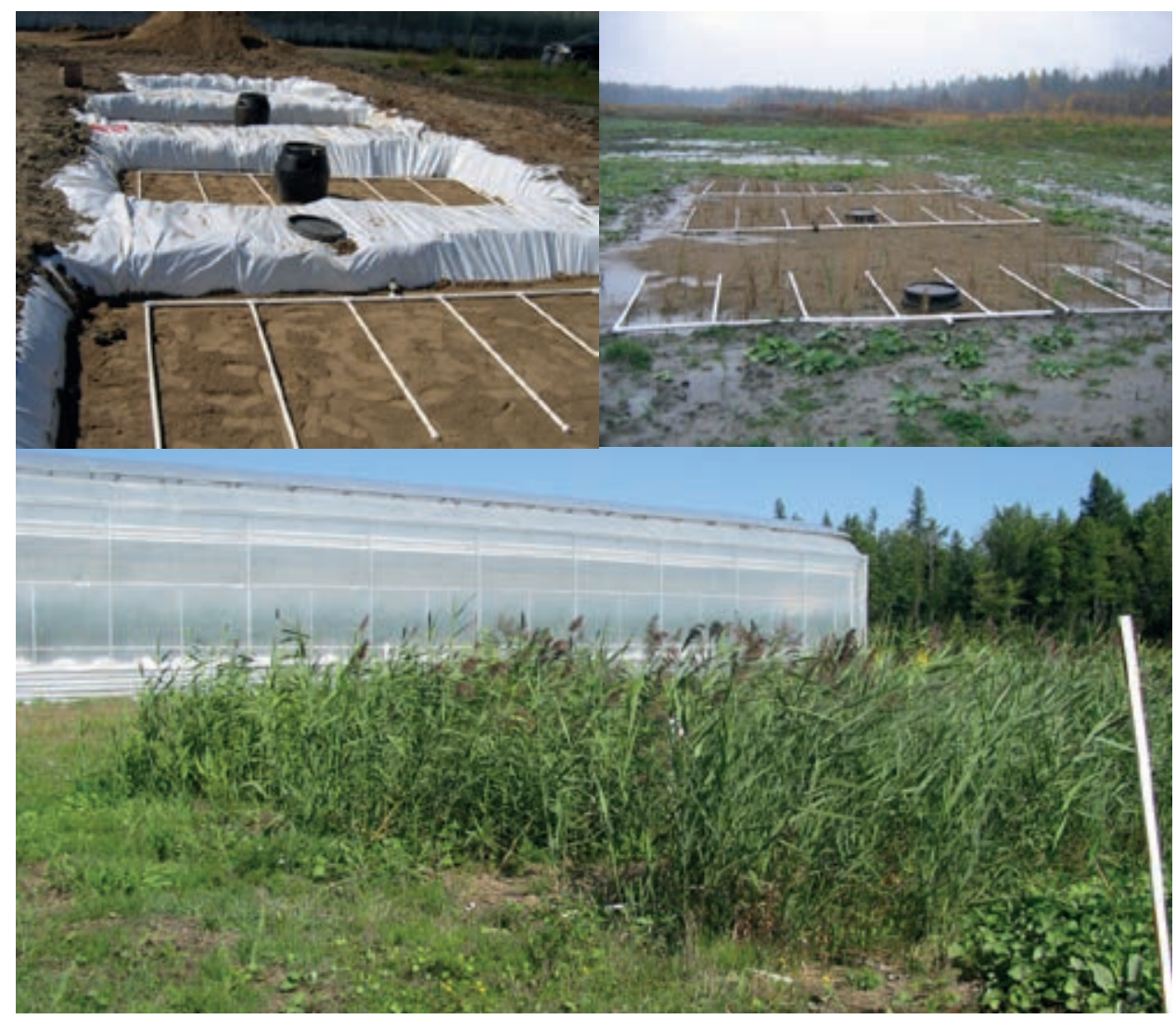

Figure 18 Vertical subsurface flow artificial wetland with three units colonized with Pragmites australis. Due to seasonal variations and frozen soil surfaces during winter, each wetland contained two delivering systems, one at the surface for the summer and the other one at $0.5 \mathrm{~m}$ from the soil surface for winter. An agricultural drain was installed in the bottom of each wetland for the transport of water to the pump located in the barrel from each compartment. Each compartment contained a barrel of $200 \mathrm{~L}$ where a pump was installed. As the barrel filled up, the wastewater was pumped to the following barrel and so on until it had reached the last barrel (treated water) (Lévesque et al. 2011). (photos: Martine Dorais).

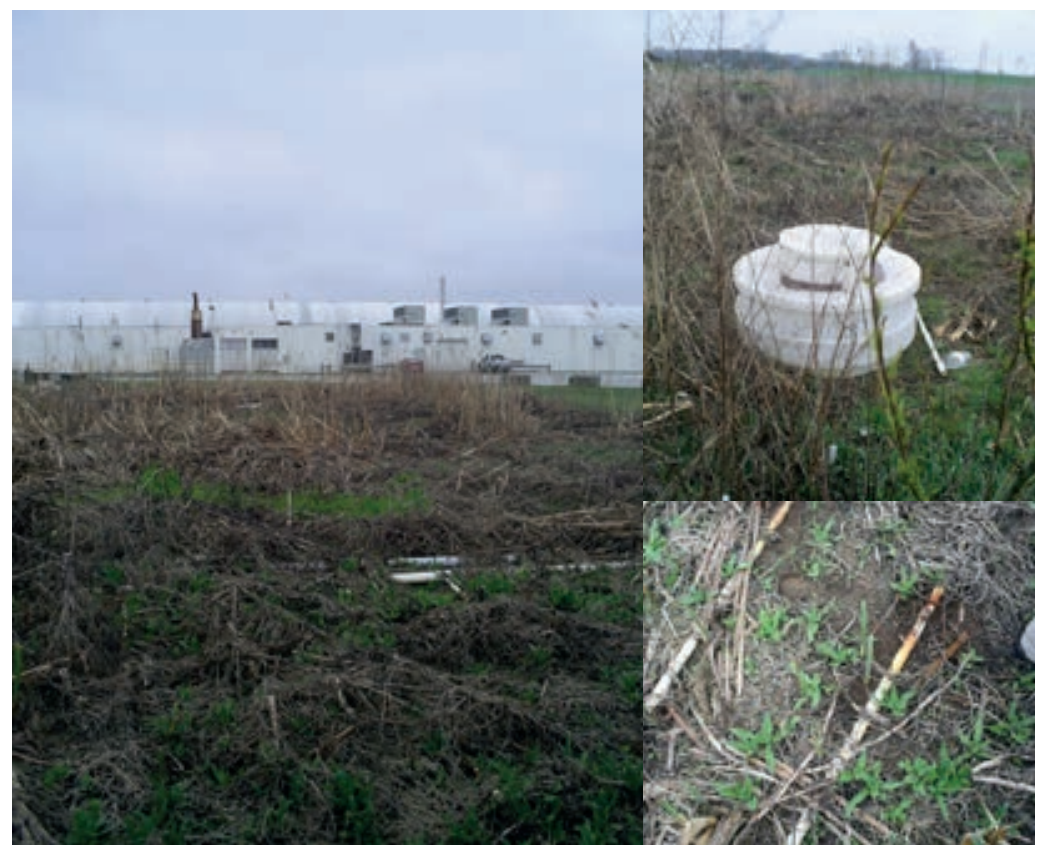

Figure 19 Vertical subsurface flow artificial wetland to treat greenhouse effluent coming from ornamental crops. (photos: Martine Dorais). 


\subsection{Cleaning of the water distribution system}

To maintain a suitable hygienic status of the irrigation water as well as an efficient passage through the water circuit, biofilm formation and clogging in the water distribution system and adjunct technology must be counteracted. Clogging of emitters has already been described in section 3.3. Biofilm formation is an unavoidable phenomenon and occurs in various parts of the irrigation water distribution system. The phenomenon does not compare to the one in distribution systems for potable water as irrigation water systems are used intermittently and not exposed to constant pressure, leading to standing water within the pipeline and consequent precipitation, biofilm formation as well as reflux within the pipeline. For the main water distribution pipelines, as well as for sprinkler irrigation systems, biofilm is not really a problem. However for the narrow capillaries in drip irrigation, the clogging-up not only decreases the flow, but most of all it boosts the heterogeneity of the water supply. As a natural process occurring in almost every water distribution system, biofilm can hardly be prevented, however the extent and negative effects can be alleviated through proper precautions (system design, filtration) and maintenance (flushing, periodically pressure increase). Furthermore, the supply of liquid organic fertilizers and water within the same distribution system provokes an additional challenge.

\subsubsection{Steam treatment}

Treating biofilm in water distribution systems is not easy. Steam treatment might be seen as the most environmentally friendly method for keeping the water distribution system free from biofilms. This is inapplicable, however, due to virtually $100 \%$ use of PVC material and the extensive water distribution systems in greenhouses. Experiences from sub-irrigation systems for organically grown herbs indicate that successful cleaning with steam needs to be assisted by mechanical cleaning.

\subsubsection{Chemical treatments}

From the previously presented list (section 6.2), we know that hydrogen peroxide, ethanol and isopropanol, along with sodium and calcium hypochlorite could be used for cleaning the distribution system or adjunct equipment. The use of ethanol and isopropanol does not appear as the first hand choice to clean irrigation water distribution systems because of the required concentrations, exposure times and volumes. In this context potential corrosion of greenhouse equipment and accelerated ageing must also be taken into account. Sodium and calcium hypochlorite were described in section 6.2. Due to the phytotoxic effects of high concentrations it is clear that cleaning should not take place where a crop is growing and that the procedure should be followed by thorough rinsing.

Hydrogen peroxide is used in conventional horticulture in drip irrigation systems during the growing season as a precaution against clogging, where they use $10 \mathrm{ppm} \mathrm{H}_{2} \mathrm{O}_{2}$, often with a peracetic acid as stabilizer, followed by a more extensive cleaning at a higher dose (up to $100 \mathrm{ppm}$ ) after the growing season.

\subsubsection{Treatment for bicarbonate clogging}

Water sources that contain bicarbonate $\left(\mathrm{HCO}_{3}\right)$ in overly high concentrations (section 3.1.1) must be treated with acids to prevent $\mathrm{Ca}$ precipitation and undesirable $\mathrm{pH}$ increases in the case of potted plants or plants in demarcated beds. According to EGTOP (2013), organic acids (citric, peracetic, formic, lactic, oxalic and acetic acid) are applicable. These acids could be used when decalcification of water distribution systems and adjunct equipment is required. However, it should be noted that organic compounds in general and organic acids in particular are readily available energy sources for microorganisms and thus contribute to clogging. This has been proven for formic and acetic acids (de Kreij et al. 2003). The relevance of formic and lactic acids also needs to be reassessed due to their disinfectant nature. Organic greenhouse horticulture should monitor on recent innovative technologies, such as hypersonic cavitation for efficient and successful cleaning of water distribution systems. 
60 Impact of water quality and irrigation management on organic greenhouse horticulture 


\section{$9 \quad$ Irrigation management}

\section{In short}

- Irrigation management is the controlled application of water to meet the needs of the soil and the crops, while conserving water resources.

- Irrigation management as defined by quantity, frequency and distribution is determined by growers based on water, soil, crop and growing system specificities, and environmental conditions.

- To support growers in their decisions for irrigation scheduling, several control tools have been developed.

- Salinity in the root environment in organic greenhouses can be controlled by leaching of salts, although this approach should not be favoured for environmental reasons.

- The fine-tuning of irrigation for organic greenhouse crops is complex due to soil and plant spatial heterogeneity, ion imbalances as well as the optimization of soil biological activity.

- Irrigation scheduling based on soil water balance determination has become the most commonly practised scheduling tool for soil-grown crops, although estimating ET can be challenging.

- Irrigation scheduling of demarcated beds is a hybrid between organic soil-bound cultivation systems and soilless conventional systems.

- A common practice in pot-based growing systems is to use an irrigation threshold (i.e. matric potential) between -5 and $-10 \mathrm{kPa}$ to maintain an adequate amount of water in substrates.

- Control tools such as ET models, soil moisture sensors and lysimeters are the general approaches used for irrigation scheduling of organic greenhouse crops.

The main purpose of the irrigation management is to compensate for evapotranspiration losses while taking into account the heterogeneity of both the water distribution and water demand within the greenhouse. A second purpose is to maintain a sufficient moisture level in the soil profile and root zone to enable soil microorganisms to thrive. Irrigation management takes into consideration quantity, frequency and distribution, and is determined by the grower. Decisions for the grower's strategy are usually based on a mixture of fixed applications, experience and assessments of soil and crop conditions. Although growers may have a fair idea about the crop water demand, irrigation based on experience and assessments may result in either over-irrigation or underirrigation. Irrigation can be controlled automatically in conventional greenhouse crops with soilless culture through drainage feedback (de Graaf 1988). Growers with soil grown crops, like most organic greenhouse growers, should rely however on tools which help them with operational irrigation management and irrigation scheduling. At present there are several supporting tools available to facilitate irrigation scheduling. The three main types of supportive tools are: (i) tools that determine either physically, mathematically or physiologically the crop water demand; (ii) tools that determine the soil water content; and (iii) methods that determine the water balance.

\subsection{Salinity management}

Salinity in greenhouse production not only affects yield but can also offer great possibilities for the control of produce quality and environmental consequences. Therefore, salinity in the greenhouse industry should not be considered as just a handicap associated with yield reduction and a need for leaching of salts with environmental pollution by nutrients (Sonneveld and Voogt 2009). Mild salinity may be a tool to control crop development and produce quality. Important factors for the management of salinity are the salinity threshold values, the required levels of nutrients and the ion distribution within the root environment. The effects of these factors are not only strongly different for different crops but they also depend on other growing factors. 
When optimising salinity for greenhouse production, the strategic and tactical decisions should be in line with the expected management. Important strategic factors in salinity management are the soil type (or choice of growing medium), the growing system and the irrigation system. These factors cannot normally be changed and adjusted during the growing season. Other factors have a more tactical character such as the primary water quality, the acceptable electrical conductivity levels, the nutrient level in relation to the residual salts and the decisions to re-use drainage water. There are opportunities for adjust these factors have during crop growth. In addition, the rate and the frequency of the water supply and fertilizer application are fully managed during crop cultivation.

In experiments, it has been found that growth is mainly determined by the lowest EC value especially for tomato, but also for cucumber with large spatial differences between EC values in the root environment. For organic greenhouse crops the questions arise with respect to interpretation especially with the use of trickle irrigation where large spatial differences occur (Voogt and van Winkel 2008). With this type of irrigation system the differences are most obvious in spots under and between the nozzles. The phenomenon of spatial variation is quite common in protected cultivation, and horizontal as well as vertical differences will be found in all types of irrigation systems. Under such conditions good alignment between the place and method of sampling, and the interpretation of analytical results is crucial.

As previously mentioned in section 3.1, salinity in greenhouse crops is a fairly high risk since a natural precipitation surplus is absent. Water quality is one of the important factors involved in salinity control. Other inputs in organic horticulture, such as manures, composts, other soil amendments, conditioners and mineral fertilizers may be responsible for high inputs of undesired salts unlike conventional cropping systems. Because of the given conditions and constraints of organic horticulture, salinity problems cannot be solved by water management on its own. Nevertheless, incorrect irrigation management may aggravate salinity problems (Sonneveld 2000).

If the water quality is not perfectly suited for greenhouse crops, or if the saline input is too high, it is important to adapt the irrigation scheduling appropriately. Salinity in the root environment in greenhouses can be controlled by leaching of salts. There are two ways: it can either be achieved by a distinct over-irrigation during crop growth to prevent salt accumulation or by flushing the soil after the growing period (Sonneveld and Voogt 2009).

The first method requires a certain degree of leaching and is suitable for soilless growing systems. The required leaching fraction can be defined as the ratio between the quantity of drainage water and the quantity of water supplied, and can be calculated using the following equation:

$$
\boldsymbol{E}=\frac{c_{w}+c_{f}-c_{u}}{c_{d}-c_{u}}
$$

Where LF = leaching fraction, $\mathrm{C}_{\mathrm{w}}=$ concentration of a certain ion in the irrigation water $\left(\mathrm{mmol} \mathrm{L}^{-1}\right) ; \mathrm{C}_{\mathrm{f}}=\mathrm{con}-$ centration increase of that ion from the fertilizer addition $\left(\mathrm{mmol} \mathrm{L}^{-1}\right), \mathrm{C}_{\mathrm{u}}=$ apparent uptake concentration of the crop grown ( $\mathrm{mmol} \mathrm{L}^{-1}$ ), and $\mathrm{c}_{\mathrm{d}}=$ accepted concentration of that ion in the drainage water ( $\left.\mathrm{mmol} \mathrm{L}^{-1}\right)$. This equation is applicable for specific ions as well as for calculations based on the total salt concentrations (EC). The apparent uptake concentration is represented by the sum of all ions, i.e. an "apparent EC uptake".

In this way the consequences of the mineral content of the irrigation water can be calculated and the results taken into consideration. Other factors have to be taken into account in such considerations such as salt sensitivity of crops, climatic conditions, salt accumulations in the root environment, leaching fractions, irrigation methods, temporal and spatial variations, yield reductions, quality aspects of the produce, and effects of environmental pollution. For soil-grown crops it is too complicated to define guidelines for required leaching fractions since the soil-buffer is very much larger and more variable than it is for soilless systems. 


\subsection{Irrigation scheduling}

The optimum moisture conditions for organic greenhouse crops depend on a wide range of parameters such as the hydrological situation, soil type, organic matter content, growing medium, and growing system design. The fine-tuning of irrigation for organic greenhouse crops is much more complex than in conventional culture. This greater complexity is mainly due to plant heterogeneity and ion imbalances in addition to the optimization of soil biological activity, which is an important factor of plant productivity. Because fruit vegetable plants are generally sensitive to high soil moisture and poor soil oxygen content, excessive irrigation on poorly draining organic soils or growing media can limit productivity by reducing or inhibiting root respiration, mineral uptake, and water movement into the roots. This results in reduced stomatal conductance and photosynthesis, and enhanced plant susceptibility to root diseases such as Pythium.

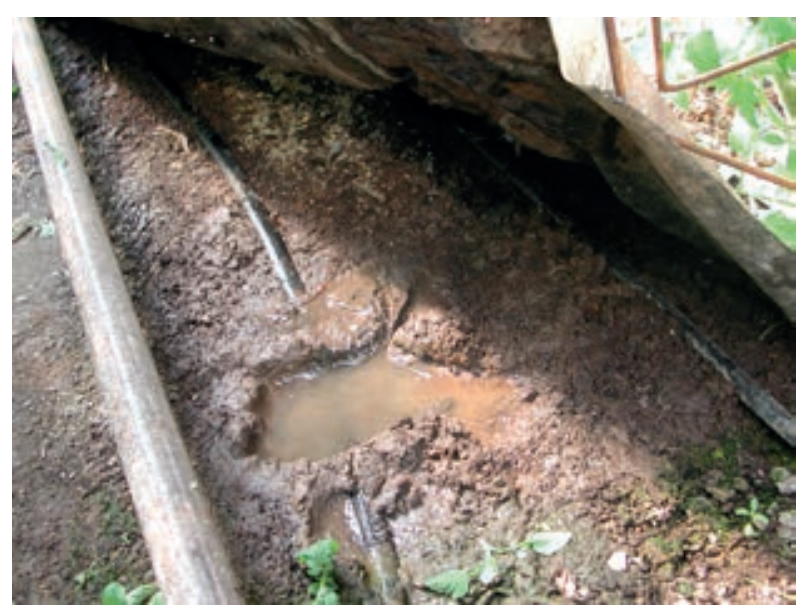

Figure 20 Excessive irrigation in an organic greenhouse tomato crop (photo: Steeve Pepin).

\subsubsection{Soil bound cultivation systems}

During the growing season the soil must be kept sufficiently wet. This is necessary to optimize water supply to the crop as a precondition for growth and yield, and to promote the activity of soil microorganisms, which also depend on the water status. Excessively dry conditions reduce decomposition and mineralisation of organic matter, whereas wet conditions stimulate denitrification and other reduction processes (Birch 1964, de Neve and Hofman 2002). Therefore the objectives of irrigation management can be clearly stated: 'Maximize net return, minimize irrigation costs, maximize yield, optimally distribute a limited water supply, and minimize groundwater pollution'. To reach these goals, it is necessary to schedule irrigation accordingly, or in other words, to decide 'which crop area should be irrigated, when and by how much'. Over-irrigation can have negative effects on root activity and the activity of soil microorganisms, and may reduce product yields and quality. It will also enhance the loss of nutrients by leaching, which in particular does not fit with organic horticulture (Voogt 2014). On the other hand, deficit irrigation may cause dry spots and areas, and induce salinity problems. The scheduling element of irrigation management therefore requires knowledge of the soil and soil-behaviour, and of the crop water demand. For example, based on soil activity, physiological parameters, yield, and fruit quality, matric potential thresholds of -40 to -100 mbar were proposed for organic greenhouse tomatoes grown in a sandy loam soil (Pepin et al. 2011). However, similar mineralization rates were observed for organic soils at -35 and -250 mbar matric potentials (Pepin et al. 2008). Maintaining a higher soil matric potential ( $<-30$ mbar) resulted in a lower soil mineral content. 
Various methods and tools have been developed to determine when the crop requires water and when irrigation needs to be applied. They include various soil and plant monitoring techniques along with a range of scheduling methods based on soil-water balances, and simulation models. Soil monitoring methods include gravimetric determinations, tensiometers, gypsum blocks, time-domain reflectometry sensors and neutron probes (devices which use electromagnetic and dielectric constant correlations) (Pardossi et al. 2009). Plant monitoring methods determine various stress characteristics such as trunk or branch diameter change, leaf water potential and sap flow. Canopy temperature measured through radiometers and infrared devices, including remote sensing, has also shown interesting applications (Cohen et al. 2005).

Although some of the soil and crop devices have been in use for a long time and their validity has been shown, their use has been restricted in most cases to industrial farms, or irrigation advisers and researchers. Irrigation scheduling based on soil water balance determination has become the most commonly practised scheduling tool. The main difficulty of this approach is estimating evapotranspiration ET. This method (also known as the water balance method) consists in estimating the change in soil moisture over a period as the difference between the irrigation and the losses [crop ET, drainage, and runoff]. The method involves three basic steps: 1) the available water (AW) in the root zone is estimated from soil texture and rooting depth; 2 ) the allowable water deficit (AWD) is selected depending on crop species, growth stage, soil water capacity, and the irrigation system's pumping capacity [AWD is the portion (ranging from $40 \%$ to $60 \%$ ) of AW that can be extracted without causing crop damage]; 3) the soil water balance is computed each day to assess water deficit; irrigation is needed whenever the AWD is exceeded (Pardossi and Incrocci 2008). 


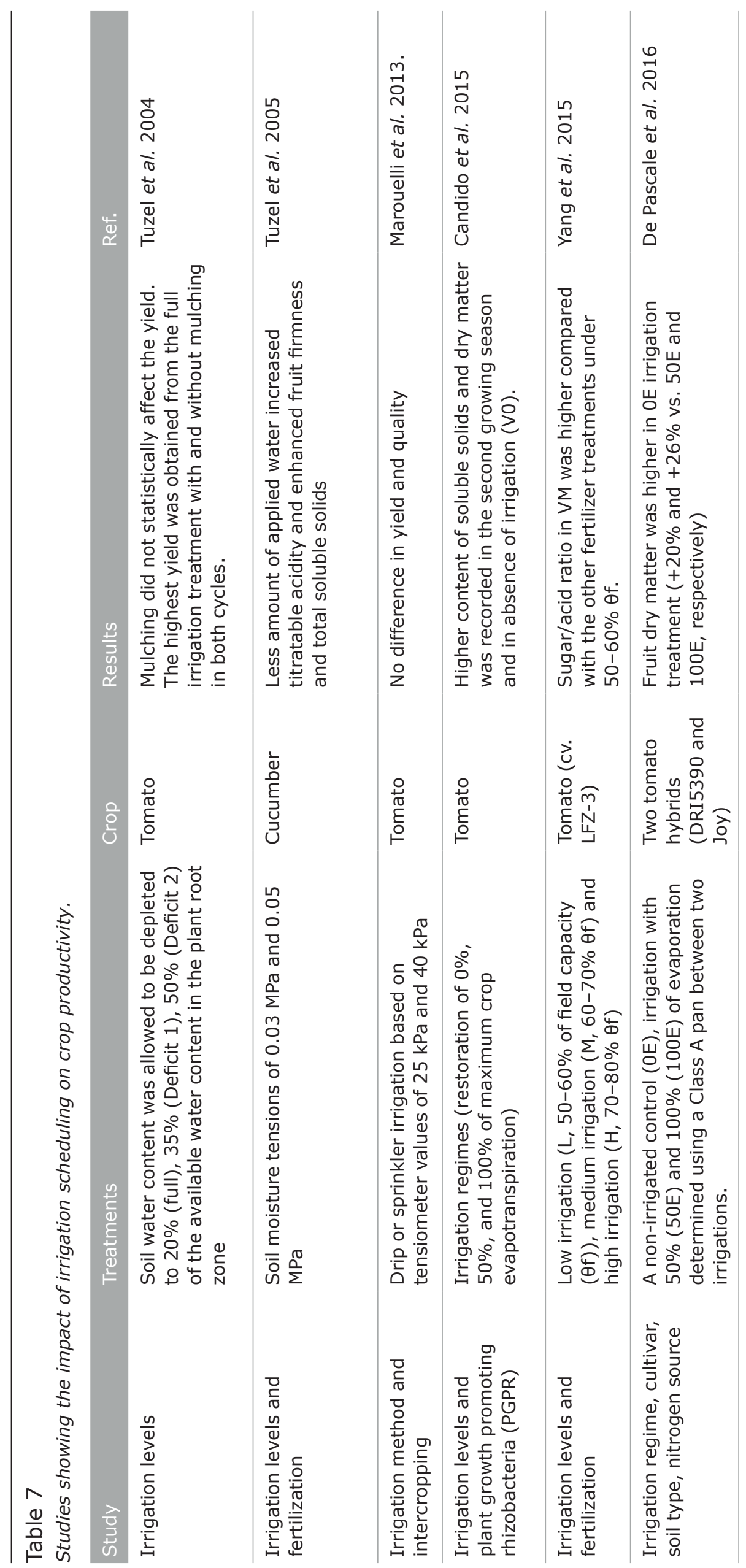

Impact of water quality and irrigation management on organic greenhouse horticulture | 65 


\section{2 .2}

Growing media used for the production of organic greenhouse vegetables in demarcated beds should be made from constituents certified for organic production. They are usually based on a mix of peat, coir, perlite and compost. They can also have a small proportion of clay and other natural mineral components. Sawdust and biochar can also be used for peat replacement. Because the physical properties of the substrates change over production cycles, an initial air-filled porosity of about $40 \%$ should be targeted to ensure good water drainage and soil drying during low solar radiation periods. Bed designs should also optimize air diffusion to achieve soil-drying cycles, which are required to keep plant balance, optimize soil mineralization rate, avoid root-borne diseases, and ensure product quality. Irrigation scheduling is a hybrid between organic soil based cultivation systems and conventional soilless systems. As in soil-based cultivation systems, irrigation management should limit water drainage and nutrient leaching. Minimal drainage might be required when soil salinity is observed under specific conditions (e.g. ion unbalance related to nutrient amendments, poor water quality, over fertilization). Drained water is usually collected and recycled to the crops (closed growing system) or treated before disposal to remove environmentally harmful nutrients. Drip tape and/or mist systems are usually used to ensure uniform soil moisture. Dry zones should be avoided to ensure soil microbial activity and mineralization of nutrients.

For a greenhouse tomato crop grown in small containers $(\sim 14 \mathrm{~L})$ filled with a peat-sawdust based growing medium, a matric potential ranging from -22 to -15 mbar relative to a container capacity of -6 mbar was beneficial for improving plant photosynthetic activity and yield (Lemay et al. 2012). For demarcated beds (60$100 \mathrm{~L}$ organic growing media per $\mathrm{m}^{2}$ ), however, a matric potential of around -30 to $-40 \mathrm{mbar}$ is recommended in order to limit leaching and to provide adequate water to the crops (Figure 21). This threshold, however, varies according to soil physical properties. Furthermore, soil microbial activity and yield were shown to be similar irrespective of the position of the irrigation system (surface bound or buried) (Gravel et al. 2011). Note that the use of demarcated beds in EU organic production is not allowed, except for the small number of holdings already in existence in Nordic countries.

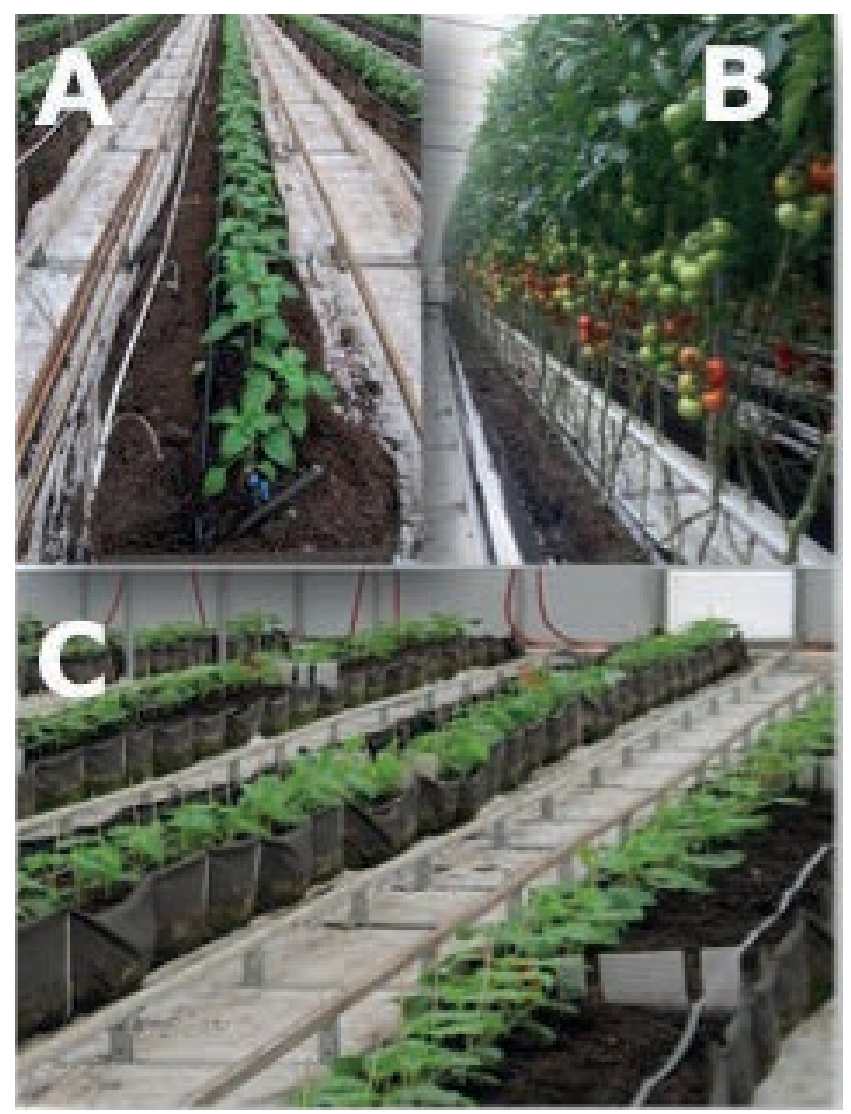

Figure 21. Examples of organic demarcated bed growing systems for vegetable crops. A: Organic sweet pepper at Les Serres Lefort, QC, Canada, B: Organic tomato, C: Organic cucumber at Les Serres Lefort, QC, Canada (photos: Martine Dorais). 


\subsubsection{Pot-based cultivation system}

Containerized systems for plant production in organic greenhouse horticulture are similar to demarcated beds in that they must be based on organically certified or approved substrate constituents, such as peat, coir, and compost. The growing medium of pot-based systems may also include perlite, wood fibres and biochar as substitutes for peat (Caron et al. 2005, Caron and Rochefort 2013, Steiner and Harttung 2014). Among the physical properties of importance for peat-based growing media are those related to air and to water storage and availability. Substrate particle sizes, water retention capacity, air-filled porosity and bulk density are key characteristics that determine how efficient growing media are in supplying water to plant roots. One should also take into account the substrate components, the geometry of the containers, the potting procedure, the irrigation systems (e.g. drip tape, boom sprinkler, capillary mat) and the crop management when designing and using substrates for OGH (Caron et al. 2014). An optimal value of $40 \%$ is recommended for air-filled porosity of young substrates. Indeed, growing media with air-filled porosity lower than $10-20 \%$ may result in hypoxic conditions after excessive irrigation and consequently, decrease plant growth (Heiskanen 1997). It is also important to note that deep containers have greater air-filled porosity than shallow ones.

A common practice in pot-based growing systems is to use an irrigation threshold (i.e. matric potential) between -5 and $-10 \mathrm{kPa}$ to maintain an adequate amount of water in substrates and meet plant requirements (Caron et al. 2014). The aeration properties of growing media are also important for optimal crop yield. It has been shown that coarse particles (e.g. bark, wood fragments, biochar) improve air storage in growing media but they can also hinder gas diffusion (Nkongolo and Caron 2006). Although an overabundance of fine peat particles increases the water-holding capacity of substrates, it usually results in lower air-filled porosity and a reduction of pores available for gas exchange. Water availability of growing media is also influenced by large particle sizes (>4 mm) because of insufficient unsaturated hydraulic conductivity (Raviv et al. 1999), particularly with subirrigation devices (e.g. capillary mat).

The hydraulic conductivity of a growing medium indicates how fast water can move in the substrate from one part of the container to the roots to match plant water uptake. Hence, in addition to storage properties such as available water and air-filled porosity, the following characteristics of growing media should be determined to verify if water supply within the substrate is adequate: gas diffusivity, respiration rate, and saturated and unsaturated hydraulic conductivity (Caron et al. 2014). Several in situ methods have been developed to characterize such dynamic parameters in substrates (Caron et al. 2008). Because the transfer properties of substrates differ considerably whether they are measured during drainage or rewetting, specific methods should take this phenomenon of hysteresis into account as it has significant consequences for water flow, aeration and wettability processes in growing media (Naasz et al. 2009).

Irrigation scheduling in pot-based growing systems is similar, to some extent, to that in demarcated beds. Clearly, a substrate that has high water retention at a matric potential of $-5 \mathrm{kPa}$ will require less frequent irrigation than a substrate with lower water retention. As with previously mentioned cultivation systems, soil water content sensors may be used to trigger sub-irrigation in pot-based growing systems. For instance, Ferrarezi et al. (2015b) monitored and controlled an ebb-and-flow sub-irrigation system for containerized hibiscus plants using capacitance moisture sensors. They investigated five soil moisture $(\theta)$ thresholds $(0.10$, $0.18,0.26,0.34$ and $0.42 \mathrm{~m}^{3} \mathrm{~m}^{-3}$ ) and reported significant reductions in the number of irrigation events ( $81 \%$ ) and nutrient solution use (70\%) in the lowest $\theta$ threshold treatment compared to the highest one. They also observed a significant decrease in shoot height (30\%) and dry weight (74\%) as well as compactness (63\%) in the $0.10 \mathrm{~m}^{3} \mathrm{~m}^{-3}$ threshold treatment compared with the $0.42 \mathrm{~m}^{3} \mathrm{~m}^{-3}$ threshold thus demonstrating that soil moisture devices are useful tools for controlling sub-irrigation and manipulating of plant growth characteristics (Ferrarezi et al. 2015b). As pointed out for demarcated beds, irrigation management should limit water drainage and nutrient leaching. However if salinity builds up in growing media during the production period due to an accumulation of fertilizers or salts, some drainage might be necessary. 


\subsection{Irrigation management control tools}

Historically growers have irrigated their crops based on experience and fairly fixed irrigation schedules. The growers' experience is still the most important factor in irrigation. Growers naturally base their irrigation management on all kinds of information from their crop, the soil and of course the season, actual weather conditions and weather forecasts. Soil moisture content is often estimated by assessing the colour or by assessing a handful of soil from the root zone (sometimes collected using an auger). However these methods are not sufficiently robust and modern times require more precise irrigation strategies. Three general approaches are used for irrigation management of crops: (a) models, to estimate crop water requirements based on crop evapotranspiration $\left(\mathrm{ET}_{\mathrm{c}}\right)$, (b) soil moisture sensors to assist in determining the timing and volumes of irrigation, and (c) lysimeters, by which actual leaching is determined.

\subsubsection{Models}

As discussed in Chapter 5, there are several models describing crop transpiration and soil evaporation processes, and water demand and crop uptake can be estimated using them. The on-going depletion of water from the root zone can therefore be monitored virtually using such models. Depending on the strategy and scheduling, the depleted amount can be compensated by irrigation. This can even be used for automatic control, especially with drip irrigation systems. Application of this method requires a computer with appropriate software that must be fed with data about the greenhouse climate and irradiation. This is available in modern greenhouses, but not applicable in low-tech situations. Moreover, if the irrigation technology is poor, there is no point in relying on sophisticated methods to calculate precise levels of water consumption. A modelling approach for irrigation management has been used in practice in the Netherlands in organic greenhouses (Voogt et al. 2012).

\subsubsection{Soil moisture sensors}

As the name suggests, these sensors are used to measure parameters in the soil that can be used to estimate the moisture conditions of the soil. There are two types of sensors that are generally used for greenhouse production: tensiometers and soil moisture sensors (Figure 22). 


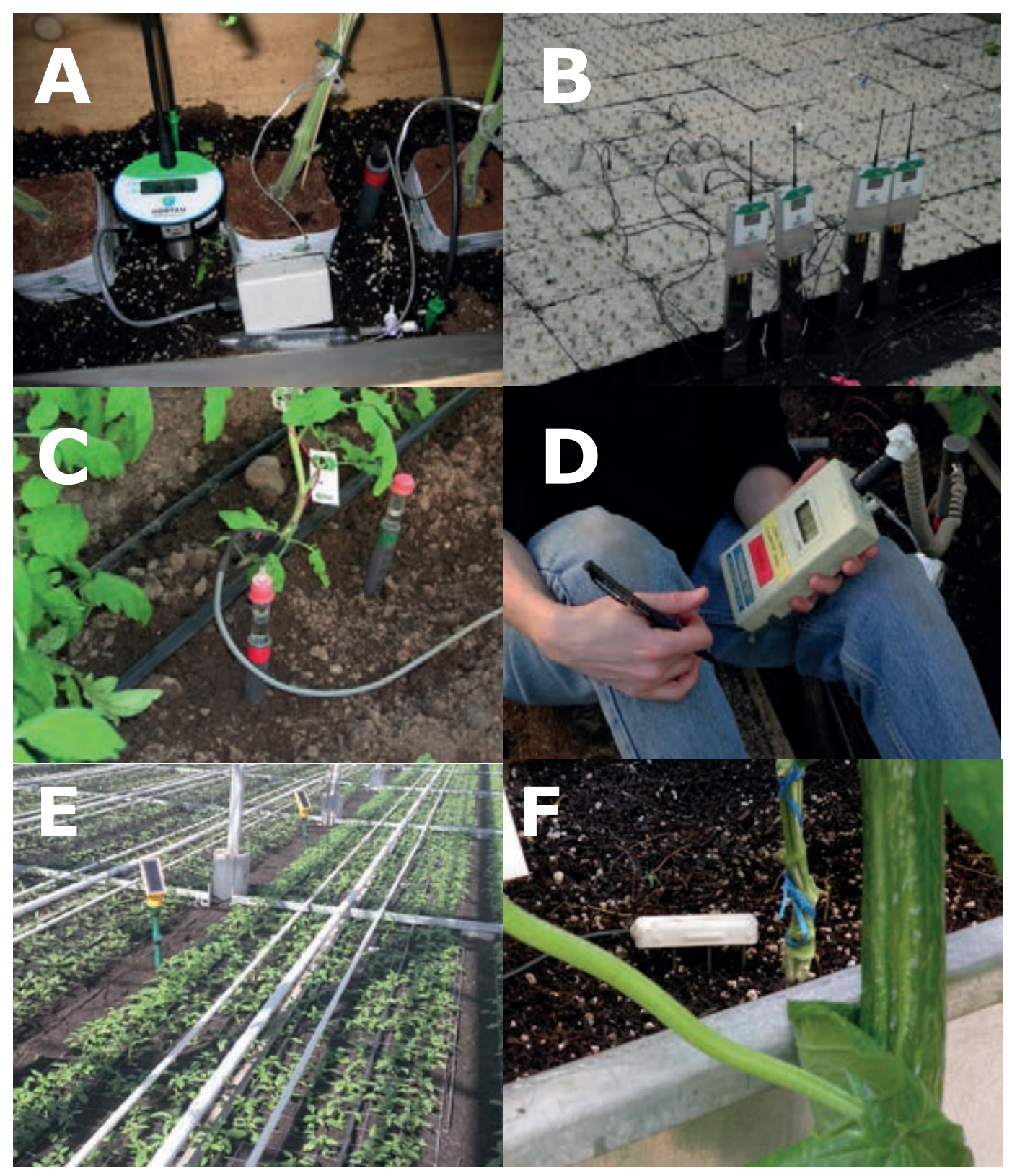

Figure 22 Soil moisture sensors and tensiometers for controlling the irrigation system. A and B: Wireless tensiometers; C and D: Home-made tensiometers installed at different depths in order monitor the soil water potential. E : Wireless soil moisture sensor (FD) with solar panel; $F$ : Soil moisture, temperature and electrical conductivity sensor (GS3, Decagon Devices, Pullman, WA, USA) in a demarcated bed of an organic cucumber crop (photos: Steeve Pepin and Wim Voogt).

\subsubsection{Tensiometers}

These sensors measure the matric water potential in the soil. They have a porous ceramic cup, which makes contact with the soil matrix. It is connected to a tube filled with water that is closed at the top. The water column in the tube will stay in equilibrium with the matric potential of the surrounding soil and can be measured by sensing the vacuum in the air above the water column. As water is removed from the soil by plants and evaporation, the vacuum inside the tube increases. As water is added to the soil, for instance during irrigation, the vacuum inside the tube pulls moisture from the soil and it decreases.

Depending on the specific properties of a soil, the tensiometer indirectly measures the water content of the soil (Pardossi et al. 2009). Traditionally, tensiometers are equipped with a manometer and readings must be done visually. Today, electronic versions of tensiometers are on the market that can determine the vacuum by an electronic pressure transducer and the signal can be transferred to a datalogger or computer either by a wired or wireless connection. 


\subsubsection{Soil moisture sensors}

These sensors measure indirectly the volumetric water content in soil, by using a parameter of the soil, such as electrical resistance dielectric constant, or interaction with neutrons, as a proxy for the moisture content. The relationship between the measured property and the volumetric soil moisture must be calibrated and may vary depending on environmental factors such as soil type, temperature and electric conductivity. These sensors are electronic and will be equipped with connections (wired or wireless) for dataloggers or direct readings by computers or even mobile devices like smartphones. The direct and on-line availability of the data is of great help in day-to-day water management (Pardossi et al. 2009).

\subsubsection{Lysimeters}

Lysimeters are scientific instruments that are mainly used to determine crop water balances and the nutrient concentrations of leachates (Richie 1968, Stanhill 1986). Lysimeters are essentially big tanks made of thick concrete or synthetic material that are filled with soil or substrate, with a collection device for leachate at the bottom. This concept was used recently to design a robust lysimeter system applicable to commercial greenhouse practice. The aim is to determine leaching quantitatively and to use these data as feed-back in the irrigation management (Voogt et al. 2011). These practical lysimeters are large tanks made of thick polyester with a $15 \mathrm{~cm}$ rim of stainless steel. The rim is reinforced with a profiled rod to enable tractors to drive over without damaging it. The total depth of the soil inside the tank is $90 \mathrm{~cm}$. The lysimeter is sunk in the soil with the rim at surface level. The tank is filled with the natural soil, representing the original soil profile as much as possible. The depth is roughly the same as the ground water table in the case of soil profiles with groundwater within reach of the rooting zone. The width is exactly $1.80 \mathrm{~m}$, which is the usual width of two plant rows in the greenhouse, the length is $2.20 \mathrm{~m}$, thus covering a total surface area of $4 \mathrm{~m}^{2}$. The lysimeter is equipped with a drainage system and provided with a pump to collect the leached water (Voogt et al. 2012). The drained quantity can be measured manually or electronically using a water meter. Lysimeters are the only devices that can measure real leaching. Lysimeters have been successfully used in projects with organic greenhouse crops and have shown that it is possible to irrigate the crop with a minimum of leaching (Voogt et al. 2014).
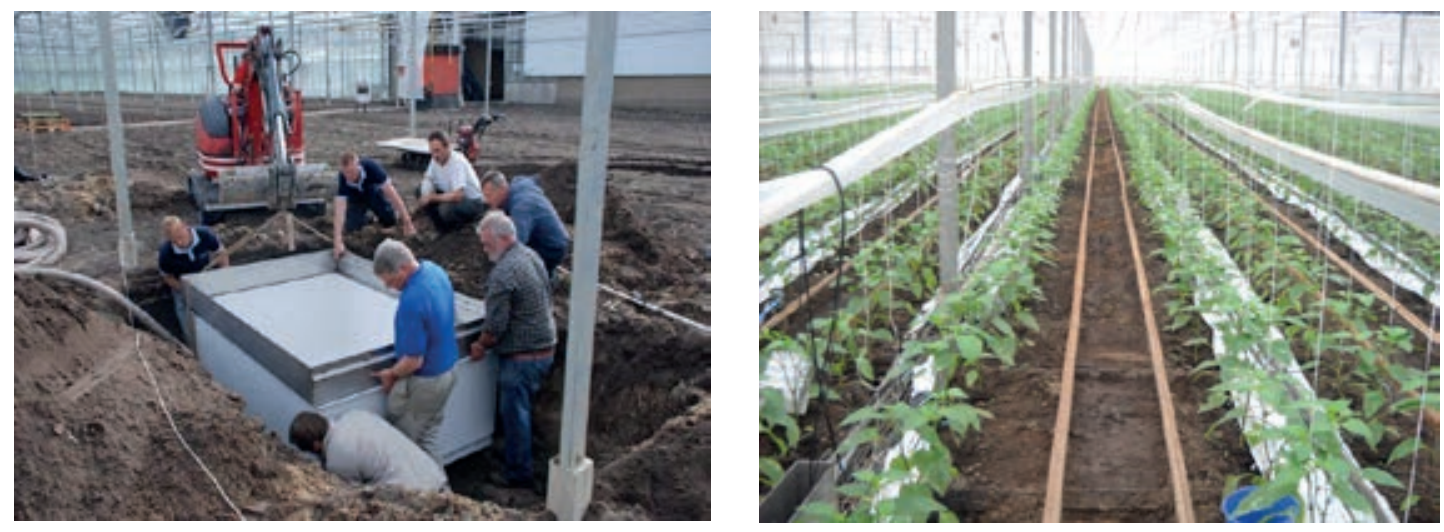

Figure 23 Installation of a lysimeter in a greenhouse $(A)$ and after installation with a young sweet pepper crop (B) (photos: Wim Voogt). 


\subsubsection{Decision support systems}

Various computer based decision support systems (DSS) have been developed for irrigation in commercial practice. The term computer refers not only to PC's and process computers but also to mobile devices such as smart phones and tablets, and the DSS's can be stand alone or web-based programs. The use of computer technology enables the use of frequent calculations are inputs of climate and soil and plant data to be considered. Comparisons with historic records and simulation models can be made using stored data. To use drip irrigation, frequent calculation are essential which makes it possible to fine-tune supply and demand to a high degree of accuracy. Today DSS's with varying degrees of complexity are available. Often these systems combine irrigation with fertiliser supply. Nutrient management by fertigation is of course not applicable in organic cropping but the irrigation element of the system can usually be applied separately. There is a wide variety of DSS's available which changes every year and ranges from relatively simple DSS with few data requirements such as VEGSYST (Gallardo 2013), which is well-suited for on-farm use, to more sophisticated DSS's that use more inputs. An example is the program FERTIRRIGERE introduced by Battilani et al. (2003) for tomato crops in Mediterranean regions. The main inputs are daily climate data and some basic soil parameters. The output is the daily recommended irrigation. It has been in use in Italy at different farms and the use of FERTIRRIGERE reduced $\mathrm{N}$ application by $46 \%$ on average, with no significent effects on production and quality (A. Pardossi, pers. commun.). The "Fertigation model" of Voogt (2000) combines a crop evapotranspiration model with an empirical nutrient uptake model. It calculates the on-going crop demand based on crop-specific parameters such as cropping phase, plant height, LAI and real-time greenhouse climate data. The model is compatible with all modern greenhouse climate computers.

\subsubsection{Other irrigation tools}

Several plant physiological indicators that might be used for irrigation scheduling are mentioned in the literature. These include leaf temperature measured by infrared cameras, stomatal conductance, leaf fluorescence, stem diameter and sap-flow sensors, as well as integrated devices with multiple tools. These tools are interesting and useful for scientific and applied research. However, interpretation of data is not that straightforward for crop water demand. Moreover, these tools require proper installation and maintenance which is rather time consuming, therefore their use in commercial practice is not yet applicable. 
72 I Impact of water quality and irrigation management on organic greenhouse horticulture 


\section{Interaction between irrigation, crop development and product}

\section{In short}

- Suboptimal water scheduling affects crops differently, depending on their genotype, environmental growing conditions, duration and interaction with other stress factors, and the physiological developmental stage when this event occurs.

- Excess irrigation results in physiological plant disorders and the reduction of quality attributes.

- A moderate controlled water deficit may increase quality attributes with no or or only a slight reduction in yield.

- A moderate water deficit increases fruit soluble sugars, organic acids and aroma compounds, which constitute important taste attributes.

- A moderate water deficit stress may stimulate secondary plant metabolism resulting in an increase in compounds that have human health benefits.

- Water scheduling should be well balanced with other stress factors that may occur during the growing season and that have an impact on quality attributes.

- Poor water quality may impair product quality in terms of human health (heavy metals, human pathogens, pesticides and contaminants).

\subsection{Effects on plant growth and productivity}

For greenhouse crops, irrigation management is directly related to plant growth and productivity as plants are protected against natural precipitations. Both over- and under- irrigation may affect crop productivity and product quality, resulting in lower crop profitability. However, a moderately controlled water deficit can have positive effects on quality, while high productivity is maintained or only slightly reduced. Nevertheless, salinity problems may occur in the long term under water deficit conditions.

\subsubsection{Effects on plant growth}

In addition to inducting nutrient leaching, excess of irrigation results in physiological plant disorders such as epinasty, a reduction in stem elongation, leaf senescence, poor root health, and consequently, reduced nutrient uptake. Over-irrigation also promotes root diseases such as Pythium. On the other hand, water stress, related to a significant lack of water, increases leaf abscisic acid content, which influences stomatal aperture and ethylene production. Factors observed under water deficit conditions include the reduction of transpiration rate, photosynthetic activity and plant growth, along with an increase photo-oxidative stress involving secondary metabolites. Nevertheless, plant water status as expressed by its water potential may not be affected by moderate water stress when osmotic adjustment (e.g. accumulation of soluble sugars, organic acids, ions) and photosynthetic adaptation occur. However, it is important to note that water stress may cause fruit abortion and negatively regulations fruit setting. 
In order to reduce water use and avoid any nutrient leaching in the groundwater, several studies were conducted using deficit irrigation or partial root drying. For a range of different tomato genotypes, a soil water deficit resulted in plant osmotic adjustments, leaf growth reduction, and photosynthetic acclimatisation, in particular an increase in chlorophyll leaf content and cyclic electron flow (Ripoll et al. 2016). It was also reported that plants might have a "memory" of a water stress period resulting in a reduction of its negative impact during the following water stress period; the response mechanisms are being associated with increased gene expression. Nevertheless, deficit irrigation used for water conservation was linked to tomato flower abortion and higher incidence of blossom-end rot, although fruit gustatory quality may be improved (section 10.2.1). Deficit irrigation also affected negatively the number and fruit weight of greenhouse peppers. The quality of ornamental crops was also reduced by deficit irrigation strategies, while moderate stress can control the plant morphological development (Costa et al. 2007).

\subsubsection{Effects on yield}

The differences between organic and conventional productivity vary according to the crop species and cultivars, the soil characteristics, the growing system used, the climatic conditions (growing area), the cultural practices and the grower's know-how, including irrigation management. Fine tuning of the irrigation management combined with optimal nutrient balance may be challenging for organic greenhouse crops, and can lead with lower yields compared to conventional crops (Dorais and Alsanius, 2015). Although meta-analysis studies have reported that organic fruits and vegetable yields are on average $72 \%$ and $80 \%$ of conventional yields respectively, productivity of organic greenhouse crops reached on average $94 \%$ compared with conventional crops, while $102 \%$ was reached with high tunnel organic crops (Dorais and Alsanius 2015). When observed, lower productivity is often related to pest and disease infestation (e.g. nematodes) rather than irrigation and fertilization management (Table 8). However, some nutrient limitations may occur under some environmental conditions depending on the soil health, cropping systems and cultural management. For example, irrigation management of poor soil structure (e.g. compaction, poor wettability) is extremely complex, resulting in lower yield. Suboptimal water scheduling affects crops differently according to their genotype. For example, large fruit tomato genotypes are more sensitive to water stress than cherry in terms of fruits growth, probably due to differences in water flux on fruit expansion, and in carbon supply by leaves and carbon demand by fruits (Ripoll et al. 2016). Nevertheless, crop responses to soil water stress are highly variable and depend on many factors among which are species sensitivity and genotypes; physiological developmental stages at which the stress occurs; the intensity, duration and frequency of the stress; and the environmental growing conditions. 


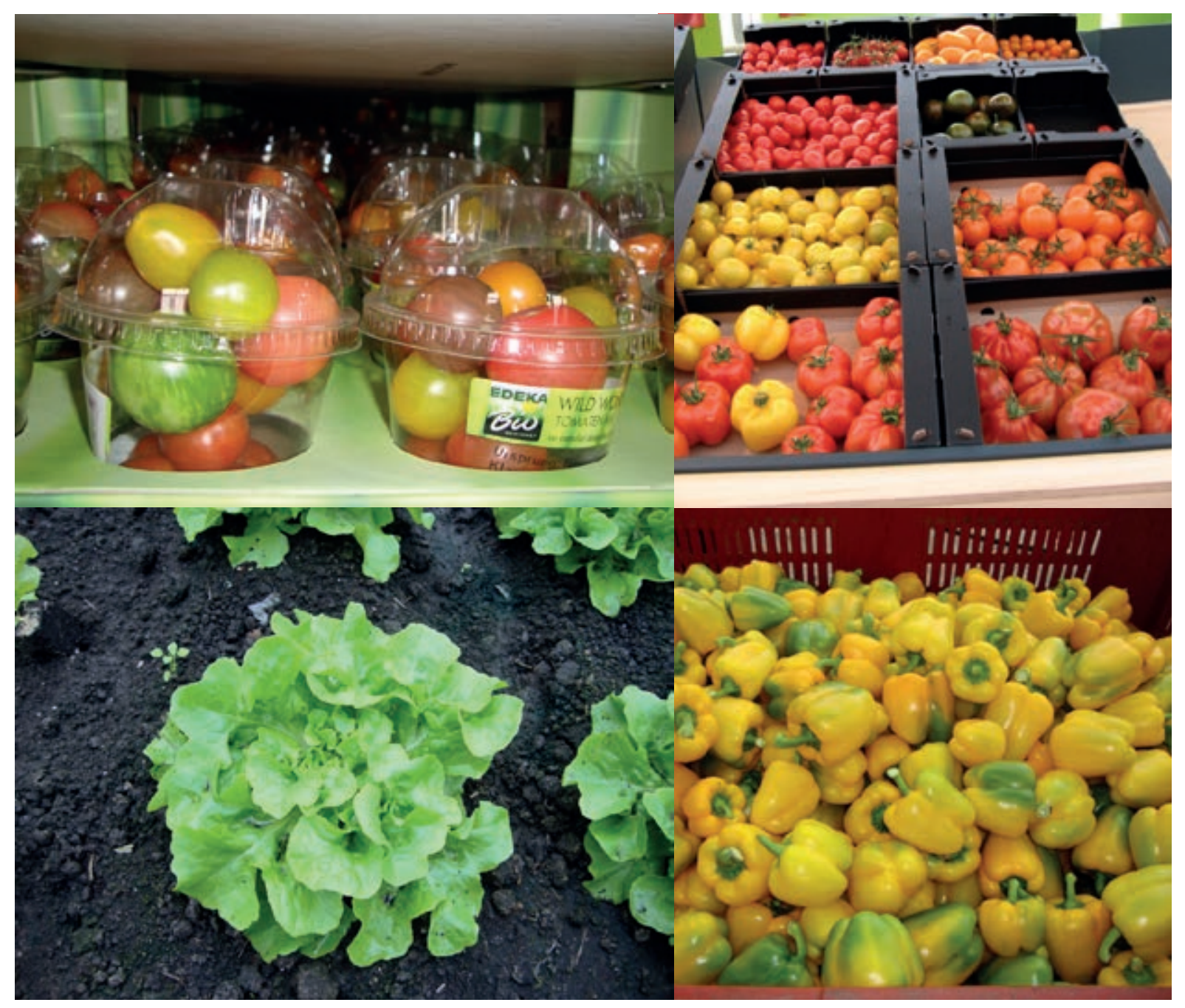

Figure 24. Water management impacts quality attributes of organic horticulture, which are key marketing criteria for consumers (photos: Martine Dorais). 


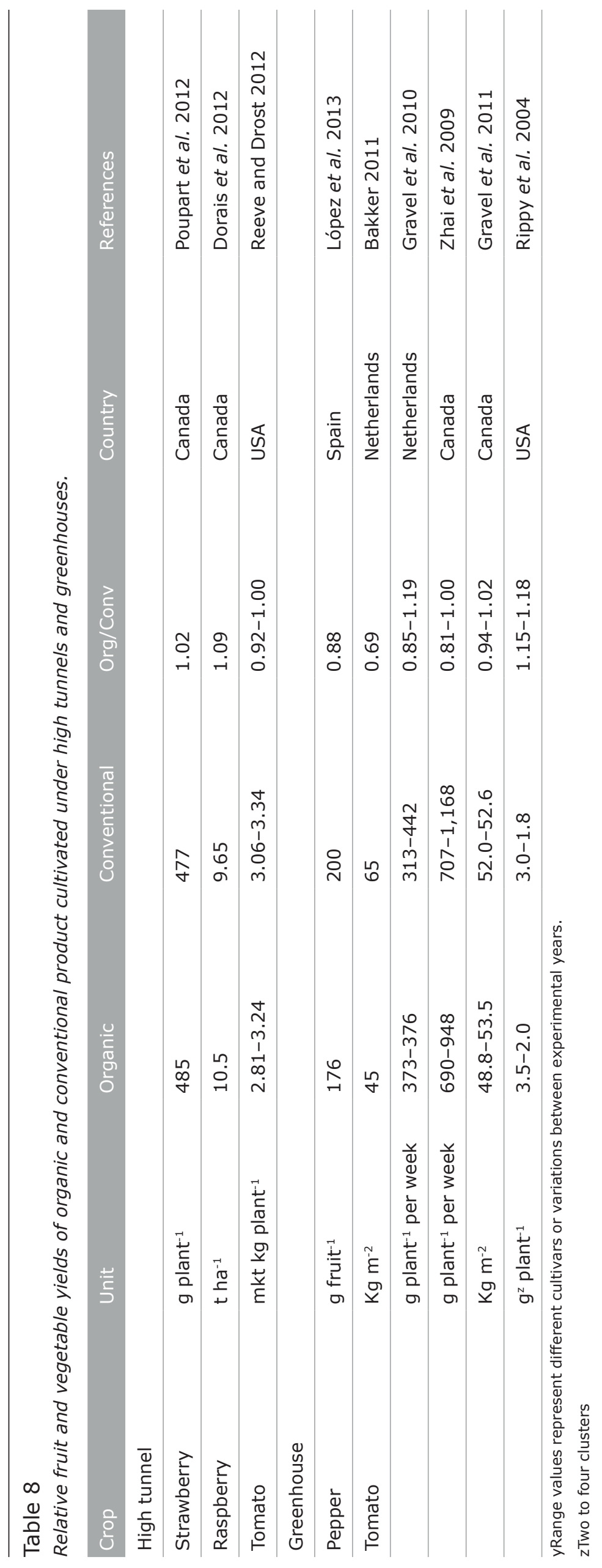

76 I Impact of water quality and irrigation management on organic greenhouse horticulture 


\subsection{Effects on nutritive quality attributes}

Organic fruits and vegetables are generally perceived by consumers as more nutritious, tastier, and richer in healthy components than conventional products (Dorais and Alsanius 2015). However, the higher nutritional value of organic fruits and vegetables remains to be scientifically proven. Although organic fruits and vegetables have in general lower nitrate, and higher vitamin $\mathrm{C}$ and phenolic compound content as compared with conventional produce, the product quality of organic greenhouse crops might be lower than conventionally grow farm crops when same cultivars are used due in difficulties to fine-tuning soil water content and nutrient availability (Dorais and Alsanius, 2015; Gravel et al. 2011).

\subsubsection{Irrigation management}

Lower soil electrical conductivity due to a limited soil mineralization rate and over-irrigation can favour plant water uptake resulting in poor nutrient and gustatory quality of fruit and vegetable crops (Dorais et al. 2001, Dorais et al. 2008). Fruit firmness, fruit cracking/russeting and shelf life are also negatively influenced by nonoptimal irrigation management (Dorais et al. 2004). For tomato, it has been clearly shown that sub-optimal irrigation management increases fruit dry matter but reduces fruit size, while over-irrigation management results in soft and tasteless fruits due to a dilution effect that leads to lower levels of sugars, organic acids and aroma compounds (Dorais et al. 2001). Table 7 presents some studies on the effect of water management on greenhouse crop quality.

Water shortage provides a powerful tool for improving the quality attributes of organic greenhouse crops. The main responses of plant/fruit composition to water deficit have been attributed to concentration effects, active solute accumulation or the breakdown of storage carbohydrate (Ripoll et al. 2016), contributing to their osmotic adjustment. The effects of water deficit on cell size and cell turgor may also impact quality attributes. Indeed, a positive relationship between tomato fruit dry matter or total soluble solids and firmness was observed, although conflicting results between moderate water stress and firmness were reported (Ripoll et al. 2014).

In general, moderate water deficits increase levels of fruit soluble sugars, organic acids and aroma compounds. These are all important taste attributes (Ripoll et al. 2014). However, organic acids may not be positively affected by water deficit in some species, such as strawberry. For tomato, an increase in fruit sugar content under water deficit was largely observed in numerous studies but conflicting results were reported for their organic acid content, despite the fact that positive correlations were observed.

Moderate water deficit stress also stimulates secondary plant metabolism resulting in an increase in compounds with human health benefits (Ripoll et al. 2014). In general, the content of phenolic compounds is positively related to water stress. Its effect on carotenoids, however, varies according to crop species, environmental factors and stress intensity. For example, fruit phytochemical responses (ascorbic acid and carotenoids) of tomato to water deficit varied between genotypes and stress severity (intensity duration) from negative to positive. Water deficit during fruit ripening also reduced the accumulation of some carotenoids after several water shortage events (Ripoll et al. 2016).

Although water deficit may increase gustatory and health-promoting phytochemicals of greenhouse crops, water deficit events (intensity, duration, frequency) may result in reduced productivity and fruit size. This is because the determination of the appropriate stress threshold is complex and depends on species, cultivars and the physiological stage of development when stresses occur. Large soil moisture content fluctuations should therefore be avoided in order to prevent physiological disorders, and the amount of irrigation water provided should match the amount of water required by the plants and soil microorganisms in real time. 


\subsubsection{Indirect factors and multiple stresses}

Lack of balanced amendments combined with sub-optimal water quality and/or irrigation scheduling may result in the build-up of undesirable ions such as $\mathrm{Na}, \mathrm{Cl}$, and $\mathrm{SO}_{4}$ which can compete with the uptake of desirable ions (e.g. $\mathrm{Ca}, \mathrm{Mg}, \mathrm{K}, \mathrm{NO}_{3}$ ), and reduce product quality. Nevertheless, limited nitrogen under organic farming, along with abiotic and biotic stresses, generally result in higher secondary plant metabolites which are considered beneficial for human health (Dorais and Alsanius 2015, Orisini et al. 2015). Moderate salt stresses may increase fruit quality via similar mechanisms to water deficits (De Pascale et al. 2007, De Pascale et al. 2012). Plants growing under greenhouse conditions plants may be exposed simultaneously to more than one abiotic or biotic stress at a time, so the effects of multiple stresses on yield and quality attributes should be considered. For example, tomato plant fruits exposed to the combined effect of water and nematode stresses had higher sugar content than the fruits of plants exposed to either water or nematode stress (Atkinson et al. 2011). The accumulation of carotenoids and phenolic compounds was also influenced by combined stresses, although their effects are not additive and difficult to predict. In fact, the presence of an abiotic stress can reduce or enhance the susceptibility to a biotic stress, and vice versa (Atkinson and Urwin 2012), thus affecting their nutritional value. However, interactions among multiple stresses (e.g. high temperature and water deficit; severe salinity and water deficit) may also impair plant health, counteracting their potential benefits for product quality and crop productivity. Consequently, water deficit should be well balanced with other stress factors that may occur during the growing season.

In addition to reducing plant growth and crop productivity, poor water quality can also impair product quality in terms of human health. Risks related to the uptake of heavy metals by the crop as well as contamination by human pathogens/toxins (e.g. Escherichia coli, Salmonella spp., Listeria monocytogenes) should be carefully considered and their transmission route evaluated (Dorais and Alsanius 2015). 


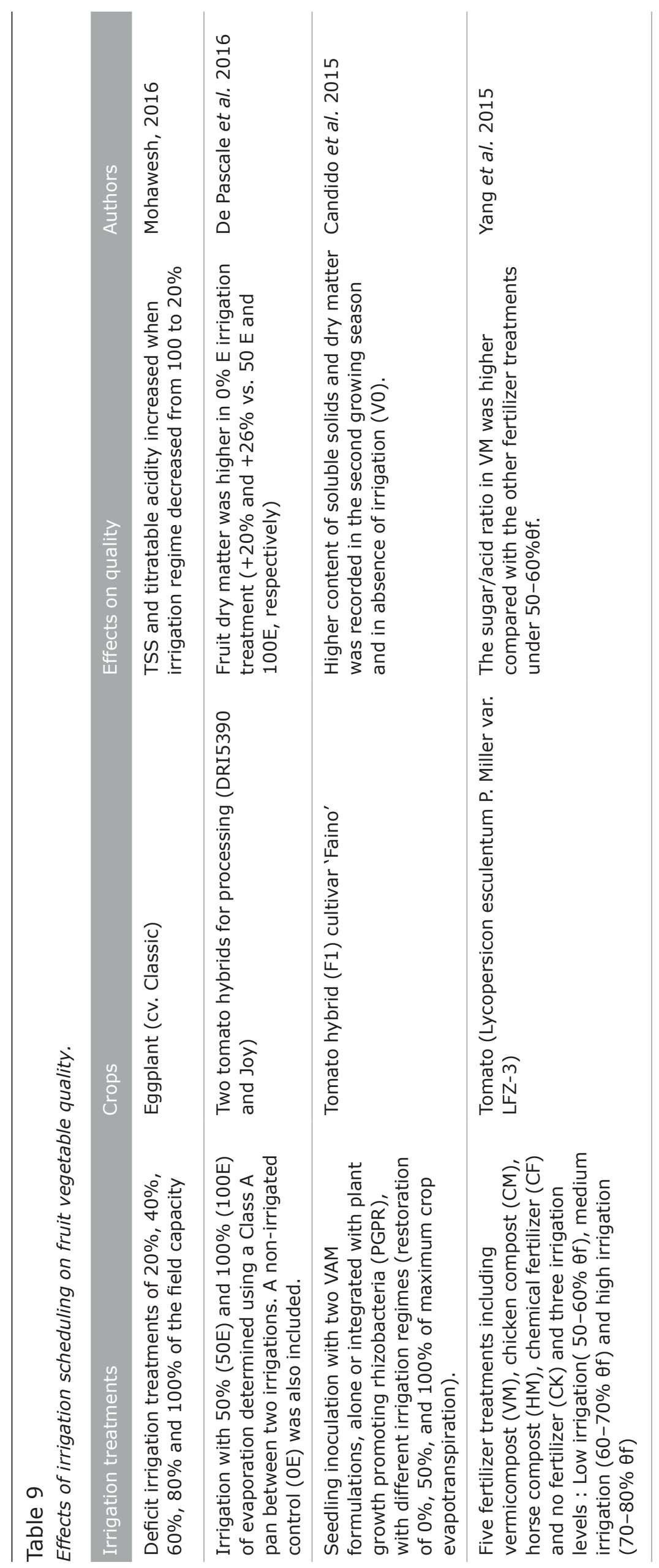

Impact of water quality and irrigation management on organic greenhouse horticulture 179 
80 Impact of water quality and irrigation management on organic greenhouse horticulture 


\section{Sustainability and water conservation}

\section{In short}

- Improvement of crop water use efficiency (WUE) contributes significantly to water conservation.

- Water conservation is improved by using the appropriate irrigation technology and control tools.

- Breeding and selection of species and varieties having high WUE contribute to water conservation.

- Substantial deficit irrigation of greenhouse crops saves water but may result in losses in marketable yield.

- Reducing soil evaporation, preventing build-up of spatial soil salinity, a low relative irrigation supply, and the development of an adequate root system contribute to water conservation.

- Water recycling for organic crops may be challenging depending on the cropping and irrigation systems.

- The performance of water use for organic crops can be objectively evaluated via the water footprint concept, although good indicators still have to be developed.

The water use efficiency (WUE) of each type of crops is an important indicator for the reduction of the environmental footprint of water used for organic greenhouse production. Consequently, each component of the water flows (section 2.0) has to be optimized according to the growing system used. Considering internal greenhouse processes, over-irrigation, which is excess irrigation compared to crop- and soil demand, is a key issue. Other factors like leakages and free-drainage (open growing systems) should also be minimized while the collection of condensed water and the reuse of drainage water should be maximized. When considering the bigger picture, the use of renewable sources like rainwater (collection and storage) should be encouraged and depletion of aquifers should be discouraged. Consequently, irrigation management should use the appropriate technology in terms of control tools (section 8.3) and scheduling (section 8.2) to fulfil plant water requirements in real time and limit any water and nutrient leaching into the surface or groundwater. Naturally this management must be such that soil quality and soil ecology as well as yield and product quality are not negatively affected (Chapter 10). Eventually the total water management strategy at farm level will lead to a reduced water footprint per unit of product.

\subsection{Strategies}

\subsubsection{Appropriate crop species and controlled deficit irrigation}

Growers can significantly contribute to water conservation by selecting crop species, growing systems, and crop management but a major contribution is made by adequate irrigation management. It has been clearly shown that specific rootstocks and cultivars are more tolerant to deficit irrigation (drought resistant cultivars/species) and salinity stress while still achieving high productivity. As stated in section 10.1, deficit irrigation has been identified as a tool to save water, particularly in dry and hot climate areas where water is a scarce resource. Although deficit irrigation and partial root drying have been identified as potential ways to increase water savings for some horticultural crops such as grapevine and fruit tree crops, significant losses in marketable yield have been reported for vegetable and ornamental crops (Costa et al. 2007; section 10.1). Before using this water saving strategy, good knowledge of how rootstocks and cultivars react to deficit water is needed, along with specific soil characteristics, soil biological activity, and soil spatial variability. Precise monitoring of the soil and/ or plant water status is also required to efficiently manage the deficit irrigation level. Moreover, an appropriate understanding of the interaction effect of deficit water with other abiotic and biotic stresses (section 10.2.2) is advisable before using this technique for high value crops such as organic greenhouse horticulture.

Finally, for greenhouse crops, the success of deficit irrigation is highly dependent on water and soil quality. As explained in sections 6.1 and 9.1, salinity is a high risk in $\mathrm{OGH}$, due to the sometimes unavoidable unbalanced and high inputs of residual salts. Moreover, in case of water sources with certain background concentrations of residual salts, these strategies will lead to high saline soil spots. These EC and salt heterogeneities can only be restored at the expense of high water uses for salt leaching, since natural precipitation is excluded. 


\subsubsection{Appropriate irrigation systems and tools}

Sub-optimal WUE can be caused by an inaccurate type of irrigation system (Chapter 7). For example, a large proportion of the irrigated water can miss the plant roots when a boom irrigation system is used for spaced crops/pots when compared to drip irrigation. For potted plants, the use of a sub-irrigation system such as ebb-and-flow has been shown to save more than $50 \%$ of water compared with overhead irrigation (Ferrarezi et al. 2015a). Specifically, water use for potted plants has been reported to be 0.4 to $0.8 \mathrm{~m}^{3}$ water per $\mathrm{m}^{2}$ per year for ebb-and-flow benches and troughs, while drip irrigation uses 0.8 to $1.6 \mathrm{~m}^{3}$ water per $\mathrm{m}^{2}$ per year, and hand or sprinkler irrigation uses 1.2 to 2.4 water $\mathrm{m}^{3}$ water per $\mathrm{m}^{2}$ per year (Roeber 2010). However, sub-irrigation needs effective nutrient management in order to minimize risks associated with osmotic stress (salinity) while fulfilling the required plant nutrient requirements. Although sub-irrigation is mainly used for potted plants (herbs, ornamentals, seedlings), it could also be used for demarcated beds when the fertilizers used are relatively well balanced with plant nutrient requirements. For soil-grown crops, the consequences of heterogenic water distribution have been discussed in section 7.2

\subsubsection{Appropriate crop management}

Strategies for reducing irrigation water waste also include 1) reducing soil/cultivable surface evaporation, 2) reducing leaching below the crop root zone (Chapter 9), 3) promoting adequate root development throughout the growing media/zone, and 4) preventing the build-up of salinity and unbalanced nutrients within the soil profile and growing media (Chapter 6; section 9.1). Mulches, which are often used by organic vegetable greenhouse growers, can improve the WUE of greenhouse crops by limiting soil water evaporation (Voogt and van Winkel, 2008). Highly porous biodegradable pots (e.g. wood fiber, peat, rice straw, manure) often show higher evaporation rates than plastic pots despite their environmental benefits (Ferrarezi et al. 2015a).

Reduction of soil spatial variability in terms of hydraulic properties, improvement of soil health and irrigation scheduling adapted to soil physicochemical properties may also significantly contribute to the promotion of adequate root development and a reduction of leaching, thus improving the WUE of greenhouse crops. In fact, soil compaction, often observed under certain types of soil and cultural practices, slows the infiltration of water into the subsoil, promotes water evaporation and limits crop productivity. In particular cases the soil hydraulic conductivity can also be reduced by some bacteria producing extracellular polymeric substances (Or et al. 2007). For soil-based cultivation systems, irrigation water should penetrate the soil easily and rapidly in well-structured soils. Non-uniform water distribution related to suboptimally designed irrigation systems results in too little or too much water being applied at some cultivated locations, which can cause water and nutrient leaching losses and sub-optimal crop productivity. On the other hand, recycling of the drainage water generally may result in a reduction in the groundwater used by a third, in addition to a substantial reduction in the leaching of minerals, such as $\mathrm{NO}_{3}$ and $\mathrm{K}$.

To maximize greenhouse crop productivity, water and fertilizers are often provided in excess of crop demand, thus impacting the groundwater when closed systems are not implemented. Few studies have been performed on the environmental footprint of water used for organic greenhouse crop production until now. It has been reported that intensive organic agriculture relying on solid organic matter, such as the use of composted manure as the sole fertilizer that is incorporated in the soil prior to planting, resulted in significant down-leaching of nitrate to the groundwater (Dahan et al. 2014). However, when part of the fertilizer requirement was provided in liquid form during the growing season (fertigation), lower down-leaching of nitrate was observed. In fact, by only using solid organic fertilizers such as compost and guano, the unsynchronized release of nutrients with respect to the crop developmental stage and uptake capacity may occur (Dahan et al. 2014). Consequently, fragmented solid applications should be performed in combination with the use of liquid organic fertilizers to better match with the increasing crop uptake capacity during the growing season, which will limit nutrient leaching into the groundwater. 


\subsection{Challenges}

Organic growers have to overcome several additional challenges compared with conventional growers. First, dissemination of root pathogens is a key issue for water recycling because only a limited number of products are allowed to control fungi, and bacterial or virus plant pathogens dispersed by water. As crops are often grown in soil, reuse of drained water might be difficult when the groundwater level is high and/or contaminated by surrounding agriculture or industrial activities. Although the soil surface should be keept relatively dry to reduce soil water evaporation and consequently to improve WUE, soil surface moisture is needed for soil biological activity and the appropriate mineralization rates of organic fertilizers. Reuse of the drained water and the treatment of run-off water could also be challenging because organic particles or humic compounds often observed in wastewater may counteract UV or ozone water treatments (Chapter 9). Filters or membrane technology can be used as a pre-treatment but they incur additional production costs. As organic amendments are rarely balanced with plant nutrient requirements, unbalanced soil nutrients and the built-up of salinity often occur for long season crops such as fruit vegetables. Consequently, growers may wash their soil after the growing season to reduce undesirable ions such as $\mathrm{SO}_{4}, \mathrm{Na}$ and $\mathrm{Cl}$. Unfortunately, this practice also leaches nitrate ions causing an environmental burden and reducing the pool of nitrogen available for the next culture.

Adequate irrigation scheduling requires monitoring tools such as soil water sensors (section 9.3) that are able to measure small and rapid water content changes. These are often expensive for growers and need to be calibrated for the particular soil used. Moreover, the number of sensors needed per cultivated area depends on soil spatial variability, and greenhouse zone climatic uniformity.

\subsection{Water used for greenhouse crops}

The efficient use of water for greenhouse crops varies according to several factors such as the type of crop and cultivars, the type of system used (open, semi-closed or closed systems), the irrigation method used, the type of soil or growing media, the available sources of water (water scarcity), their quality (salinity and contaminants), the climatic conditions and cultural practices of a given production area and farm, and the management decisions and irrigation skills of farmers. Various performance indicators for irrigation were proposed (Bos 1997). In order to evaluate the performance of the use of water for a given product and its environmental impact, the water footprint concept has been recently developed (reviewed by Berger and Finkbeiner 2010), and improvements to methods have been suggested by several research groups (e.g. Bayart et al. 2010, Hospido et al. 2013, Todorovic et al. 2016). In fact, information about irrigation management such as excess water, deficit irrigation and water needed for cropping practices must be part of the crop water footprint analysis at the farm level (Morillo et al. 2015). Consequently, hotspots in the irrigated system used can be identified and specific actions can be defined to improve crop water use efficiency and reduce environmental burdens related to water use, while still maintaining high crop productivity and quality. However, clear water sustainability indicators have to be considered and models should be optimized using holistic and multi-objective approaches, including overexploitation of groundwater (Mays 2013), climate changes, and eco-efficiency indicators and eco-efficiency assessment (Todorovic et al. 2016).

A study conducted in a concentional Mediterranean conventional greenhouse showed that reuse of agricultural wastewater had environmental advantages in terms of eutrophication, aquatic ecotoxicity and energy use compared with desalinated water and groundwater, while the use of groundwater had a lower salinization potential compared with the other sources of water studied (Muñoz et al. 2010). Contaminants coming from recycled water and groundwater should, however, be considered. The use of desalinated water via reverse osmosis is a high-energy demanding process leading to high environmental impacts in terms of global warming, energy use, soil quality and aquatic ecotoxiciy. In addition, the high costs of desalinated water have discouraged farmers from using it (Sanchez et al. 2015). 
Relative irrigation supply (RIS) is also an indicator that can be used to assess irrigation management of greenhouse crops (Sanchez et al. 2015). It is defined as the ratio of the total annual volume of water used for irrigation and the total theoretical/calculated irrigation needs of the crops per irrigation season (Morillo et al. 2015). Under Mediterranean greenhouse growing conditions, an overall RIS value of 1.12 was observed, showing that moderate leaching occurs thus contributing significantly to the risk of salinization of the aquifer and a drop in the groundwater table (Sanchez et al. 2015). 


\section{Conclusions and knowledge gaps}

\section{In short}

- Water management of organic horticulture has been poorly studied in scientific literature, with only $3 \%$ of the total papers published over the last 40 years.

- Multidisciplinary studies on water management must be conducted from microbial, soil, plant, and environmental perspectives.

- Technical approaches and tools to evaluate hygienic aspects in relation to irrigation and fertigation management are needed to overcome the safety issue related to organic farming.

- Alternative water treatments and system cleaning products such as new approaches to oxidizing chemicals should be developed and proposed to growers to reduce risks related to water recycling and clogging.

- Long-term effects of $\mathrm{Na}, \mathrm{Cl}, \mathrm{Ca}, \mathrm{Mg}$, and $\mathrm{SO}_{4}$ on soil and growing systems in non-leaching systems need to be better understood and thresholds defined for sustainable plant productivity.

- Affordable and highly efficient control tools for growers to optimize their irrigation management should be developed and implemented at the farm level.

- Knowledge about the environmental impact of various water management strategies and water sources used for organic greenhouse horticulture should be developed in order to identify hotspots and improve the sustainability of these intensive growing systems.

- Gaps between knowledge and transfer to practice (e.g. leaching, management tools) limit the achievement of the full potential of organic greenhouse horticulture and its market expansion.

- Gaps between organic principles and practical applications should be revised and adapted to local specificities conditions in order to achieve sustainability and profitability for producers located in different worldwide growing areas.

Increasing demand for organic fruits and vegetables combined with problems of water eutrophication and scarcity of high quality water, especially in arid areas, offer great opportunities for organic greenhouse growers to extend their market shares. However, the expansion of organic greenhouse horticulture should follow the principle of organic farming that the "health of soil, plant, animal and man are one and indivisible" (Balfour 1947). Organic farming should use cultural practices that maintain land resources and ecological balance in addition to the promotion of biodiversity, biological cycles, and soil biological activity, while minimizing the use of off-farm inputs. For organic greenhouse crops, one of the most important cultural parameters is irrigation management that supports soil microbiological activity and plant productivity, while water resources constitute a key system input. Consequently, sustainable management of water in terms of quality and use is unavoidable for organic greenhouse horticulture. Moreover, water recycling is an important issue for organic farming to optimize the use of resources and limit its environmental footprint.

\subsection{Summary}

The two main water flows for greenhouse crops, evapotranspiration and the need for irrigation, are driven by radiation, while the other important water flows, condensation and reuse of drained water, can be considered as re-used water. The re-use of water should be enforced to fulfil organic farming principles. While the re-use of drained water can be challenging for soil-based growing systems, water recycling in organic soilless growing systems is similar to conventional growing systems, although water treatments should follow the organic regulations. Special care, however, should be taken to limit biofilm development and clogging. Undesirable chemicals and microbial contaminants should be removed from drained water prior to re-use or disposal. Physical, chemical and biological treatments are used to reduce or eliminate plant pathogens and/or undesirable compounds such as ions, pesticides and other contaminants. Water treatment may also be required when available irrigation water is of poor quality. 
Water quality is a key issue for greenhouse crops in order to limit salinity problems and soil or product contamination by plant and human pathogens, contaminants (e.g. heavy metals, pesticides) and illicit compounds. Organic compounds and the microbial load in irrigation water can also cause clogging and consequently reduce crop productivity and quality. Ideally, the electrical conductivity of the irrigation water should be less than $0.5 \mathrm{mS} \mathrm{cm}^{-1}$, while its content in terms of $\mathrm{Na}$ and $\mathrm{Cl}$ concentrations should be less than 1 $\mathrm{mmol} \mathrm{L}^{-1}, \mathrm{Mg}$ and $\mathrm{SO}_{4}$ should be less than $0.7 \mathrm{mmol} \mathrm{L}^{-1}$ and $\mathrm{Ca}$ less than $1.5 \mathrm{mmol} \mathrm{L}^{-1}$. Fe should be less than $10 \mu \mathrm{mol} \mathrm{L}^{-1}$ to avoid clogging of the irrigation system, and less than $100 \mu \mathrm{mol} \mathrm{L}^{-1}$ to prevent leaf burning. $\mathrm{HCO}_{3}$ should be less than $5 \mathrm{mmol} \mathrm{L}^{-1}$ to avoid any problem related to high $\mathrm{pH}$ as well as sodicity.

The main sources of water use for organic greenhouse crop irrigation are ground water, surface water, rainwater, process waters and municipal water. Condensed water and rainwaters are the most sustainable sources of water, although their availability cannot fully meet plant water requirements. Municipal waters often have high concentrations of $\mathrm{Na}, \mathrm{Cl}$ and $\mathrm{SO}_{4}$, which are unsuitable for organic greenhouse crops. Ground water is of highly variable quality and might not be the main source of irrigation for renewability and availability reasons. On the other hand, surface waters might contain undesirable components, some of which are not allowed in organic farming such as pesticides. Treated or untreated wastewaters might constitute a sustainable source of water depending on their specific quality characteristics. For example, digestate and fish effluent, in addition to providing water, may constitute significant sources of nutrients such as K, P and N. On the other hand, the cost of desalinization may limit its use by growers.

Water demand by greenhouse organic crops is mainly determined by crop evapotranspiration. It should fulfil plant water requirements for optimal growth, productivity and product quality as well as ensuring appropriate soil bacterial and fungal activities, and proper mineralization rates. Climate conditions, crop type, water quality, soil characteristics, growing systems and cultural practices all influence the crop evapotranspiration and consequently crop water demand. Many approaches have been proposed to estimate crop evapotranspiration based on climate, plant growth parameters, and empirical and mechanistic models. New methods based on the volatile metabolomics are also promising to monitor metabolic processes and the determination of water plant status (waterlogging or shortage). Volatile organic compound signatures can also be good indicators of other abiotic and biotic stresses.

Poor water quality is a major cause of soil salinity in greenhouse crops, although the use of organic fertilizers also contributes significantly to soil salinization due to unbalanced nutrients. Crops can be affected by salinity via an osmotic effect (high salt content) and/or an ionic effect (ion toxicity, unbalanced ion content at the cell level), resulting in lower plant growth and yields. Salt accumulation also affects soil structure through sodicity, which may reduce mineralization rates. However, salinity can also increase product quality attributes. Factors affecting the salinity impact on crops are species, cultivars, rootstock, type of soil, type of growing systems, environmental conditions (radiation, temperature, humidity, $\mathrm{CO}_{2}$ concentration), irrigation and fertilization management.

During recent decades, major progress has been achieved in the improvement of irrigation management of greenhouse crops via the development of efficient irrigation systems (drip, strip, mini sprinkler) combined with control tools. Each system has its own advantages and disadvantages with respect to the cultivated crops and growing systems. However, spatial heterogeneity of soil moisture constitutes a significent challenge for organic greenhouse crops, which is inherent in the design of the irrigation distribution system, clogging potential and plant growth. For potted plants, sub-irrigation has high water use efficiency, but build-up of salinity and plant pathogen dispersion may occur. Irrigation management integrates quantity, frequency and distribution of water application which is in turn based on water quality, soil characteristics, crop and growing system specificities, environmental conditions, and control tools. The fine-tuning of irrigation management for organic greenhouse crops is complex due to soil and plant spatial heterogeneity, ion imbalances as well as a need for the optimization of soil biological activity. Control tools such as ET models, soil moisture sensors and lysimeters are the general approaches used for irrigation scheduling in organic greenhouse crops.

Irrigation scheduling greatly influences crop growth, yield and quality. While excess irrigation may result in a reduction of quality attributes, controlled moderate water deficit may increase quality attributes with little or no reduction in yield. On the other hand, poor water quality may impair product quality in terms of human health (heavy metals, human pathogens, pesticides and contaminants). 
In terms of sustainability, any water and irrigation management strategy that improves crop water use efficiency (WUE) will contribute significantly to water conservation. Appropriate irrigation technology and control tools should therefore be used along with the selection of species and varieties having high WUE. Irrigation techniques such as water deficit and partial root drying may be valuable for certain crops. Other approaches for water conservation include reducing soil evaporation and soil spatial variability, preventing build-up of salinity, using a low relative irrigation supply that limits leaching, and by healthy plants having an adequate root system. Water recycling should be promoted for organic greenhouse horticulture whenever possible. The performance of water use of water in organic crops can be objectively evaluated via the water footprint concept, although good indicators still have to be developed.

\subsection{Knowledge gaps}

Despite an increasing interest in and demand for organic fruits and vegetables in the last decade, research studies published on organic horticulture farming represent less than $10 \%$ of the total number of papers produced on agriculture and farming (Dorais and Alsanius 2015). Water management has been poorly studied in this scientific literature on organic horticulture, accounting for only $3 \%$ of the total papers published over the last 40 years. Good quality water is globally becoming a scarce resource, especially in arid regions and under climate changes, and this limits crop productivity and, in some cases, product quality. Better water management for organic protected horticulture should therefore be identified as one of the more important research priorities, and new methods and innovative systems need to be implemented. New control tools and developments in irrigation management for conventional greenhouse crops can nevertheless be adapted to organic greenhouse horticulture. Similarly, some water treatments of drained or collected waters such as thermal, UV, ozone and biological treatments can be used by growers according to their organic regulation. However, since reduced irrigation strategies enhance the risk of salinity, attention should be paid to limiting the inputs of residual salts from fertilization and water.

Organic greenhouse horticulture should maintain and promote biodiversity and equilibrium in the agro-ecological system, while achieving an acceptable and competitive profitability and fulfilling consumer expectations. Multidisciplinary studies on water management must therefore be conducted from microbial, soil, plant, and environmental perspectives. Furthermore studies on improved nutrient management to minimize ion and $\mathrm{pH}$ imbalances and to address the issues of $\mathrm{N}$ leaching and excess soil $\mathrm{P}$ under certain organic growing systems are strongly linked with water management and should be conducted. Better understanding of the temporal dynamics of plant and soil microbial water needs in relation to sustainable productivity and high WUE is needed along with effects on pest- and disease-susceptibility in greenhouse horticultural crops. A reduction in spatial and temporal crop heterogeneity should result from improved growing systems and better water and crop management. Specifically, among research gaps for organic greenhouse horticulture, research is particularly needed in the fields of:

Water quality in terms of relevant thresholds for contaminants such as PPCP and PPP in the irrigation water and other illicit compounds (nanoparticles, hormones, antibiotics). A better understanding of their uptake by the root and translocation to the edible plant organ under different types of soil and growing conditions is needed to support regulation. Their impacts on soil microflora and microfauna, and consequently soil heath, need to be better understood. Sources of water irrigation contaminations by plant and human pathogens should be well defined for each type of growing system to minimize risks associated with the use of agricultural and animal waste products and reuse of wastewaters. Knowledge of the risks of human pathogens invading the crop through irrigation (is soil a perfect filter for unhygienic water) is a key research gap in terms of food safety. Technical approaches and tools to evaluate hygienic aspects in relation to irrigation and fertigation management are needed to overcome safety issues related to organic farming.

Efficient measures to prevent clogging of the irrigation systems should be developed as this problem is common and has a significant impact on crop productivity, quality and product uniformity. Until now, there are few efficient methods available to growers who have to use water of suboptimal quality due to its scarcity. 
Alternatives water treatments and system cleaning products such as new approaches to oxidizing chemicals should be developed and proposed to growers to reduce the risks related to water recycling in terms of plant and human pathogen content, undesirable compounds (e.g. $\mathrm{Na}, \mathrm{Cl}, \mathrm{SO}_{4}$, heavy metals, pesticides), biofilm development, and clogging.

Long-term effects of $\mathrm{Na}, \mathrm{Cl}, \mathrm{Ca}, \mathrm{Mg}$, and $\mathrm{SO}_{4}$ on soil and growing systems in non-leaching systems need to be better understood and thresholds defined for sustainable plant productivity. Knowledge gaps concerning input/ output balances and in situ soil situations such as undesirable ion build-up should be addressed.

Affordable and highly efficient control tools (e.g. new reliable sensors) for growers to optimize their irrigation management should be developed and implemented at the farm level. Current control tools are expensive and/ or do not take into account spatial variability.

Knowledge about the environmental impact of different water management and water sources used for organic greenhouse horticulture should be developed in order to identify hotspots and improve the sustainability of these intensive growing systems. Indicators for water footprint and life cycle assessment should be defined in order to objectively characterize the long term impact of water use and management on environmental factors (e.g. global warming, $\mathrm{CO}_{2}$ footprint, aquatic and terrestrial ecotoxicity, energy use, resource depletion such as water), as well as social and economic aspects. This knowledge will contribute to regulatory development and define sustainable politic at the regional and international levels.

Important gaps between knowledge and the transfer to practice (leaching, management tools, soil moisture sensors) that has limited the achievement of the full potential of organic greenhouse horticulture production and its market expansion. "In theory" well eco-integrated growing systems of organic farming that encompass microorganisms, soil (biostimulant and suppressivenness properties) and plants, should produce higher yields as well as high plant resilience when compared to conventional systems. However, more research is needed to close knowledge gaps thus allowing the achievement of the full potential of organic greenhouse horticulture in terms of productivity, profitability and sustainability.

In order to respect both sustainable management and organic principles, new organic growing systems have to be developed, based on scientific evidence and then adapted by the sector. Consequently, gaps between organic principles and practical applications should be revised and adapted to local conditions to allow producers located in different growing areas worldwide to achieve sustainability and profitability. 


\section{References}

Abbate, C., Borzi, D., Caboni, P., Baglieri, A., 2007.

Behavior of fenhexamid in soil and water. Journal of Environmental Science and Health Part B 42: 843849.

Abbate, C., Borzi, D., Baglieri, A., Gennari, M., 2009.

Degradation of the fungicide pyrimethanil in water and soil. Agrochimica 53: 1-7.

Adin, A., 1986.

Problems associated with particulate matter in water reuse for agricultural irrigation and their prevention. Water Science \& Technology 18(9): 185-195.

Allen, R.G., Pereira, L.S., Raes, D., Smith, M., 1998.

Crop evapotranspiration: guidelines for computing crop water requirements. Paper 56. FAO, Rome.

Alrøe, H. F., Kristensen, E. S., 2004.

Why have basic principles for organic agriculture?... and what kind of principles should they be? Ecology \& Farming: 27-30.

Alsanius, B. W. (2011).

Mikroorganismer, organiska ämnen \& Co. Landskap Trädgård Jordbruk Rapportserie 2011:40.

Alsanius, B.W., 2014.

Hygien och bevattning. Landskapsarkitektur Trädgård Växtproduktionsvetenskap Rapportserie, Rapport 2014:10.

Alsanius, B.W., Brand, T., 2000.

Reningsalternativ för näringslösning i slutna odlingssystem. En handbok för odlare, rådgivare och beslutsfattare. Alnarp. ISBN 91-576-6010-7.

Alsanius, B. W., Bergstrand, K.-J., 2007.

Make the difference - om att sluta systemet. Resultat från ett demonstrationsförsök i tre skånska tomatodlingar. Alnarp.

Alsanius, B.W., Bergstrand, K.-J., 2014.

Degradation of pesticides in nutrient solution from closed hydroponic systems. Acta Horticulturae 1034:33-39.

Alsanius, B. W., et al. 2011.

Decontamination of irrigation water under field conditions: preliminary results." Acta Horticulturae 922: 61-66.

Alsanius, B.W., Bergstrand, K.-J., Rosberg, A.K., 2011. Att hålla koll - om rutinkontrollåtgärder i näringslösning vid odling av grönsaker och bär i slutna odlingssystem i växthus. LTJ-fakultetens faktablad 2011:37, 1-4.

Alsanius, B.W., Bergstrand, K.-J., Burleigh, S., Gruyer, N., Rosberg, A.K., 2013. Persistence of fenhexamid in the nutrient solution of a closed cropping system. Agricultural Water Management 127, 25-30.

Alsanius, B.W., Rosberg, A.K., Hultberg, M., Khalil, S., Jung, V., 2014.

Understanding and utilizing naturally occuring microbes against plant pathogens in irrigation water, in: Hong, C., Moorman, G.W., Wohanka, W., Büttner, C. (Eds.), Biology, detection, and management of plant pathogens in irrigation water. APS Press, St Paul, pp. 347-364.

Alsanius, B.W., Alam, M., Larsson, C., Sylla, J., Rosberg, A.K., Olsson, C., Mogren, L., Ahrné, S., Molin, G., Jensén, P., 2016.

Microbial community structure of the free water phase in a field irrigation system submitted.

Assinck, F.B.T., Heinen, M., 2001.

Modelverkenning naar het effect van niet-uniform verdeelde watergiften op de opname van chrysanten onder glas. 6pp. Alterra Instituut Wageningen, Report 393. 36 pages.

Atkinson, N.J., Urwin, P.E., 2012.

The interaction of plant biotic and abiotic stresses: from genes to the field. J. Exp. Bot. 63:3523-3543.

Atkinson, N.J., Dew, T.P., Orfila, C., Urwin, P.E., 2011.

Influence of combined biotic and abiotic stress on nutritional quality parameters in tomato (Solanum lycopersicum). J. Agric. Food. Chem. 59:9673-9682.

Baille, M., Baille, A., Laury, J.C., 1994.

A simplified model for predicting evapotranspiration rate of nine ornamental species vs climate factors and leaf area. Scientia Horticulturae 59: 217-232. 
Bakker, J.C., 2011.

New technologies developed for conventional growing systems: possibilities for application in organic systems. Acta Horticulturae 915: 47-54.

Balfour, E.B., 1947.

The living soil, evidence of the importance to human health of soil vitality, with special reference to post-war planning. 7th ed. Faber and Faber Ltd., London, UK.

Battilani, A., Bussières, P., Dumas, Y., 2003.

Fertirrigere: a simple tool-model for managing water and nutrient supply in drip-irrigated processing tomatoes. Acta Horticulturae 613: 155-158.

Bayart, J.-B., Bulle, C., Deschênes, L., Margni, M., Pfister, S., Vince, F., Koehler, A., 2010.

A framework for assessing off-stream freshwater use in LCA. Int J Life Cycle Assess 18:881-890.

Berger, M., Finkbeiner, M., 2010.

Water footprinting: How to address water use in life cycle assessment? Sustainability 2:919-944.

Bernstein, L., 1975.

Effects of salinity and sodicity on plant growth. Annual Review of Phytopathology 13: 295-312.

Beulke, S., van Beinum, W., Glass, R., Van Os, E.A., Holterman, J., Sapounas, A., Voogt, W., van de

Zande, J., de Zwart, F., Garratt, J., 2011.

Estimation/calculation of emissions of plant protection products from protected crops (greenhouses and cultvations under cover to support the development of risk assessment methodology under regulation (EC) nr 1107/2009 and council directive 91/414/EEC. EFSA,, Parma.

Bezemer, J., Voogt, W., 2008.

Elke kuub water van bron tot sloot in beeld gebracht (interview met Wim Voogt) - Met nieuw rekenmodel kan teler zijn watermanagement optimaliseren." Onder Glas 5(2): 46-47.

Birch, H. F., 1964.

Mineralisation of plant nitrogen following alternate wet and dry conditions. Plant and Soil 20(1): 43-49.

Bitton, G., 2011.

Wastewater microbiology, 4th ed. Wiley-Blackwell, Hoboken, N.J.

Bloem, J., de Ruiter, P.C., Koopman, G.J., Lebbink, G., Brussaard, L., 1992.

Microbial numbers and activity in dried and rewetted arable soil under integrated and conventional management. Soil Biology and Biochemistry 24(7): 655-665.

Blumenthal, U.J., Mara, D.D., Peasey, A., Ruiz-Palacios, G., Stott, R., 2000.

Guidelines for the microbiological quality of treated wastewater used in agriculture: Recommendations for revising WHO guidelines. Bulletin of the World Health Organization 78: 1104-1116.

Blumenthal, U.J., Cifuentes, E., Bennett, S., Quigley, M., Ruiz-Palacios, G., 2001.

The risk of enteric infections associated with wastewater reuse: the effect of season and degree of storage of wastewater. Transactions of the Royal Society of Tropical Medicine and Hygiene 95, 131-137.

Borken, W., Matzner, E., 2009.

Reappraisal of drying and wetting effects on $\mathrm{C}$ and $\mathrm{N}$ mineralization and fluxes in soils. Global Change Biology 15(4): 808-824.

Bos, M.G., 1997.

Performance indicators for irrigation and drainage. Irrigation and Drainage Systems 11:119-137.

Boulard,T., Wang, S., 2000.

Greenhouse crop transpiration simulation from external climate conditions. Agriculture Forest and Meteorology 100(1):25-34.

Boulard T., Jemaa R., Baille A., 1997.

Validation of a Greenhouse Tomato Crop Transpiration Model in Mediterranean Conditions. Acta Hort. (ISHS) 449:551- 560.

British Columbia Ministry of Environment, 2001.

Water quality criteria for microbiological indicators, in: British Columbia Ministry of Environment (Ed.), http://www.env.gov.bc.ca/wat/wq/BCguidelines/microbiology/microbiology.html.

Canadian Council of Minsters of Environment, 1999.

Canadian water qualtiy guidelines for the protection of agricultural water uses. C. e. q. guidelines. Winipeg, CCME Publications: 2 pages.

Candido, V., Campanelli, G., D’Addabbo, T., Castronuovo, D., Perniola, M., Camele, I., 2016.

Growth and yield promoting effect of artificial mycorrhization on field tomato at different irrigation regimes. Scientia Horticulturae 187:35-43.

90 I Impact of water quality and irrigation management on organic greenhouse horticulture 
Capra, A., Scicolone, B., 2004.

Emitter and filter tests for wastewater reuse by drip irrigation. Agricultural Water Management 68: $135-149$.

Capra, A., Scicolone, B., 2007.

Recycling of poor quality urban wastewater by drip irrigation systems. Journal of Cleaner Production 15: 1529-1534.

Carmassi, G., Incrocci, L., Maggini, R., Malorgio, F., Tognoni, F. and Pardossi, A., 2007, An aggregated model for water requirements of greenhouse tomato grown in closed rockwoll culture with saline water, Agricultural water management 88: 73-82.

Caron, J., Elrick, D.E., Beeson, R., Boudreau, J., 2005. Defining critical capillary rise properties for growing media in nurseries. Soil Sci. Soc. Am. J. 69:783-793.

Caron, J., P. Morel, L.-M. Rivière, and G. Guillemain. 2010. Identifying appropriate methodology to diagnose aeration limitations with large peat and bark particles in growing media. Can. J. Soil Sci. 90:481-494.

Caron, J., Parent, L.E., Elrick, D.E. Naasz, N., 2008. Physical properties of organic soils and srowing media: water and air storage and dynamics. In M.R. Carter (ed), Soil Sampling and Methods of Analysis, CRC Press, Boca Raton, Florida.

Caron, J., Pepin, S., Périard, Y., 2014.

Physics of growing media in a green future. Acta Horticulturae 1034:309-317.

Caron, J., Rochefort, L., 2013.

Use of peat in growing media: state of the art on industrial and scientific efforts envisioning sustainability.

Acta Horticulturae 982:15-22.

Castilla, N., 1999.

Drip irrigation management and water saving in protected culture. In: "Protected cultivation in the Mediterranean region (Eds: Choukr-Allah R.)". Cahiers Options Méditerranéennes; n. 31, pages 189-202.

Cohen, Y., Alchanatis, V., Meron, M., Saranga, Y., Tsipris, J., 2005.

Estimation of leaf water potential by thermal imagery and spatial analysis. Journal of Experimental Botany 56(417): 1843-1852.

Colla, G., Rouphael, Y., Cardarelli, M., Rinaldi S. Rea, E., 2009.

Water use efficiency and transpiration of greenhouse geranium crop, Acta Horticulturae 807: 271-276.

Copes, W. E., Barbeau, B., Castagner, G. A., 2014.

Chlorine dioxide for irrigation water treatment. In: Hong, C., Moorman, G.W., Wohanka, W., Büttner, C. (Eds.), Biology, detection, and management of plant pathogens in irrigation water. APS Press, St Paul, pp. 251-267.

Costa, J.M., Ortuño, M.F., Chaves, M.M., 2007.

Deficit irrigation as a strategy to save water: physiology and potential application to horticulture. Journal of Integrative Plant Biology 49:1421-1434.

Cripps, S.J., Bergheim, A., 2000.

Review: Solids management and removal for intensive land-based aquaculture production systems. Aquaculture Engineering 22: 33-56.

Dahan, O., Babad, A., Lazarovitch, N., Russak, E.E., Kurtzman, D., 2014 Nitrate leaching from intensive organic farms to groundwater. Hydrol. Earth Syst. Sci. 18:333-341.

Dannehl, D., Josuttis, M., Ulrichs, C., Schmidt, U., 2014. The potential of a confined closed greenhouse in terms of sustainable production, crop growth, yield and valuable plant compounds of tomatoes. Journal of Applied Botany and Food Quality 87: 210-219.

Dazhuang, Y., Zhihui, B., Rowan, M., Likun, G., Shumei, R., Peiling, Y., 2009. Biofilm structure and its influence on clogging in drip irrigation emitters distributing reclaimed wastewater. Journal of Environmental Sciences 21: 834-841.

De Bes, S. S., 1986.

Tussentijds overzicht Verstoppende materialen druppelsystemen. Internal report, 1986, 4 pages.

De Graaf, R., 1988.

Automation of the water supplied of glasshouse crops by means of calculating the transpiration and measuring the amount of drainage water. Acta Horticulturae 229: 219-231.

de Kreij, C., van der Burg, A.M.M., Runia, W.T., 2003. Drip irrigation emitter clogging in Dutch greenhouses as affected by methane and organic acids. Agricultural Water Management 60, 73-85. 
De Neve, S., Hofman, G., 2002.

Quantifying soil water effects on nitrogen mineralization from soil organic matter and from fresh crop residues. Biology and Fertility of Soils 35(5): 379-386.

De Pascale,S.,Martino, A.,Raimondi, G.,Maggio, A., 2007.

Comparative analysis of water and salt stress-induced modifications of quality parameters in cherry tomatoes. Journal of Horticultural Science and Biotechology. 82:283-289.

De Pascale, S., Orsini, F., Caputo, R., Palermo, M. A., Barbieri, G., Maggio, A., 2012.

Seasonal and multiannual effects of salinisation on tomato yield and fruit quality. Funct. Plant Biol. 39 :689698.

De Pascale, S., Maggio, A., Orsini, F., Barbieri, G., 2016. Cultivar, soil type, nitrogen source and irrigation regime as qualitydeterminants of organically grown tomatoes. Scientia Horticulturae 199:88-94.

DIN 19650, 1999.

Bewässerung. Hygienische Belange von Bewässerungswasser. Beuth, Berlin, pp. 1-4.

Dorais M., Gaudreau, L., Bordeleau, M., Gosselin, A., Gauthier, L., Desjardins, Y., Khanizadeh, S., 2012. High tunnel production of organic raspberries: effects of fertilization management. Book Abstr, ISHS, Organic fruits. Leavenworth, WA.

Dorais, M., Alsanius, B.W., 2015.

Advances and trends in organic fruit and vegetable farming research. Horticultural reviews 43:185-267.

Dorais, M., Dubé, Y., 2011.

Managing greenhouse organic wastes: a holistic approach. Acta Horticulturae 893:183-197.

Dorais, M., Papadopoulos, A.P., Gosselin, A., 2001. Influence of EC Management on Greenhouse Tomato Yield and Fruit Quality. Agronomie 21:367-384.

Duran-Ros, M., Puig-Bargués, J., Arbat, G., Barragán, J., Ramírez de Cartagena, F., 2009. Effect of filter, emitter and location on clogging when using effluents. Agricultural Water Management 96 : 67-79.

Eggen, T., Normann Asp, T., Grave, K., Hormazabal, V., 2011. Uptake and translocation of metformin, ciprofloxacin and narasin in forage and crop plants. Chemosphere 85: 26-33.

EGTOP (2013).

Final report on greenhouse production (protected cropping). Directorate H Sustainability and Quality for Agriculture and Rural Development H.3. Organic farming. Brussels, European Commission DirectorateGeneral for Agriculture and Rural Development. EGTOP/6/13: 1-36.

European Union, 1998. COUNCIL DIRECTIVE 98/83/EC of 3 November 1998 on the quality of water intended for human consumption, in: European Union (Ed.), 98/83/EC. European Union, Brussels, pp. 1-23.

European Union (2007). Council Regulation on organic production and labelling of organic products and repealing Regulation (EEC) No 2092/91. L189. E. Union. Luxemburg, European Union. LEX-FAOC072928: 23.

European Commission, 2008. Kommissionens förordning (EG) nr 889/2008 av den 5 september 2008 on tillämpningsföreskrifter för rådets förordning (EG) nr 834/2007 om ekologisk produktion och märkning av ekologiska produkter med avseende på ekologisk produktion, märkning och kontroll, in: European Commission (Ed.). European Commission,, Brussels, pp. 1-85.

Fatta-Kassinos, D., Meric, S., Nikolaou, A., 2011. Pharmaceutical residues in environmental waters and wastewater: current state of knowledge and future research. Anal Bioanal Chem 399: 251-275.

Ferrarezi, R.S., Weaver, G.M., van Iersel, M.W., Testezlaf, R., $2015 a$. Subirrigation: Historical Overview, Challenges, and Future Prospects. HortTechnology 25:262-276.

Ferrarezi, R.S., van Iersel, M.W., Testezlaf, R., 2015b. Monitoring and controlling ebb-and-flow subirrigation with soil moisture sensors. HortScience 50:447-453.

Fisher, S.G., Likens, G.E., 1973.

Energy flow in Bear Brook, New Hampshire: an integrative approach to stream ecosystem metabolism. Ecological Monographs 43: 421-439. 
Gallardo, M., Thompson, R.B., Fernández, M.D., 2013.

Water requirements and irrigation management in Mediterranean greenhouses: the case of the southeast coast of Spain. In: Good Agricultural Practices for Greenhouse Vegetable Crops: Principles for Mediterranean Climate Areas. FAO, pp. 109-136.

Gartlehner, G., Hansen, R.A., Nissman, D., Lohr, K.N., Carey, T.S., 2006.

Criteria for distinguishing effectiveness from efficacy trials in systematic reviews, in: RTI-International (Ed.), AHRQ Publication. University of North Carolina Evidence-based Practice Center Research, Triangle Park, NC, 28 pages.

Gilbert, R.G., Nakayama, F.S., Bucks, D.A., French, O.F., Adamson, K.C., Johnson, R.M., 1982.

Trickle irrigation: predominant bacteria in treated Colorado river water and biologically clogged emitters. Irrigation Science 3: 123-132.

Gravel V., Blok, W., E. Hallman, E., Carmona, C., Wang, H., Van de Peppel, A., Condor Golec, A.F., Dorais, M. van Meeteren, U., Heuvelink, E., Rembialkowska, E., Van Bruggen, A.,2010. Differences in N uptake and fruit quality between organically and conventionally grown greenhouse tomatoes. Agron. Sustain. 30:797-806.

Gravel V., Dorais M., Dey D., Vandenberg G., 2015.

Fish effluents promote root growth and suppress fungal diseases in tomato transplants. Can J Plant Sci 21: 23-27.

Greenwood, D.J., Zhang, K., Hilton, H.W., Thompson, A.J., 2010. Opportunities for improving irrigation efficiency with quantitative models, soil water sensors and wireless technology. Journal of Agricultural Science 148: 1-16.

Göhler, F., Molitor, H.-D., 2002.

Erdelose Kulturverfahren im Gartenbau. Ulmer, Stuttgart.

Halling-Sörensen, B., Nors Nielsen, S., Lanzky, P.F., Ingerslev, F., Holten Liitzhofl, H.C., Jorgensen, S.E., 1998. Occurrence, Fate and Effects of Pharmaceutical Substances in the Environment- A Review. Chemosphere 36: 357-393.

Heberer, T., 2002.

Occurrence, fate, and removal of pharmaceutical residues in the aquatic environment: a review of recent research data. Toxicology Letters 131: 5-17.

Heiskanen, J. 1997.

Air-filled porosity of eight growing media based on sphagnum peat during drying from container capacity. Acta Hortic. 450, 277-286.

Herklotz, P.A., Gurung, P., Vanden Heuvel, B., Kinney, C.A., 2010. Uptake of human pharmaceuticals by plants grown under hydroponic conditions. Chemosphere 78 : $1416-$ 1421.

Hirsch, R., Ternes, U.T., Haberer, K., Kratz, K.-L., 1999.

Occurrence of antibiotics in the aquatic environment. Science of the Total Environment 225: 109-118.

Hong, C., Moorman, G.W., Wohanka, W., Büttner, C., 2014. Biology, detection, and management of plant pathogens in irrigation water. APS Press, St Paul.

Hospido, A., Núñez, M., Antón, A., 2013. Irrigation mix: how to include water sources when assessing freshwater consumption impacts associated to crops. Int J Life Cycle Assess 18:881-890.

IFOAM EU Group, 2013.

Position paper on organic greenhouse production - updated position, in: IFOAM EU Group (Ed.). IFOAM,, Brussels, pp. 1-7.

Karnjanapiboonwong, A., Chase, D.A., Cañas, J.E., .Jackson, W.A., Maul, J.D., Morse, A.N., Anderson,

T.D., 2011.

Uptake of 17a-ethynylestradiol and triclosan in pinto bean, Phaseolus vulgaris. Ecotoxicology and Environmental Safety 74: 1336-1342.

Kemper, N., 2008. Veterinary antibiotics in the aquatic and terrestrial environment. Ecological Indicators 8, 1-13.

Koprivnjak, J.F., Moore, T.R., 1992.

Sources, sinks and fluxes of dissolved organic carbon in sub-arctic fen catchments. Arctic and alpine research 24: 204-210.

Kramer, A., Assidian, O. 2008.

Wallhäussers Praxis der Sterilisation, Desinfektion, Antiseptik und Konservierung. Thieme Verlag, Stuttgart.984 pages. ISBN:978-3-13-141121-1. 
Krauthausen, H.-J., Laun, N., Wohanka, W., 2011. Methods to reduce the stread of the black rot pathogen, Xanthomonas campestris, in brassica transplants. Journal of Plant Disease and Protection 118 (1), 7-16.

Kreuger, J., Graaf, S., Patring, J., Adielsson, S., 2010.

Pesticides in surface water in areas with open ground and greenhouse horticultural crops in Sweden 2008, Ekohydrologi. Division of Water Quality Management, Uppsala, Report 117, 49 pages.

Laura, R. D., 1974.

Effects of neutral salts on carbon and nitrogen mineralisation of organic matter in soil. Plant and Soil 41(1): 113-127.

Lester, J.N., Birckett, J.W., 1999.

Microbiology and Chemistry for Environmental Scientists and Engineers, 2nd ed. E. \& FN. Spon, New York.

Li, J., Chen, L., Li, Y., 2009.

Comparison of clogging in drip emitters during application of sewage effluent and groundwater. Transactions of the ASABE 52: 1203-1211.

López, A., J. Fenoll, P. Hellín, and P. Flores. 2013.

Physical characteristics and mineral composition of two pepper cultivars under organic, conventional and soilless cultivation. Scientia Hort. 150:259-266.

Madigan, M.T., Martinko, J.M., Bender, K.S., Buckley, D.H., Stahl, D.A., 2015.

Brock Biology of Microorganisms, 14th ed. Pearson, Boston.

Manzoni, S., Schimel, J.P., Porporato, A., 2012.

Responses of soil microbial communities to water stress: Results from a meta-analysis. Ecology 93(4): 930938.

Marouelli, W.A., da Costa Lage, D.A., Gravina, C.S., Filho, M.M., Souza, R.B., 2013.

Sprinkler and drip irrigation in the organic tomato for single crops and when intercropped with coriander.

Revista Ciência Agronômica 44 (4): 825-833.

Mays, L.W., 2013.

Groundwater Resources Sustainability: Past, Present, and Future. Water Resour Manage 27:4409-4424.

Migliore, L., Cozzolino, S., Fiori, M., 2000.

Phytotoxicity to and uptake of flumequine used in intensive aquaculture on the aquatic weed, Lythrum salicaria L. Chemosphere 40: 741-750.

Morillo, J.G., Diaz, J.A.R., Camacho, E., Montesinos, P., 2015.

Linking water footprint accounting with irrigation management in high value crops. Journal of Cleaner production 87:594-602.

Muñoz, I., Gómez, M. del M., Fernández-Alba, A.R., 2010.

Life Cycle Assessment of biomass production in a Mediterranean greenhouse using different water sources: Groundwater, treated wastewater and desalinated seawater. Agricultural Systems 103:1-9.

Münster, U., 1993.

Concentrations and fluxes of organic carbon substrates in the aquatic environment. Antonie van Leeuwenhoek 63: 243-274.

Möller, K., Schultheiß, U., 2014.

Organische Handelsdüngemittel im ökologischen Landbau - Charakterisierung und Empfehlungen für die Praxis. KTBL-Schrift 499. KTBL Darmstadt, 392 pp.

Möller, K., Schultheiß, U., 2016.

Chemical characterization of commercial organic fertilizers. Archives of Agronomy and Soil Science (in press)

Naasz, R., Caron, J., Legault, J., Pichette, A., 2009.

Efficiency Factors for Bark Substrates: Biostability, Aeration or Phytotoxicity. Soil Sci. Soc. Am. J. 73:780791.

Nakayama, F.S., Bucks, D.A., 1991.

Water quality in drip/trickle irrigation: A review. Irrigation Science 12: 187-192.

National Swedish Food Administration, 2006.

Information om kemiska parametrar i Livsmedelsverkets föreskrifter (2001:30) om dricksvatten, bilaga

2, i bokstavsordning, in: National Swedish Food Administration (Ed.), 2001:30. National Swedish Food Administration,, Uppsala, pp. 1-21.

NHS, 2015.

Decontamination policy. 7. Royal Cornwall Hospital Trust. 54 pages. http://www.rcht.nhs.uk/

RoyalCornwallHospitalsTrust/DocumentLibrary/DocumentSearch.aspx. Accessed March 7, 2015. 
Nkongolo, N.V., and J. Caron. 2006.

Pore space organization and plant response in peat substrates: I. Prunus cistena and Spiraea japonica. Sci. Res. Essays 1:77-89.

Or, D., Phutane, S., Dechesne, A., 2007.

Extracellular polymeric substances affecting pore-scale hydrologic conditions for bacterial activity in unsaturated soils. Vadose Zone Journal 6:298-305.

Orchard, V. A., Cook, F. J. 1983.

Relationship between soil respiration and soil moisture. Soil Biology and Biochemistry 15(4): 447-453.

Orsini, F., Maggio, A., Rouphael. Y., De Pascal, S. 2016.

"Physiological quality" of organically grown vegetables. Scientia Hort Special issue Organic Horticulture (accepted, in press).

Pachepsky, Y., Morrow, J., Guber, A., Shelton, D., Rowland, R., Davies, G., 2011.

Effect of biofilm in irrigation pipes on microbial quality of irrigation water. Letters in Applied Microbiology 54: 217-224.

Pardossi, A., Incrocci, L., Incrocci, G., Malorgio, F., Battista, P., Bacci, L., Rapi, B., Marzialetti, P.,

Hemming, J., Balendonck J., 2009.

Root zone sensors for irrigation management in intensive agriculture. Sensors 9: 2809-2835.

Pathak, H., Rao, D. L. N., 1998.

Carbon and nitrogen mineralization from added organic matter in saline and alkali soils. Soil Biology and Biochemistry 30: 695-702.

Persson, P., 1991.

Soft rot Erwinia ssp. attacking potatoes in Sweden with spcial reference to E. carotovora ssp. atroseptica, Department of Forest and Plant Pathology. Swedish University of Agricultural Sciences, Uppsala.

Piedrahita, R.H., 2003.

Reducing the potential environmental impact of tank aquaculture effluents through intensification and recirculation. Aquaculture 226: 35-44.

Ravina, I., Paz, E., Sofer, Z., Marcu, A., Schischa, A., Sagi, G., Yechialy, Z., Lev, Y., 1997. Control of clogging in drip irrigation with stored treated municipal sewage effluent. Agricultural Water Management 33: 127-137.

Raviv, M., R. Wallach, A. Silber, Sh. Medina, and A. Krasnovsky. 1999.

The effect of hydraulic characteristics of volcanic materials on yield of roses grown in soilless culture. J. Am. Soc. Hortic. Sci. 124:205-209.

Reeve, J., and D. Drost. 2012. Yields and soil quality under transitional organic high tunnel tomatoes. HortScience 47:38-44.

Ripoll, J., Urban, L., Bertin, N., 2016.

The Potential of the MAGICTOM Parental accessions to explore the genetic variability in tomato acclimation to repeated cycles of water deficit and recovery. Frontier Plant Sci. 6:1172.

Ripoll, J., Urban, L., Staudt, M., Lopez-Lauri, F., Bidel, L.P.R., Bertin, N., 2014. Water shortage and quality of fleshy fruits-making the most of the unavoidable. J. Exp.Bot. 65:4097-4117.

Rippy, J.F.M., Peet, M.M., Louws, F. J., Nelson, P.V., Orr, D. B., Sorensen, K. A., 2004. Plant development and harvest yield of greenhouse tomatoes in six organic growing systems. HortScience 39:223-229.

Ritchie J.T., Burnett, E., 1968. A precision weighing lysimeter for row crop water use studies. American Society of Agronomy 60(5): 545549.

Roeber, R.U., 2010.

Environmentally sound plant production by means of soilless cultivation. Comunicata Scientiae 1:1-8.

Ross, D.S., 2014.

Water resources and designs of recycling irrigation systems for health crops, in: Hong, C., Moorman, G.W., Wohanka, W., Büttner, C. (Eds.), Biology, detection, and management of plant pathogens in irrigation water. APS Press, St Paul, pp. 321-332.

Rydén, K., 1965. Kan gurkmosaikvirus spridas med vatten? Växtskyddsnotiser 5 : 68-69.

Sánchez J.A., Reca, J., Martínez, J., 2015. Water productivity in a Mediterranean semi-arid greenhouse district. Water Resource Management 29:5395-5411. 
Sarkar, M.A., Biswas, P.K., Roy, S., Kole, R.K., Chowdhury, A., 1999.

Effect of $\mathrm{pH}$ and type of formulation on the persistence of imidacloprid in water. Bulletin of Environmental Contamination and Toxicology 63, 604-609.

Shelton, D.R., Kiefer, L.A., Pachepsky, Y.A., Blaustein, R.A., Martinez, G., 2012.

Coliform retention and release in biofilms formed on new and weathered irrigation pipes. Irrigation Science 10.1007/s00271-012-0373-x.

Shenker, M., Harush, D., Ben-Ari, J., Chefetz, B., 2011.

Uptake of carbamazepine by cucumber plants - A case study related to irrigation with reclaimed wastewater. Chemosphere 82: 905-910.

Sigee, D.C., 2005.

Freshwater Microbiology. Wiley, Chichester.

Skopp, J., Jawson, M.D., Doran, J.W., 1990.

Steady-state aerobic microbial activity as a function of soil water content. Soil Science Society of America Journal 54(6): 1619-1625.

Sonneveld, C. 2000.

Effects of salinity on substrate grown vegetables and ornamentals in greenhouse horticulture.

Omgevingswetenschappen. Wageningen, Wageningen. Ph.D.: 151.

Sonneveld, C., van der Burg, A.M.M., 1991.

Sodium chloride salinity in fruit vegetable crops in soilless culture. Netherlands Journal of Agricultural Science. 39: 115-122.

Sonneveld, C., Voogt, W., 2009.

Plant nutrition of greenhouse crops. Springer Netherlands, $431 \mathrm{p}$.

Stanhill, G., 1986.

Water use efficiency. Advances in Agronomy 39: 53-85.

Steiner, C. Harttung, T., 2014.

Biochar as a growing media additive and peat substitute. Solid Earth 5:995-999.

Todorovic, M., Mehmeti, A., Scardigno A., 2016.

Eco-efficiency of agricultural water systems: Methodological approach and assessment at meso-level scale. Journal of Environmental Management 165:62-71.

Tuzel, I.H., Tunali, U., Tepecik, M., Tuzel, Y., Oztekin, G.B., 2014.

Automated irrigation management of organic greenhouse tomatoes. Acta Horticulturae 1041:109-118.

Tuzel, Y., Gul, A., Tuncay, O., Anac, D., Madanlar, N., Yoldas, Z., Gumus, M., Tuzel, I.H., Engindeniz, S.,

2005.

Organic cucumber production in the greenhouse: A case study from Turkey. Renewable Agriculture and Food Systems: $20(4) ; 206-213$

Wall H., Heiskanen, J., 2003.

Effect of air-filled porosity and organic matter concentration of soil on growth of picea abies seedlings after transplanting. Scan. J. For. Res. 18:344-350.

Van den Ende, J., 1970. Kwaliteitsnormen voor het gietwater. Bedrijfsontwikkeling 1(7): 45-51.

Van der Burg, A.M.M., Hamaker, P., 1987. Variatie in waterafgifte druppelaars en wateropname. Groenten en Fruit 42 (19): 30-33.

Van Schie, J.J., Voogt, W., Sonneveld, C., Beekmans G., 1982. Voorlopige resultaten druppelbevloeiingsonderzoek. Vakblad Bloemisterij 37(30): 32-33.

Verloo, M.G., 1980.

Peat as a natural complexing agent for trace elements. Acta Horticulturae 99: 51-65.

Vermeulen, T., van der Linden, A.M.A., van Os, E.A., 2010.

Emissions of plant protection products from glasshouses to surface water in the Netherlands, Wageningen UR Greenhouse Horticulture, GTB-1002, Wageningen, p. 76 pp.

Wichern, J., Wichern, F., Joergensen, R.G., 2006.

Impact of salinity on soil microbial communities and the decomposition of maize in acidic soils. Geoderma 137:100-108.

Winker, M., Clemens, J., Reich, M., Gulyas, H., Otterpohl, R., 2010.

Ryegrass uptake of carbamazepine and ibuprofen applied by urine fertilization. Science of the Total Environment 408: 1902-1908. 
Wohanka, W., Lindemann, S., 2004.

MENNO-Florades ( $9 \%$ benzoic acid) as an additive to the nutrient solution of a hydroponically grown tomato crop. Acta Horticulturae 648: 209-215.

Voogt, W., 2005.

Fertigation in greenhouse production. Proceedings of the International Symposium on fertigation, Beijing, China, Horgen Switzerland, Int. Potash inst.

Voogt, W., 2009. Normen gietwaterkwaliteit glastuinbouw. Wageningen UR glastuinbouw. Bleiswijk, Wageningen UR glastuinbouw: 20 .

Voogt, W., 2014.

Soil fertility management in organic greenhouse crops; a case study on fruit vegetables. Acta Horticulturae 1041: 21-35.

Voogt, W., van Winkel, A., 2008.

Vocht en verdeling van nutrienten in de bodem onder invloed van de watergift en mulching in biologische teelt. . Wageningen University Research, . Wageningen, Greenhouse Horticulture. Report 2008-12: 44.

Voogt, W., Heinen, M., Balendonck, J., Klap, J., Welles, H., 2011.

Can lysimeters be used to reduce emission in soil based glasshouse horticulture? Proceedings of the Wageningen Conference on Applied Soil Science - Soil Science in a Changing World - 18 - 22 Sept. 2011, Wageningen, The Netherlands, Wageningen, Wageningen UR, Communication Services, Wageningen, The Netherlands.

Voogt, W., de Visser, P.H.E., van Winkel, A., Cuijpers, W.J.M., van de Burgt, G.J.H.M., 2012. Nutrient management in organic greenhouse production: Navigation between constraints. Acta Horticulturae 951: 75-82.

Voogt, W., Swinkels, G.-J., van Os, E., 2012.

'Waterstreams': A model for estimation of crop water demand, water supply, salt accumulation and discharge for soilless crops. Acta Horticulturae 957:123-130.

Voogt, W., Zwinkels, F., Balendonck, J., van Dorland, H., van Winkel, A., 2012.

Ontwikkeling emissiemanagementsysteem grondgebonden teelt; de lysimeter en drainmeter. Bleiswijk, Wageningen UR Glatuinbouw: 52.

Voogt, W., et al. 2014.

Implementatie emissiemanagementsysteem grondgebonden teelten. Beiswijk, Wageningen UR Glastuinbouw.

Voogt, W., J.A. Kipp, J.A., R. de Graaf, R, Spaans, L., 2000.

A fertigation model for glasshouse crops grown in soil. . Acta Horticulturae 537: 495-502.

Yang, L., Zhao, F., Chang, Q., Li, T., Li, F., 2015.

Effects of vermicomposts on tomato yield and quality and soil fertility in greenhouse under different soil water regimes. Agricultural Water Management 160:98-105.

Zhai Z., Ehret, D.L., Forge, T., Helmer, T., Lin, W., Dorais, M., Papadopoulos, A.P. 2009. Organic fertilizer regimes for greenhouse tomatoes: productivity and substrate microbiology HortScience 44:800-809. 
98 I Impact of water quality and irrigation management on organic greenhouse horticulture 

COST (European Cooperation in Science and Technology) is a pan-European intergovernmental framework. Its mission is to enable break-through scientific and technological developments leading to new concepts and products and thereby contribute to strengthening Europe's research and innovation capacities. It allows researchers, engineers and scholars to jointly develop their own ideas and take new initiatives across all fields of science and technology, while promoting multi- and interdisciplinary approaches. COST aims at fostering a better integration of less research intensive countries to the knowledge hubs of the European Research Area. The COST Association, an International not-for-profit Association under Belgian Law, integrates all management, governing and administrative functions necessary for the operation of the framework. The COST Association has currently 36 Member Countries. www.cost.eu.

Link to the Action:

http://www.cost.eu/COST_Actions/fa/FA1105

And:

http://www.biogreenhouse.org/ 